(1) norden

\title{
Making the environment count
}

- Nordic accounts and indicators for analysing and integrating environment and economy

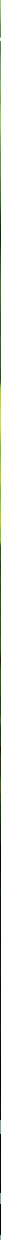







\section{Making the environment count}

- Nordic accounts and indicators for analysing and integrating environment and economy

Olle Björk, Viveka Palm, Nancy Steinbach, Øyvind Lone, Kristine Kolshus, Ole Gravgård Pedersen, Signe Krarup, Leo Kolttola and Annika Lindblom

TemaNord 2016:507 
Making the environment count

- Nordic accounts and indicators for analysing and integrating environment and economy Olle Björk, Viveka Palm, Nancy Steinbach, Øyvind Lone, Kristine Kolshus, Ole Gravgård Pedersen, Signe Krarup, Leo Kolttola and Annika Lindblom

ISBN 978-92-893-4466-1 (PRINT)

ISBN 978-92-893-4467-8 (PDF)

ISBN 978-92-893-4468-5 (EPUB)

http://dx.doi.org/10.6027/TN2016-507

TemaNord 2016:507

ISSN 0908-6692

(C) Nordic Council of Ministers 2016

Layout: Hanne Lebech

Cover photo: ImageSelect

Print: Rosendahls-Schultz Grafisk

Copies: 150

Printed in Denmark

This publication has been published with financial support by the Nordic Council of Ministers. However, the contents of this publication do not necessarily reflect the views, policies or recommendations of the Nordic Council of Ministers.

\section{www.norden.org/nordpub}

\section{Nordic co-operation}

Nordic co-operation is one of the world's most extensive forms of regional collaboration, involving Denmark, Finland, Iceland, Norway, Sweden, and the Faroe Islands, Greenland, and Åland.

Nordic co-operation has firm traditions in politics, the economy, and culture. It plays an important role in European and international collaboration, and aims at creating a strong Nordic community in a strong Europe.

Nordic co-operation seeks to safeguard Nordic and regional interests and principles in the global community. Common Nordic values help the region solidify its position as one of the world's most innovative and competitive.

\section{Nordic Council of Ministers}

Ved Stranden 18

DK-1061 Copenhagen K

Phone (+45) 33960200

www.norden.org 


\section{Contents}

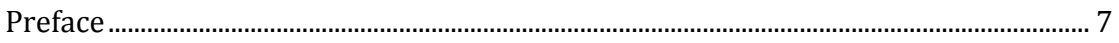

Foreword by the chair of the Ad Hoc group .................................................................... 9

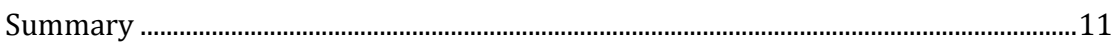

The mission of the Ad Hoc Group .................................................................................12

The recommendations of the Ad Hoc Group..............................................................12

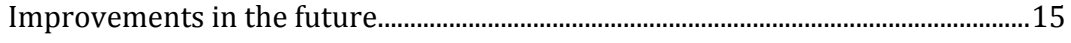

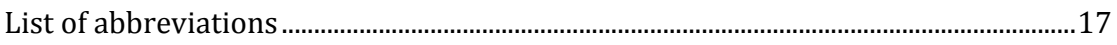

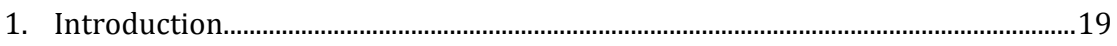

1.1 Purpose and the mandate ............................................................................19

1.2 Linking economy, environment and social issues .........................................20

1.3 International developments of integrated policy and indicators...............26

$1.4 \quad$ Measuring sustainable development .............................................................28

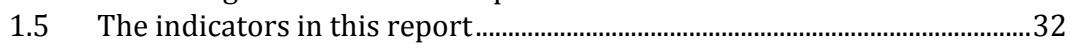

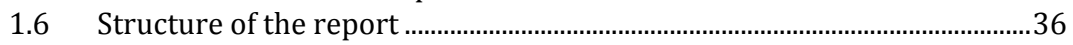

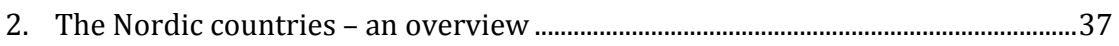

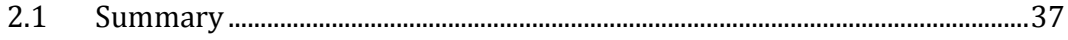

2.2 Integrating the economy and the environment ...............................................38

3. Driving forces - from the economy and society ......................................................4

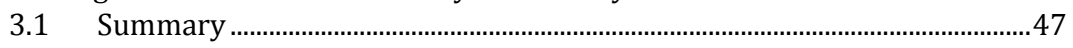

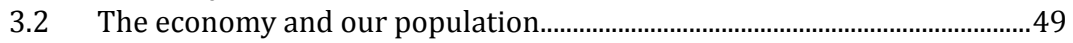

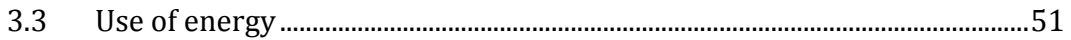

3.4 The need for materials ......................................................................................5

3.5 Other drivers of environmental pressures ..................................................61

3.6 Recommendations and future use ...................................................................62

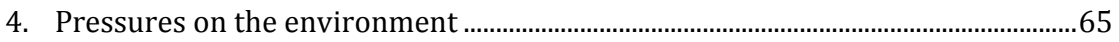

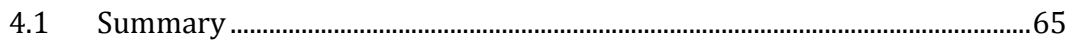

4.2 Preconditions for climate change policy in the Nordic countries ..............66

4.3 Acidifying emissions in the Nordic countries ................................................69

4.4 Emissions of particles to our atmosphere.........................................................72

4.5 Other environmental pressures ………..........................................................74

4.6 Recommendation and future use .................................................................

5. Responses - environmental economic instruments.................................................77

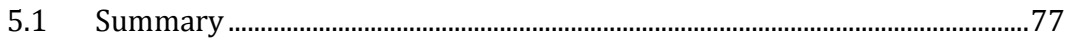

5.2 Environmental taxes .......................................................................................78

5.3 The EU Emissions trading system (EU ETS) ..................................................81

5.4 Producers of environmental goods and services (EGSS) .............................84

5.5 Environmental protection expenditure ...........................................................87

5.6 Other environmental policy responses ........................................................

$5.7 \quad$ Recommendation and future use .....................................................................92 
6. Extensions and analysis - options for data and policy use ......................................93

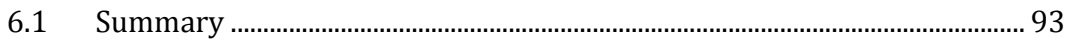

6.2 Consumption - or demand-related environmental impacts ...................... 94

6.3 Analysing drivers of greenhouse gas emissions ......................................... 97

6.4 Environmental economic instruments - the price of $\mathrm{CO}_{2}$ emissions....... 99

6.5 Environmental economic modelling..............................................................102

6.6 Recommendations and future use ...............................................................105

7. Social indicators .....................................................................................................107

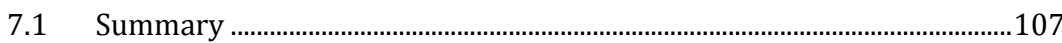

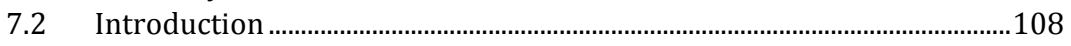

7.3 Sustainable development indicators (SDI) .................................................109

7.4 Recommendations and future use ...............................................................112

8. Ecosystem services ....................................................................................................113

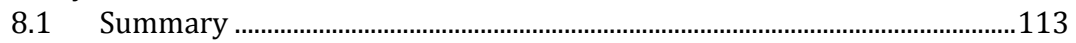

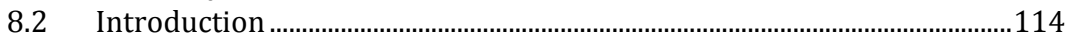

8.3 UN SEEA experimental ecosystem accounts ...............................................115

8.4 TEEB - Economics of Ecosystems and Biodiversity...................................118

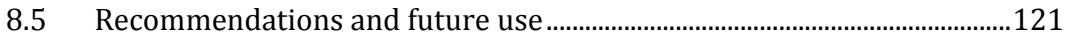

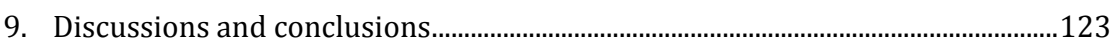

9.1 Thoughts on indicators - and the framework to use .................................123

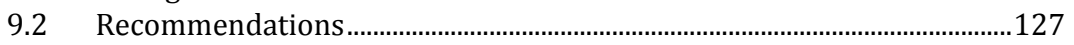

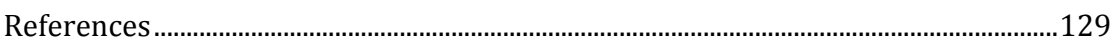

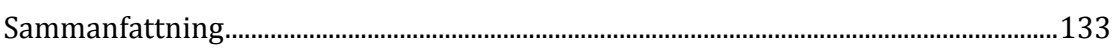

Ad hoc-gruppens uppgift.........................................................................................134

Rekommendationerna från ad hoc-gruppen..........................................................134

Förbättringar i framtiden..........................................................................................137

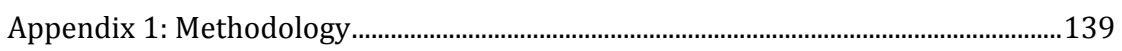

GDP and beyond ....................................................................................................139

National accounts: GDP and value added ..............................................................142

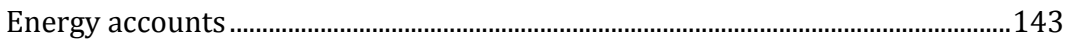

Economy-Wide Material Flow Accounts..................................................................143

Air emissions accounts...............................................................................................144

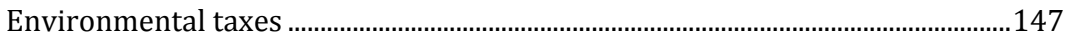

Environmental goods and services sector ............................................................149

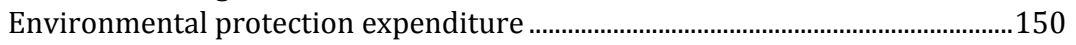

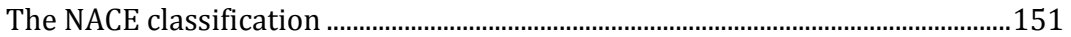

Appendix 2: On-going initiatives and processes ..........................................................153

The Nordic Council of Ministers (NCM) ................................................................153

National initiatives including Statistical Offices ...................................................154

Outside the Nordic region ....................................................................................159 


\section{Preface}

To follow the developments and trends in our economy is vital. Just as vital, however, is to enhance our understanding of how economic development links to broader aspects of welfare, such as environmental sustainability. Therefore, it is pertinent to start looking beyond economic indicators such as GDP to find useful and relevant complements to these indicators. GDP, while important, is not sufficient or suitable to reflect the environmental challenges of our time.

In 2013, the Nordic Ministers for the Environment decided to strengthen the measurement of green estimates of welfare and socioeconomic developments. Today, we can celebrate the results of the work of experts from the Nordic countries in environment, economics and statistics in the form of this report, Making the environment count Nordic accounts and indicators for analysing and integrating environment and economy. For the first time, a wide set of indicators linking the environmental development to the socioeconomic progress is compiled to reflect the trends in the Nordic region.

Developing appropriate indicators and accounting systems for the integration of economic information with environmental issues and policy targets has long been a focus of attention for environmental policy, internationally, in the Nordic countries and in the Nordic Council of Ministers. In recent years, several major initiatives have been taken internationally in order to move towards integrated analysis and decision making; the EU has established a regulation on the monitoring of environmental economic information and the United Nations has defined a new set of goals for sustainable development. The report at hand provides an ambitious input to the international debate on the integration of alternative aspects of welfare to the economic decision-making. It delivers a Nordic contribution to the important and complex work that aims at setting the stage for measuring and following up the newly reinforced sustainability commitments. 
On behalf of the secretariat of the Nordic Council of Ministers, I thank the Ad hoc Group on Complementary Measures for Welfare for its contribution and dedication in general and regarding this report, in particular. I look forward to further progress in this field. In the Nordic region, we aim to continue as forerunners in integrating economic and environmental data and information.

Copenhagen, November 2015

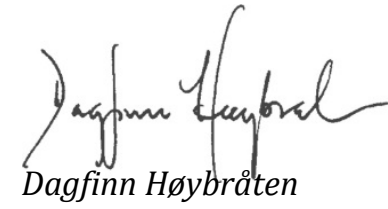

Secretary General

Nordic Council of Ministers 


\section{Foreword by the chair of the Ad Hoc group}

The Nordic ministers for the environment decided at their meeting the 7th February 2013 in Jukkasjärvi, Finland to strengthen the measurement of green estimates of welfare and socioeconomic developments to move beyond the constraints of economic development. The ministers decided to establish an Ad Hoc working group to promote this work and invited the representatives from ministries of finance and industry as well as the statistical offices to take part in this work.

The Ad Hoc Group on Complementary Measures for Welfare was given a mandate consisting of tasks to point out directions on how to integrate economic and environmental information and analysis through existing statistics. The present report is a contribution to the important and complex works that aims at setting the stage for measuring and follow up the sustainability commitments that have decided upon in the wake of the Rio plus 20 conference. The group was asked to focus on environmental matters but also mandated to consider the future potential of also including social issues into the realm of integration.

In this spirit the Nordic Council of Ministers is hereby recommended to take steps to pave the way for a yearly integrated follow-up of the development of the economy, the environment and social conditions in Nordic countries. Such coordination will help to bring forward a more integrated discussion of society's development.

Viveka Palm and Nancy Steinbach, Statistics Sweden, provided the project lead and secretariat. Members of the group are Øyvind Lone, Ministry of Climate and Environment, Norway and Kristine Kolshus, Statistics Norway, Leo Kolttola, Statistics Finland and Annika Lindblom, Ministry of the Environment, Finland, Ole Gravgård Pedersen, Statistics Denmark and Signe Krarup, Ministry of Environment, Denmark, Ingrid Hasselsten, Ministry of Environment and Energy, Sweden and 
Anette Askerøi-Waldmann, Nordic Council of Ministers (secretariat). Members of the group have also been Satu Reijonen at the Nordic Council of Ministers and Sigrid Døvling Søndergaard formerly at the Nordic Council of Ministers, Petronella Troselius, and Teresa Hellgren Swedish Ministry of Environment and Energy, Ida Björk, Sebastian Constantino, Statistics Sweden and Maja Cederlund and Michael Troyanovsky formerly at Statistics Sweden.

I thank the members of the Ad Hoc Group for their contributions and dedicated work.

Olle Björk

Chair of the Ad Hoc Group 


\section{Summary}

The Nordic Council of Ministers is taking steps to make a yearly coordinated follow-up of the development of the economy, the environment and the social conditions in Nordic countries through the committees under its umbrella. Such coordination will help to bring forward a more integrated discussion of these topics. Despite many efforts at measuring sustainable development from different angles, more efforts are needed to provide a consistent basis for the discussion of what a green, inclusive and prosperous development can look like.

The results by the Ad Hoc Group for Complementary Measures of Welfare show how far the Nordic region and separate Nordic countries in the areas of environmental economic statistics and accounts have come. It also shows initiatives to expand the knowledgebase of ecosystem services and the expansion to environmental economic modelling. The access of economic data on production and consumption, combine these with data on energy use, emissions of climate gases and extend the knowledgebase to economic instruments allows for analyses of policies. At the same time these data provides comparable overarching indicators.

The results and recommendations in this report are directed to and could be used by a range of stakeholders. Ministries, such as those of Finance, Environment and Industry could benefit from the evidence-based approach of the proposed indicators. Research institutes could benefit from using the same input-data into different types of environmental and economic models.

It is important to note that the data needed for the proposed monitoring indicators already exist in Nordic countries. No added reporting requirements or data collection will be necessary. The proposal focuses on demonstrating the use of existing data in new contexts. The only area where international comparable data are not currently available in the Nordic countries is related to ecosystems. 


\section{The mission of the Ad Hoc Group}

The group was mandated to consider eight tasks. This consisted of, e.g., to provide suggestions on how to increase the use of already existing indicators and statistics. These should be used to complement the Gross Domestic Product (GDP) measure starting with how to use the known information in a broader analysis of welfare, focusing initially on the environmental dimension.

An inventory of ongoing efforts and international processes within the Nordic countries in the field of integrating environmental and economic accounts was made. Policy needs are strengthening the development towards an integrated environmental and economic platform for decision making. From policy and strategy initiatives from the UN, the OECD and the European Union, it is becoming clear that the knowledge base for the assessment of sustainable development is expanding (and improving when it comes to statistical quality).

For over 25 years the global statistical community has developed the area and framework of the System of environmental-economic accounts (SEEA). With the publications of SEEA central framework (SEEA-CF 2012) in 2014 and its approval as a statistical standard, a consensus has been reached within the statistical community on how to produce statistics using this statistical framework. Simply put, the framework takes economic statistics and links them to environmental statistics. The link between the two statistical areas is established using common classifications, for economic actors in production and consumption activities, such as industries, public authorities and households. This means that economic analysis methodologies, such as input-output analysis, can be extended to include environmental aspects.

\section{The recommendations of the Ad Hoc Group}

The main recommendation from the Ad Hoc Group is to continue the development of the environmental-economic accounting. With regards to the issue on how to use existing data in new areas and in new contexts, the recommendation is to integrate economic data with environment statistics using the UN System of Environmental and Economic Accounts (SEEA-CF) and related sub-systems.

This is an area where the Nordic countries are already in the forefront among the countries worldwide. The Ad Hoc Group therefore pro- 
pose an annual Nordic Environmental and Economic Account to be produced by the Nordic Council of Ministers. Constructing and regularly publishing a basic Nordic Environmental and Economic Account would mean new indicators and tables capturing economic and environmental information together.

For example, industry level profiles could be developed which combine statistics on value added with energy use or air emissions or environmentally related taxes paid.

The Ad Hoc Group proposes that the Nordic countries will further explore how to apply a more integrated approach in their statistical systems. It should also be visual in government decision-making procedures, taking into account the economic, environmental and social aspects in a balanced way.

Hopefully the work can also trigger similar endeavours in other regions and parts of the world. In particular, contribute to the necessary monitoring and review process of the global work on the recently adopted UN Sustainable Development Goals.

Such SEEA data and accounts, consistent, exhaustive and exclusive, at detailed, disaggregated level, linked to national accounts, provide a multipurpose information basis for revealing the interactions between the economy and the environment. Examples of such analyses in the Nordic countries can be found in the main chapters of this report.

There is EU legislation that stipulates the reporting of data for certain SEEA data that are required to be reported yearly by European countries (the European Statistical System), i.e. air emission accounts, energy accounts, environmental taxes by industry, material flow accounts, environmental goods and services sector and environmental protection expenditure accounts. The system is designed so that the main economic actors and their production and consumption activities can be followed from an economic and an environmental perspective. The basic data for these areas are produced by most Nordic countries and are readily available. These data provide a coherent basis from which Nordic EnvironmentalEconomic accounts can be constructed.

In summary, the most important conclusions and recommendations are:

- To produce a yearly Nordic level Environmental and Economic Account on the web and publish it through the Nordic Council of Ministers. Existing statistical frameworks, the national accounts and the environmental accounts should be used to integrate economic data with environmental data, fully consistent and 
coherent with one another. The indicators proposed are presented in Chapter 1, Table 1.2.

- The Nordic Environmental and Economic Account can be used as a tool to analyse important policy issues, such as (i) the greening of all sectors (not just "green" sectors), (ii) analysis of structural changes and important factors contributing to environmental pressures, (iii) assessments of "footprints", and (iv) policy instrument design.

- The Nordic Environmental and Economic Accounts should begin with issues related to the use of natural resources, the use of renewable and non-renewable energy, emissions to air and climate, environmentally related economic activities such as environmental taxes and the production of environmental goods and services. As these statistics already exist and are produced on a regular basis in each of the Nordic countries, there is no need for any broad initiatives or additional resources at the national level.

- Considering that the System of Environmental-Economic Account is still an evolving field, where new fields of data are explored on a global basis, it is pertinent to review new development periodically, such as every 3 years, to ensure that new developments are quickly incorporated in the structure of measurement indicators as proposed by the Ad Hoc Group.

- The recommendation from the group concerning environmentaleconomic models is to increase the awareness of the availability of environmental-economic accounts towards model builders, in order to improve the consistency of the models. This awareness raising could be done through seminars or workshops.

- The group also recommend the establishment of a new platform where the integration of social issues into the economic and environmental sphere can be discussed and further enhanced. The Ad Hoc Group plans to stimulate such an effort through a workshop gathering relevant expertise. There is a statistical framework established already, social accounts which, just as with the case of environmental accounts is a satellite account to the national accounts. 


\section{Improvements in the future}

This report shows how an environmental-economic data set can be used for a Nordic follow-up of the environmental economic developments. With an integrated statistical system there are many more possibilities to create relevant indicators, answer specific questions and make harmonized assessments of environmental-economic issues within the Nordic countries or comparisons between the Nordic region and EU for example.

The data are also in a format that allows using them as input for environmental economic modelling and some of the existing modelling efforts in the Nordic countries are briefly described in the report. By continuing the development of new modules in the accounts there are possibilities to include new areas in the future. Such possible areas could be the development of water or forestry accounts or even new types of land accounts that could underpin studies on ecosystem services. Another interesting area is accounts for the environmental economic instruments, which could serve to enhance knowledge in the design of new policy initiatives.

An area for future development is to integrate more social data with the environmental and economic data in order to derive indicators that could be used to complement GDP in a broader analysis of welfare. There are some areas that are relatively easy to include, for example, employment and education.

Our present report and work is in line with new developments in the field of sustainability, most notably the work within the framework of the new UN Sustainable Development Goals. An early Nordic environmental economic account could serve as pioneering effort when it comes to develop reliable measures of progress towards these new sustainable development goals. It would also be in line with and contribute to the work conducted by the OECD within the strategy for Green Growth and the progress of the Nordic Council of Ministers on the "circular economy". 



\title{
List of abbreviations
}

\author{
CEPA Classification of Environmental Protection Activities \\ CLRTAP Convention on Long-range Transboundary Air Pollution \\ DMC Domestic Material Consumption \\ EGSS Environmental Goods and Services Sector \\ EPE Environmental Protection Expenditure \\ EU European Union (in 2015 consisting of 28 member countries) \\ EU-ETS European Union Emission Trading Scheme \\ EW-MFA Economy-Wide Material Flow Accounts \\ GDP Gross Domestic Product \\ GHG Greenhouse gases - includes carbon dioxides, methane and \\ nitrous oxides \\ NACE Statistical classification of economic activities in the \\ European Community \\ SDI Sustainable Development Indicators \\ SEEA-CF System of Environmental Economic Accounting - Central \\ Framework \\ SNA UN System of National Accounts \\ UN United Nations \\ UNFCCC United Nations Framework Convention on Climate Change
}





\section{Introduction}

\subsection{Purpose and the mandate}

The purpose of this project and the task of the Ad Hoc Group consisted of the following 8 tasks. The initial focus is on complementing the economy with the environmental dimension:

1. Suggest how to increase the use of already existing indictors and other measures that can complement GDP, initially with a focus on the environmental dimension, but to touch on the social dimension as well.

2. The group should look at the possibility to include a social- and health perspective within this project.

3. Investigate the possibilities and make a suggestion for a Nordic highlevel event with a theme of environmentally related welfare indicators that complement GDP.

4. Suggest a way to report an overview of ongoing Nordic initiatives on the theme of establishing regular measurements to complement GDP.

5. Suggest ways to follow-up recommendations from the TEEB Nordic report and how to apply the results of other current Nordic work on the beyond GDP theme.

6. Exchange information about functioning systems, services and practices in the different Nordic countries.

7. Investigate the possibilities for a strengthened communication about the Nordic regions and its states and trends through indicators, to be published on the web or through the Nordic statistical yearbook.

8. Suggest other possible ways of strengthening the discussion on complementing measures within the Nordic Council of Ministers such as for example economy policy overviews. 
The group and the project was initiated by the Ministers of Environment in the Nordic countries, during a Nordic ministerial meeting in Jukkasjärvi in 2013, as a means to strengthen the cross-sectorial work of complementing the GDP measure with environmental and socioeconomic aspects.

The first, second, fourth, fifth and seventh task of the project are in effect dealt with in this report. The report describes existing indicators, their connection to the economy and their use as complements to the GDP. It also describes how strengthened communication of these indicators can be achieved by publishing annual Nordic environmental-economic accounts by the Nordic Council of Ministers.

Task 3 is a process oriented task, and has been on the agenda throughout the project. Several suggestions of events have been put forward to the Nordic Council of Ministers. These proposals are not described any further in this report.

Task 4 has been discussed during the work of the Ad Hoc Group and the result has led to an inventory of the ongoing efforts to develop indicators from measurement systems that link the economy to the environment, which is available in Annex 2 of this report. The inventory goes through some new areas of developments such as measuring environmentally related subsidies, some initiatives on ecosystem management but also existing work underway on how to base policies on such information in innovative ways. Some examples are aligning the economy with green strategies or efforts to use the accounts to measure the environmental pressure from consumption.

Suggestions on how to include aspects on ecosystems services (task 5) with basic statistics are included. The work has been based on experiences from research studies from the Nordic countries such as e.g. the TEEB Nordic report.

Tasks 6 and 8 have been process oriented and taken up at each meeting of the Ad Hoc Group. Minutes from those meetings are available upon request.

\subsection{Linking economy, environment and social issues}

The project builds on existing statistical systems, services and practices in the Nordic countries, more specifically the statistical system of National Accounts and the System of Environmental and Economic Accounts (SEEA). Instead of separate indicators looking only to their own field, the aim here is to connect the economic, environmental and possibly later on social information and use it for integrated analyses. 
The indicators presented in this report are mainly based in a statistical framework called the System of Environmental and Economic Accounts (SEEA). Its strength is based on the link to the System of National Accounts (SNA), the statistical system in which the GDP has its foundation and the economic data contained therein. The system is formed so that the economic actors of a nation, industries, government and households, are described through their activities of production and consumption. This allows for new integrated environmental economics statistics to be obtained. The system can include resource use and emissions as well as relevant economic instruments and so be used to analyse the related policies that are in place or planned.

Such disaggregated data, linked to national accounts, are required to analyse several important policy issues, such as (i) greening of all sectors (not just "green" sectors), (ii) decomposition analysis, i.e. looking for explanations to specific changes in emissions, or energy use, (iii) assessment of "footprints", e.g. consumption related analysis, and (iv) policy instrument design. For example, this report shows if the industries and services of the economy are working towards improved efficiency in terms of resources or energy use. It shows how the industries choose to invest in improved green technologies and changes in the use of fossil fuels to produce the same amount of value added while reducing their impact on the environment (see for example chapter 4). Examples of how the statistics can be used to explain or to illustrate assumed causalities between production of emissions and production of goods and services and how Nordic consumption can be linked to emissions in other countries are shown in chapter 6 . In chapter 5 the report indicates the type of statistics available for the follow-up and design of environmental economic policy.

For social issues the accounts have not been used to the same extent. The approach can incorporate social data for issues like employment, gender in working life and working environment. For other aspects, such as unemployment, and for groups which are outside the workforce, such as children and retired people, further development is needed. This report has a separate chapter on social aspects that are beyond the issues of environmental-economic accounts, but that could be added in future developments. 


\subsubsection{Focusing on the link between economy and environment}

The national accounts keep track of the economic activities in a nation during a year and the environmental accounts link them to drivers of environmental pressures, the pressures themselves and responses to combat or mitigate the pressures.

Companies producing goods and services, within all types of areas, ranging from agriculture production, to manufacturing, to restaurants, hotels and financial activities are covered. The same goes for government use of economic instruments and households consumption of food, transport services etc. All of us can, through our actions, cause negative environmental effects for example by using fossil fuels, which increases levels of emissions of greenhouse gases in the atmosphere, or by choosing renewable energy sources which do not cause added impact to our climate.

We can also decrease environmental pressures, for example, by changing production methods and consumption patterns through increasing the prices on harmful substances through taxation policies or cap and trade systems.

In statistical terms indicators are sometimes described within the framework of a model named by the acronym DPSIR. According to the DPSIR-model information can be grouped under the following labels: Drivers, Pressures, State, Impact and Response. The purpose of the model is to capture information that show how different activities in society affect environment or the environmental state and what is done to prevent continued degradation. A driver for an environmental pressure is then typically energy use, population size, transport volume or changes in land use for example. Pressures can be tonnes of emissions to air or the amounts of waste produced. State show, for instance, the concentration of environmentally harmful substances in air, water or land. Impacts are the problems that the changes in concentrations are causing, such as sicknesses, corrosion or similar. Responses finally, can be environmental taxes, legislation or subsidies.

The environmental accounts can above all contribute with information that show drivers, pressure and response, the light colours in figure 1 as these groups can be described easily with statistical data. The impacts can be described through estimates of how much damages the environmental impacts are causing society. These estimates are normally produced by research institutes or government authorities. To describe the state of the environment, e.g. concentrations of various pollutants in certain habitats, measurements and research close to the environment itself is required. 
The groups of impact and state are shown as grey colour in figure 1 and these are more difficult to describe with statistical information. It is rather based on real measurements in nature (tests need to be taken from lakes, soil etc.) and research studies linking environmental degradation to e.g. human health.

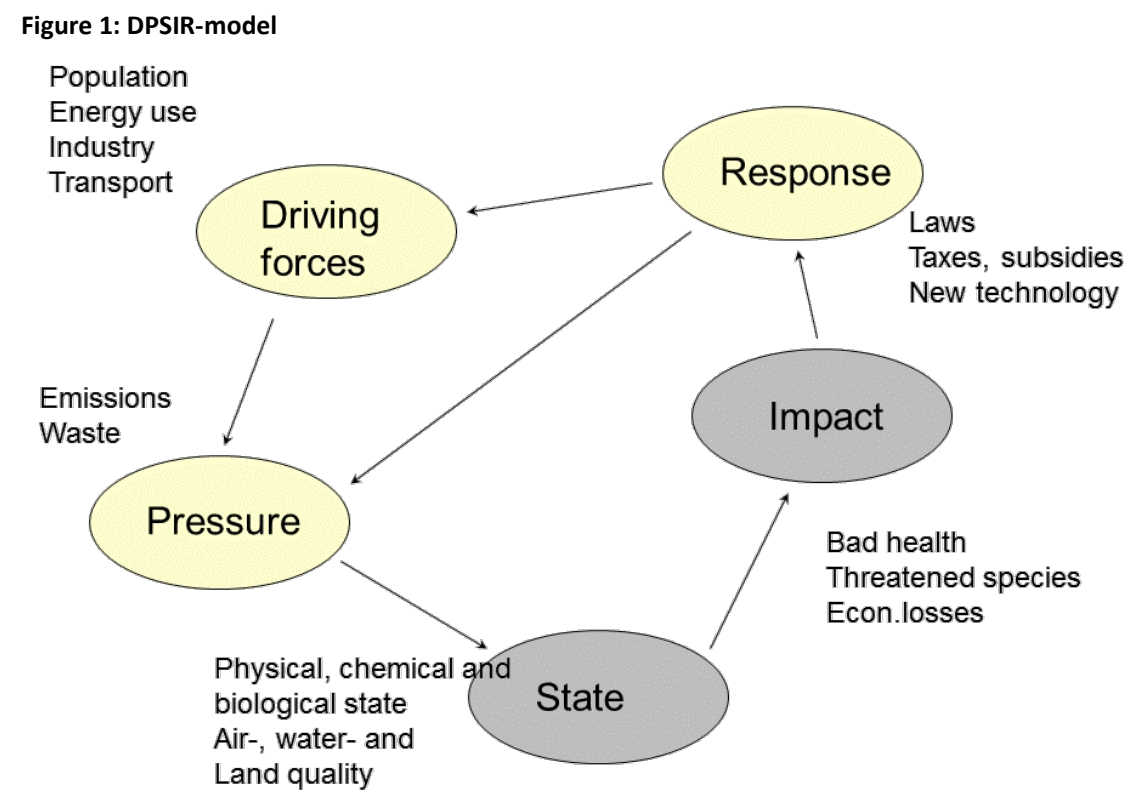

Note: Light coloured groups can be described through statistics, grey colour groups can be described through measurements in nature and research studies.

\subsubsection{What is the System of Environmental-Economic Accounts?}

The System of Environmental-Economic Accounts (SEEA) is an internationally acknowledged statistical framework which enables linking economic statistics and environmental statistics. It is based on an internationally agreed standard ${ }^{1}$ that provides the compiler of the accounts with a common set of concepts, definitions, classifications and more. It builds on the System of National Accounts which means that links between the environment and the economy can be made in consistent ways. By using the accounts that are compiled following the principles

${ }_{1}$ SEEA central framework, approved by the UN Statistical Commission in 2012, with final version published in 2014 by the United Nations, European Commission, Food and Agriculture Organization of the United Nations, Organization for Economic Co-operation and Development, International Monetary Fund and World Bank. 
of SEEA Central Framework (SEEA CF, United Nations et al., 2014), a number of policy relevant questions can be answered including questions related to the use of natural resources as well as responses made by governments to minimise environmental pressures. Basically, the SEEA CF includes:

- Physical flows of materials through the economy, e.g. the use of energy and chemicals, together with the emissions and waste to which these flows give rise.

- Economic variables that are already included in the National accounts but are of obvious environmental interest, such as investments and expenditure in the area of environmental protection, environment-related taxes and subsidies and environmental classification of activities and the employment associated with them.

- Natural resources: Environmental accounts should make it possible to describe stocks and changes in stocks of selected finite or renewable resources.

Outside of the SEEA CF are other aspects that are still covered within the frame of environmental-economic accounts. For example, the environmental accounts should deal both with questions related to the monetary valuation of this natural capital and qualitative aspects that do not have any market or other defined monetary value, e.g. the value of outdoor life and biodiversity. The SEEA experimental ecosystem accounts, which consider these issues, will be further described in chapter 8 in this report.

The SEEA brings into direct focus the relationship between the environment and well-being not revealed through traditional measures of economic activity, such as GDP and national income. The SEEA allows for multiple purposes and multiple scales of analysis. ${ }^{2}$

The SEEA was created to start a process of making sustainable assessments of the economy. In the beginning of the development of SEEA, there was a focus on creating a green net national product as an indicator from the system, but after pilot efforts in many countries, the work then moved on to explore the many different issues that are now part of the accounts (Statistics Denmark 2013, Palm, V. ${ }^{3}$ \& Samakovlis, E. ${ }^{4}$ 2004).

\footnotetext{
2 UNSD Briefing note: unstats.un.org/unsd/envaccounting/SEEA-Brochure-SC-2013.pdf

${ }^{4}$ At the National Institute of Economic Research.
} 
Figure 2 depicts some of the flows captured within the SEEA framework. The input to the economy can be anything necessary to make the economy run, for examples capital investments, energy products, materials or the work force. The economy itself buys and sells products they need to make their own production possible, called intermediate consumption, the government interacts with both companies and households through environmental economic instruments, such as the taxation system or providing subsides. The output from the activities is goods and services, measured in monetary terms, but also emissions of different kinds measured in tonnes or cubic meters (in the SEEA referred to as residuals).

Figure 2: Some important environmental and economic components described by the SEEA

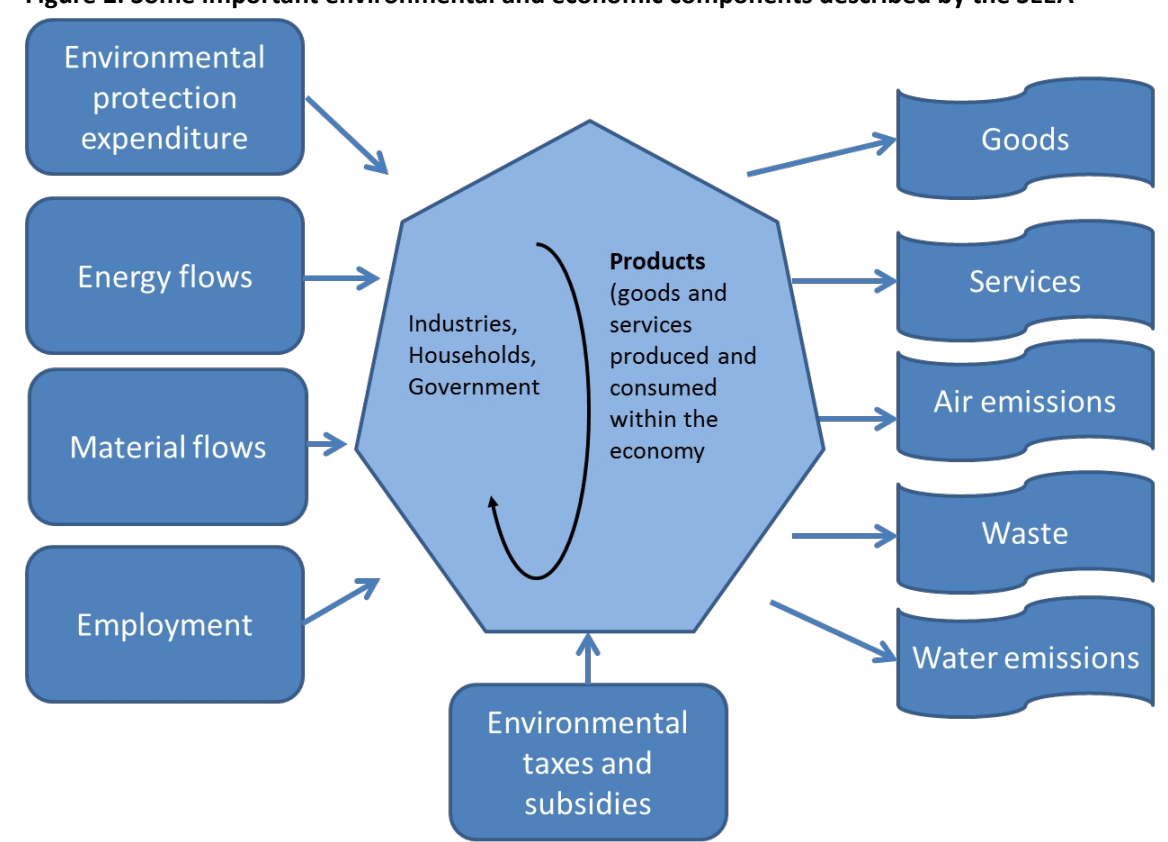

The system allows us to identify which actors in society are contributing to the economy, to the environmental pressure and how the business structure, energy systems and policies form the resulting development. Does the economy grow more or less than the emissions from production or consumption? Which actors are obliged to respond to different kinds of economic instruments, and which are these instruments (i.e. taxes, subsidies, transfers and licenses). How is employment influenced through the establishment of "green sectors"? The results of these types of questions are relevant for several ministries, such as those of finance, environment and industry. 
An important classification used within the environmental accounts is the classification of economic activities (known as "NACE" in the European Statistical System). The NACE is a statistical classification that groups economic activities into different industries, such as agriculture, manufacturing and services. The terminology industry applies to all production sectors in this report, whether it is a manufacturing industry or transport services. The list of industries included in the NACE is shown in Annex 1.

\subsection{International developments of integrated policy and indicators}

\subsubsection{The European Statistical System and environmental accounts}

Within the European Statistical System work on environmental accounts makes progress each year. Annual data for six modules of the SEEA have to be reported yearly to Eurostat, from 2017 onwards. This reporting is required base on EU Regulation 538/2014 (with EFTA relevance). ${ }^{5}$ The modules cover: Air emission accounts (14 pollutants) ${ }^{6}$, Energy accounts (natural resource input, energy products and residuals), Environmental taxes, Environmental protection expenditures, Environmental goods and services sector and Material flow accounts. These areas form the core of the data used in this report.

The regulation was put in place in order to secure the flow of information as regards sound information on the pressures and driving forces on the environment and on the policy responses. The further development of SEEA within the Europe Statistical System is described in the European Strategy for Environmental Accounts.

In the European Strategy, water and waste accounts, as well as environmental subsidies, are important modules which are prioritised for further development within the European Statistical System New inspiration is also elevating ecosystem accounting in Europe and world-wide. In Denmark, the work on developing all these areas, and others, are well underway due to renewed efforts by Statistics Denmark. Sweden has for many years produced accounts for environmentally motivated subsides and is now exploring the

${ }^{5}$ Regulation (EU) No 538/2014 of the European Parliament and of the Council of 16th April 2014 amending Regulation (EU) No 691/2011 on European environmental economic accounts.

${ }^{6}$ Carbon dioxide without emissions from biomass, Carbon dioxide from biomass, nitrous oxide, methane, perfluorocarbons, hydrofluorocarbons, sulphur hexafluoride, nitrogen oxides, non-methane volatile organic compounds, carbon monoxide, particulate matter $<10$ and $<2,5$, sulphur dioxide and ammonia. 
development of accounts for ecosystems through land use accounts. Norway improving statistics on environmental protection expenditure and is developing statistics on the environmental goods and services sector and environmentally motivated subsidies. Finland has for many years produced forestry accounts, yet another area of growing interest by policy makers in Europe and the FA0.7 Finland has also included in their material flow accounts additional information about "hidden flows" abroad of the use of materials in Finland and unused extraction of materials.

In addition, the EU 2020 strategy includes several (flagship) initiatives and "road maps", such as the one on resource efficiency. The EU work on circular economy ${ }^{8}$ also involves work on and further development of indicators for resource efficiency and circular economy. ${ }^{9}$

\subsubsection{The OECD and Green Growth}

Both the European Union (EU) and the OECD have developed strategies for green growth and/or green economy which also include proposals for indicators and accounts that are highly relevant for Nordic work and as has been pointed out in Bruvoll et al. (2012): "Green growth is not about green or not-green sectors, but about whether the economy as a whole develops in a more environmentally friendly direction given their relative starting points".

The OECD Green Growth Strategy is accompanied by extensive work on developing indicators about green growth (see for example OECD Green Growth Indicators 2014). ${ }^{10}$ The member countries are now picking up the work. In Finland for example, a study by several research institutes and Statistics Finland will be released in 2016 evaluating the proposed OECD indicators in a Finnish context.

During 2012, a "reflection group" with representatives from three OECD bodies (from statistics, environment and economics) developed a proposal for six "headline indicators" (and a seventh "placeholder") which is aimed at providing a general overview of the development for use in future OECD publications on green growth. The six indicators and the placeholder are:

\footnotetext{
${ }^{7}$ A new SEEA manual on agriculture, forestry and fishery is under development: http://unstats.un.org/ unsd/envaccounting/aff/chapterList.asp

${ }^{8}$ Circular economy in this context refers to resource flows in the economy and how renewable energy and reuse of material can help to decrease the pressure from the economy on the environment. ${ }^{9} \mathrm{http}: / /$ ec.europa.eu/europe2020/index_en.htm

10 The OECD provides recommendations and measurement tools to support countries' efforts to achieve economic growth and development, while at the same time ensure that natural assets continue to provide the ecosystem services on which our wellbeing relies (OECD Towards Green Growth 2011).
} 
- $\mathrm{CO}_{2}$ productivity (GDP divided by tonnes of $\mathrm{CO}_{2}$ emissions).

- Non-energy material productivity (GDP divided by Domestic Material Consumption).

- Multifactor productivity including environmental services. ${ }^{11}$

- Index of natural resource use.

- Changes in land use and land cover.

- Air pollution (population exposure to $\mathrm{PM}_{2.5}$ ).

- Placeholder for economic opportunities and policy responses stemming from green growth.

For both $\mathrm{CO}_{2}$ productivity and non-energy material productivity it is proposed to include both production-based and consumption-based data. The latter focus on the global "footprint" caused by or rather linked to, our consumption i.e. import-export adjusted $\mathrm{CO}_{2}$ data, etc.

In addition, the OECD is currently developing a data collection vehicle in order to respond to the Green Growth strategy. Part of the data collections will be based on the SEEA. Currently data are available for air emission accounts, environmental protection expenditure and material flows. ${ }^{12}$

\subsection{Measuring sustainable development}

"Where resources and data permit, an annual report and an audit on changes in environmental quality and in the stock of the nation's environmental resource assets are needed to complement the traditional annual fiscal budget and economic development plans. These are essential to obtain an accurate picture of the true health and wealth of the national economy, and to assess progress towards sustainable development"

(World Commission on Environment and Development 1987, the Brundtland report).

In 1990 the UN recommended the world to begin the measurement of development from a broader perspective than just economics by including environmental and social issues. The work set out in two different strands. Through the UN Agenda 21, one strand focused on setting up

\footnotetext{
11 Calculated as the difference between the rate of change of output and the rate of change of total inputs (calculated as volume indices of combined labour and capital inputs for the total economy).

12 http://stats.oecd.org/
} 
broader measurement from a local perspective with a range of indicators. The other approach was to develop an analytical measurement system that used data from the economic statistics in a satellite system. This second approach has now led to a common practice, a UN manual and a common reporting format for the EU - the SEEA (see more below).

There are several reasons for wanting to compile a specific set of indicators to measure sustainable development. Broad policy statements and strategies, such as, the EU Sustainable Development Strategy require monitoring and follow-up in order to point out directions for future steps and adjustments to responses. Another reason is to inform a broader audience how a specific country fares in the context of sustainability. The new UN goals regarding sustainability reinforce the need for relevant and reliable indicators.

\subsubsection{The Nordic countries on sustainable development}

In recent years the world has seen initiatives on many different scales; regions, nations, cities, enterprises etc. In 2013, the Nordic Council of Ministers reported on a Nordic set of Sustainable Development indicators with the purpose to provide measures linked to the objectives of the Nordic Strategy for Sustainable Development.13 The Nordic countries themselves also have their own national indicator sets. ${ }^{14}$ It differs between the Nordic countries how they are used and how often they are updated. In Norway, the indicators, with the exception of 2014, have been used in national budget analysis and most of the indicators are updated annually. In Sweden the national sustainable development indicators were first formulated in 2001 then updated in 2004.15 Since 2004, Sweden has only used the EU Sustainable Development indicator set. ${ }^{16}$ Finland carries on their commitment from the RIO+20 agreement and provides annual updates of their indicators. In 2014, Denmark launched 23 sustainable development indicators that will be up-dated in 2016 and thereafter every second year.

\footnotetext{
${ }^{13}$ www.norden.org/sdindicators

14 Norway www.ssb.no/en/natur-og-miljo/artikler-og-publikasjoner/ sustainable-development-future-challenges

Sweden www.scb.se/statistik/_publikationer/MI1303_2012A01_BR_MIFT1202.pdf Finland www.findikaattori.fi/en/kestavakehitys

Denmark: http://www.fm.dk/publikationer/2014/et-baeredygtigt-danmark-udvikling-i-balance 15 http://www.scb.se/MI1303/

${ }^{16}$ http://www.scb.se/statistik/_publikationer/MI1303_2012A01_BR_MIFT1202.pdf
} 


\subsubsection{The European Union on sustainable development}

The EU has an extensive set of indicators measuring sustainable development. The Sustainable Development Indicators (SDIs) are used to monitor the EU Sustainable Development Strategy (EU SDS) in a report published by Eurostat every second year. They are presented in ten themes. ${ }^{17}$

\section{EU themes measuring sustainable development}

1. Socio-economic development.

2. Sustainable consumption and production.

3. Social inclusion.

4. Demographic changes.

5. Public health.

6. Climate change and energy.

7. Sustainable transport.

8. Natural resources.

9. Global partnership.

10. Good governance.

\subsubsection{The United Nation and the Sustainable Development Goals}

Eradicating poverty through the increased levels of education, women's empowerment, maternal health and the preservation of the environment has been on the agenda worldwide for many years. In 2000 the United Nations Millennium Declaration was adopted. It was considered as a new global partnership to reduce extreme poverty and the goals became known as the Millennium Development Goals (MDGs), consisting of several long term goals ending in 2015 (UN 2015). Building on the MDGs are now the Sustainable Development Goals (SDGs) (UN 2014). The SDGs consist of 17 goals, each with several targets, which have been adopted by the UN General Assembly. The adopted goals, which are applicable for all countries, are:

${ }^{17}$ http://ec.europa.eu/eurostat/web/sdi/indicators 
Table 1: Adopted sustainable development goals

\begin{tabular}{|c|c|}
\hline Names & Goal \\
\hline Goal 1. & End poverty in all its forms everywhere \\
\hline Goal 2. & End hunger, achieve food security and improved nutrition and promote sustainable agriculture \\
\hline Goal 3. & Ensure healthy lives and promote well-being for all at all ages \\
\hline Goal 4. & Ensure inclusive and equitable quality education and promote lifelong learning opportunities for all \\
\hline Goal 5. & Achieve gender equality and empower all women and girls \\
\hline Goal 6. & Ensure availability and sustainable management of water and sanitation for all \\
\hline Goal 7. & Ensure access to affordable, reliable, sustainable and modern energy for all \\
\hline Goal 8. & $\begin{array}{l}\text { Promote sustained, inclusive and sustainable economic growth, full and productive employment } \\
\text { and decent work for all }\end{array}$ \\
\hline Goal 9. & $\begin{array}{l}\text { Build resilient infrastructure, promote inclusive and sustainable industrialization and foster } \\
\text { innovation }\end{array}$ \\
\hline Goal 10. & Reduce inequality within and among countries \\
\hline Goal 11. & Make cities and human settlements inclusive, safe, resilient and sustainable \\
\hline Goal 12. & Ensure sustainable consumption and production patterns \\
\hline Goal 13. & $\begin{array}{l}\text { Take urgent action to combat climate change and its impacts* } \\
{ }^{*} \text { Acknowledging that the United Nations Framework Convention on Climate Change is the primary } \\
\text { international, intergovernmental forum for negotiating the global response to climate change. }\end{array}$ \\
\hline Goal 14. & Conserve and sustainably use the oceans, seas and marine resources for sustainable development \\
\hline Goal 15. & $\begin{array}{l}\text { Protect, restore and promote sustainable use of terrestrial ecosystems, sustainably manage for- } \\
\text { ests, combat desertification, and halt and reverse land degradation and halt biodiversity loss }\end{array}$ \\
\hline Goal 16. & $\begin{array}{l}\text { Promote peaceful and inclusive societies for sustainable development, provide access to justice for } \\
\text { all and build effective, accountable and inclusive institutions at all levels }\end{array}$ \\
\hline Goal 17. & $\begin{array}{l}\text { Strengthen the means of implementation and revitalize the global partnership for sustainable } \\
\text { development }\end{array}$ \\
\hline
\end{tabular}

Source: UN 2015.

The United Nations Statistical Division (UNSD) has identified several indicators under the SDGs that could be monitored through the framework of environmental accounts (UNSD 2014). It is highlighted that it is important that the framework can ensure consistency and coherence of indicators calculated from multiple data items. It was also highlighted that the central framework of the system of environmental accounts is now a statistical standard which facilitates harmonized comparisons worldwide. 
At the same time the United Nations Environment Programme identified material flow accounts as a potential indicator candidate to follow sustainable production and consumption patterns under the SDGs (UNEP 2015).

\subsection{The indicators in this report}

Despite the comprehensive work to define common and harmonized indicator sets for sustainable development, there still remain some major challenges: the indicators are difficult to use for integrated assessments In some instances it is not possible to judge whether a positive change in the indicator should be regarded or interpreted as a sign of a positive or negative development. Therefore, approaches focusing on one aspect at the time are still prevailing both in research and policy-making.

It is the hope and proposal of the Ad Hoc Group that the Nordic countries will further explore how to apply a more integrated approach in their statistical systems as well as in their decision-making procedures, taking into account the economic, environmental and social aspects in a balanced way. Hopefully the Nordic work can also trigger similar endeavours in other regions and parts of the world, and ultimately contribute to the monitoring and review process of the global sustainable development goals.

The indicators in this report build on the framework of the environmental-economic accounts. The underlying data are a straight forward complement to GDP and provide insights on how the economy is dependent on the environment (e.g. using the natural resources as input to industries for further processing) but also from an environmental perspective of how the economy influences the environment (either through air emissions or by investing in technologies that reduces the environmental burden). Some areas are well developed, such as indicators for air emissions and environmental taxes by industry (economic activity classification NACE). Other areas within the environmental accounts are still under development, such as indicators for energy use by industry (NACE categories) or indicators that reflect ecosystem services and functions. 
The chosen indicators follow the idea of Drivers, Pressure, State, Impact and Response. Some indicators in this DPSIR framework can be derived from statistics and some require more analysis/research. In this report, the focus lie with those indicators that can be derived through statistics, and therefore only the areas of Drivers, Pressure and Responses are included.

It should be noted that indicator is a term which most often is used to describe a number (data) linked explicitly to certain scientifically determined thresholds or political goals or to phenomena, which are otherwise difficult to define or measure in an uniform way (sustainability, economic performance, welfare, etc.). Indicators should normally be seen in a specific context, which makes it possible to assess whether it is "good" or "bad" if the indicator goes up or down. Obviously this is not case for e.g. environmental tax revenues, a change of which could reflect environmental detriment as well as improvement. This also means that an aggregate can be a good indicator in one context but less useful in another depending on which goals are in focus. However, the term "indicator" is used more loosely in this report as a synonym for aggregates or data that often will be of interest in a policy context when it comes to assessments of the linkages between the economy and the environment. Keeping that meaning in mind, the indicators in this report can therefore be seen as an initial, informed selection that can be expanded on with the aid of international development of the statistical methodologies and national strategies. Such an expansion should be based on a focus on usefulness, continuity and consistency. The indictors highlighted in this report, and which are proposed to be developed at a Nordic regional level, are as follows: 
Table 2: The indicators presented in this report

\begin{tabular}{|c|c|c|c|}
\hline Name & Type & Year & Information \\
\hline \multicolumn{4}{|l|}{ Overview indicators at Nordic level } \\
\hline $\begin{array}{l}\text { Environmental economic and } \\
\text { social information }\end{array}$ & Indexed & 2008-2014 & $\begin{array}{l}\text { Shows population, number } \\
\text { of employees, GDP environ- } \\
\text { mental taxes and carbon } \\
\text { dioxide emissions }\end{array}$ \\
\hline $\begin{array}{l}\text { Contributions of environmental, } \\
\text { economic and social components }\end{array}$ & $\begin{array}{l}\text { Per cent of } \\
\text { EU28+NO+IS }\end{array}$ & 2013 & $\begin{array}{l}\text { Population, number of employ- } \\
\text { ees, GDP, environmental taxes } \\
\text { and carbon dioxide emissions }\end{array}$ \\
\hline $\begin{array}{l}\text { Country contributions to selected } \\
\text { environmental, economic and so- } \\
\text { cial components }\end{array}$ & $\begin{array}{l}\text { Per cent of Nordic } \\
\text { total }\end{array}$ & 2013 & $\begin{array}{l}\text { Population, number of employ- } \\
\text { ees, GDP, environmental taxes } \\
\text { and carbon dioxide emissions }\end{array}$ \\
\hline $\begin{array}{l}\text { Domestic extraction by material } \\
\text { category }\end{array}$ & Kilos per EUR GDP & 2013 & Type of material \\
\hline $\begin{array}{l}\text { Imports of products, by material } \\
\text { category }\end{array}$ & Kilos per EUR GDP & 2013 & Type of material \\
\hline $\begin{array}{l}\text { Energy fossil fuel use intensity, } \\
\text { by industry }\end{array}$ & $\begin{array}{l}\text { TJ per EUR value } \\
\text { added }\end{array}$ & 2008-2012 & \\
\hline $\begin{array}{l}\text { Greenhouse gases from produc- } \\
\text { tion of goods and services, } \\
\text { including households }\end{array}$ & $\begin{array}{l}\text { Tonnes } \mathrm{CO}_{2} \text { equiv- } \\
\text { alents per capita }\end{array}$ & 2013 & \\
\hline \multicolumn{4}{|l|}{ Drivers of environmental pressures } \\
\hline Real GDP growth rate & Per cent change & 2008-2013 & Volume of GDP \\
\hline Growth rate of the population & Indexed & 2002-2014 & \\
\hline Energy intensity & $\begin{array}{l}1,000 \text { tonnes oil } \\
\text { equivalents by GDP }\end{array}$ & 1990-2012 & $\begin{array}{l}\text { Gross inland energy consump- } \\
\text { tion by GDP }\end{array}$ \\
\hline $\begin{array}{l}\text { Share of renewable energy in } \\
\text { gross final energy consumption }\end{array}$ & Per cent & 2004-2012 & Structural indicator \\
\hline $\begin{array}{l}\text { Share of biofuel use of total } \\
\text { fuel use }\end{array}$ & Per cent & 2008-2011 & Structural indicator \\
\hline $\begin{array}{l}\text { Domestic extraction by material } \\
\text { category }\end{array}$ & Kilos per EUR GDP & 2013 & \\
\hline $\begin{array}{l}\text { Imports of products by material } \\
\text { category }\end{array}$ & Kilos per EUR GDP & 2013 & \\
\hline $\begin{array}{l}\text { Exports of products, by material } \\
\text { category }\end{array}$ & Kilos per EUR GDP & 2013 & \\
\hline $\begin{array}{l}\text { Domestic material consumption, } \\
\text { by material category }\end{array}$ & Kilos per EUR GDP & 2013 & \\
\hline
\end{tabular}




\begin{tabular}{|c|c|c|c|}
\hline Name & Type & Year & Information \\
\hline \multicolumn{4}{|l|}{ Pressures on the environment } \\
\hline $\begin{array}{l}\text { Greenhouse gas emission } \\
\text { intensities }\end{array}$ & $\begin{array}{l}\text { Kilos } \mathrm{CO}_{\mathrm{e}} \text { per EUR } \\
\text { GDP }\end{array}$ & 2008-2012 & Carbon dioxide equivalents \\
\hline $\begin{array}{l}\text { Share of total greenhouse gas } \\
\text { emissions, by industry (NACE) and } \\
\text { households }\end{array}$ & Per cent & 2012 & Structural indicator \\
\hline Acidifying emission intensities & $\begin{array}{l}\text { Kilos } \mathrm{SO}_{\mathrm{e}} \text { per Euro } \\
\text { GDP }\end{array}$ & 2008-2012 & Sulphur dioxide equivalents \\
\hline $\begin{array}{l}\text { Acidifying emissions per capita, by } \\
\text { industry aggregates (NACE) and } \\
\text { households }\end{array}$ & $\begin{array}{l}\text { Tonnes } \mathrm{SO}_{\mathrm{e}} \text { per } \\
\text { capita }\end{array}$ & 2012 & $\begin{array}{l}\text { Sulphur dioxide equivalents, } \\
\text { NACE aggregates }\end{array}$ \\
\hline $\begin{array}{l}\text { Emissions of particulate matter, } \\
<2.5 \mu \mathrm{m} \text {, by industry (NACE) }\end{array}$ & Per cent & 2012 & \\
\hline \multicolumn{4}{|l|}{ Responses to the drivers } \\
\hline $\begin{array}{l}\text { Environmental taxes as share } \\
\text { of total taxes and social } \\
\text { contributions }\end{array}$ & Per cent & 2008-2012 & Structural indicator \\
\hline $\begin{array}{l}\text { Energy taxes paid, by industry ag- } \\
\text { gregate (NACE) and households }\end{array}$ & EUR per capita & 2012 & Structural indicator \\
\hline $\begin{array}{l}\text { Value added and employment in } \\
\text { the environmental goods and ser- } \\
\text { vices sector }\end{array}$ & Indexed & $2003-2012$ & \\
\hline $\begin{array}{l}\text { Contributions to the EU of pro- } \\
\text { duction values from market activi- } \\
\text { ties within environmental goods } \\
\text { and services sector }\end{array}$ & Per cent of EU28 & 2012 & \\
\hline $\begin{array}{l}\text { Environmental protection ex- } \\
\text { penditures by industry aggregate } \\
\text { (NACE) }\end{array}$ & EUR per GDP & 2008-2012 & \\
\hline $\begin{array}{l}\text { Total Environmental protection } \\
\text { investments by domain and by in- } \\
\text { dustry aggregate (NACE) }\end{array}$ & Per cent & 2012 & $\begin{array}{l}\text { Areas are: air, water, waste, } \\
\text { other }\end{array}$ \\
\hline $\begin{array}{l}\text { Share of pollution prevention in- } \\
\text { vestments of total environmental } \\
\text { protection investments }\end{array}$ & Per cent & 2012 & \\
\hline \multicolumn{4}{|c|}{ Indicators based on extended analysis } \\
\hline $\begin{array}{l}\text { Greenhouse gas emissions } \\
\text { that could linked to Swedish con- } \\
\text { sumption }\end{array}$ & Tonnes $\mathrm{CO}_{2} \mathrm{e}$ & & $\begin{array}{l}\text { Carbon dioxide } \\
\text { equivalents }\end{array}$ \\
\hline $\begin{array}{l}\text { Factors affecting carbon dioxide } \\
\text { emissions in Sweden - a decom- } \\
\text { position analysis }\end{array}$ & Change in per cent & 1993-2012 & \\
\hline $\begin{array}{l}\text { Average tax (Implicit price) on car- } \\
\text { bon dioxide emissions by industry } \\
\text { (NACE) }\end{array}$ & $\begin{array}{l}\text { Euro } \mathrm{CO}_{2} \text { tax reve- } \\
\text { nue by Tonnes } \mathrm{CO}_{2}\end{array}$ & 2011 & $\begin{array}{l}\text { Including spot price of emission } \\
\text { permit (EUA) }\end{array}$ \\
\hline
\end{tabular}




\subsection{Structure of the report}

This report uses the idea of the DPSIR model, to explain the drivers, the pressures and the response to the phenomenon of the pressure created through human activities. Each chapter is followed by recommendations proposed by the Ad Hoc Group on each area, and a discussion about the benefits and care that should be taken when looking at specific indicators.

Chapter 2 begins with the provision of main Nordic indicators stemming from the proposed framework of environmental accounts.

Chapter 3 begins by using the DPSIR model to describe the main drivers of environmental pressures composing of economic and population growth, energy use and the use of materials in the economy. Chapter 4 shows different aspects of air pollution and climate change. Chapter 5 focuses on responses, not only actions by governments, but also from other actors within the economy.

Chapter 6 describes some of the models used to incorporate environmental and economic information and address interactions between the environment and the economy.

Chapter 7 discusses the aspect of social issues moving beyond GDP but which are part of the national accounts although some of these topics are outside the framework of environmental-economic accounts.

Chapter 8 looks into the new and emerging field of ecosystem accounts and the current international and Nordic initiatives of constructing and compiling data on ecosystems and ecosystem services.

Chapter 9 finally provides a platform for discussion and thoughts that the Ad Hoc Group has dealt with during the time of the project and presents some final conclusions.

Appendix 1 describes how the statistics presented in this report has been compiled and the underlying methodology that follows the statistics. It also provides a brief account of the beyond GDP debate.

Appendix 2 presents activities and processes that are on-going in the Nordic countries, under the Nordic Council of Ministers' auspices and outside the region, which area part of Task 4. 


\section{The Nordic countries - an overview}

\subsection{Summary}

This chapter brings together data from the environmental and national accounts at a Nordic level. The indicators presented cover times series combining drivers, pressures and responses to environmental degradations, foremost greenhouse gas emissions.

The environmental economic profiles, as shown in Figure 5, illustrate specific contributions of several factors. In this case, statistics on environmental taxes and GDP are shown together with statistics in physical terms such as carbon dioxide emissions. Through this kind of profile the magnitude of each aspect is visualised and can be compared nation-wide and region-wide.

The statistics can be shown using different levels of aggregation. Figure 8 shows energy intensities by industries and services according to the NACE classification. Whereas in Figure 9, the statistics are aggregated to show total emissions from the national production of goods, production of services and consumption by households. Since the detail in the underlying data is conserved, it is possible to make these types of aggregations provided that the standard statistical categories are used for the aggregations.

The development of the integrated system for environmental and economic accounts in the Nordic countries is now at a stage where the data can be combined to give a yearly overview of the environmentaleconomic situation of the Nordic countries. For the following macro indicators we have compiled and discussed the data and recommend that they inform policies of the region about the pace of the greening of the Nordic economy.

The Ad Hoc Group recommends that the Nordic Council of Ministers should provide an annual publication of indicators visualised below by:

- Environmental, economic and social information. See Figure 3.

- Contributions to selected environmental, economic, and social information. See Figure 4. 
- Contributions to the Nordic region, by country, environmental taxes, $\mathrm{CO}_{2}$ emissions, number of employees, GDP and population, per cent. See Figure 5.

- Domestic extraction by material category Kilos per Euro GDP, Year. See Figure 6 below.

- Imports of products, Kilos per Euro GDP. See Figure 7.

- Energy fossil fuel use intensity, TJ per Euro, by industry, NACE. See Figure 8.

- Greenhouse gas emissions by industry (NACE) and households. Million tonnes per capita. See Figure 9.

\subsection{Integrating the economy and the environment}

\subsubsection{Introduction}

The Nordic countries, Iceland, Norway, Denmark, Finland and Sweden share many things. They share a similar background of social democracy, free speech and access to good healthcare and education. Our countries also have a wealth of natural resources including forests, minerals and water in Finland, Sweden and Norway; wild fish stocks in Iceland, Norway and Denmark; and Denmark and Norway have oil and natural gas resources.

The countries also share a history of willingness to take care of the land and nature and take responsibility for our part in reducing climate change and its impacts. The trends show that it is possible to do this and maintain healthy economies.

The Nordic countries cooperate in many areas and have had an interest in promoting sustainable development for a long time. The countries are different in their industrial development but still share values on the importance of the healthy environment, sustainable economic growth and wellbeing for all citizens. From a statistical point of view the Nordic countries share a long history of sharing practises and ideas on the further developments of statistics and accounts environmental-economic accounts, the Nordic countries have been close partners in testing and developing this integrative area of statistics since the early 1990s. In 1995 the Nordic Natural Resource and Environmental Accounting report was published, in 2000 the publication Nordic environmental economic indicators and in 2003 Energy taxes in the Nordic countries - does the polluter 
pay was published under the auspices of the Nordic Council of Ministers and the European Commission.

The Nordic region was the first geographical region in the world adopting a Strategy for Sustainable Development in 2001. The most recent Strategy "A good life in a sustainable region" was adopted in 2013 by the Nordic Council Ministers. The strategy explains that all work conducted by the Nordic Council of Ministers will incorporate a sustainability perspective. This strategy provides not only a direction but also guidelines for the Nordic countries to continue to improve the welfare and quality of life for present and future generations. The strategy will take us into 2025 with focus areas such as: the Nordic welfare model, viable ecosystems, changing climate, sustainable use of the earth's resources, and education, research and innovation (Nordic Council of Ministers, 2013).

The natural resources dependent activities such as oil and natural gas extraction, mining, timber and pulp, paper and wood industries, fishing and agriculture are important in the Nordic region. It is also a region that has invested in renewable energy and has established carbon taxes as an incentive to steer development towards a greener energy system. Crosssectoral working groups on Environment and Economy as well as climate change mitigation have been established under the Nordic Council of Ministers to deal with relevant environmental economic matters of common Nordic interest.

The statistical offices in the Nordic countries have a long history of working with environmental accounting and in modelling. Nordic countries have also identified national indicators for sustainable development, encompassing a wide range of socio-economic and environmental indicators to better serve the policy-makers on emerging issues and trends. The need to develop broader measures of progress and more integrated statistical systems and analyses has been identified at the Nordic level.

An overview of some of the challenges, polices, achievements and remaining problems in combining economic development and ambitious environmental policies in the Nordic Countries over the past few decades is given in the report "Greening the economy: Nordic experiences and challenges" (Magne Skjelvik, Bruvoll \& Ibenholt, 2011).

The challenges described in that report include the need for the enhancement of environmental economic instruments including the pricing of pollution, and how these different instruments can be combined in a cost-effective manner. 


\subsubsection{The Nordic situation}

Being part of the European Economic Area (EU + EFTA countries) means that our economies have free access to larger markets and free movement of people. But this also means new demands and restrictions. Some restrictions can relate to taxation systems, emission levels, employment conditions, etc.

Generally speaking the overall trends in the Nordic region are positive, both in terms of economic growth, and also importantly, in the reduction of carbon dioxide emissions, an important Greenhouse gas, as seen in Figure 3. The population is increasing steadily, but employment is unchanging. Interesting to notice is that the income generated through environmental taxes is on the increase. The impact of the financial crisis is seen in the Nordic region. Examining GDP, employment and environmental tax revenues all decreased in 2009. Employment did not recover until after 2010.

Figure 3: Environmental, economic and social information 2008-2014; Nordic countries total, Indexed 2008=100

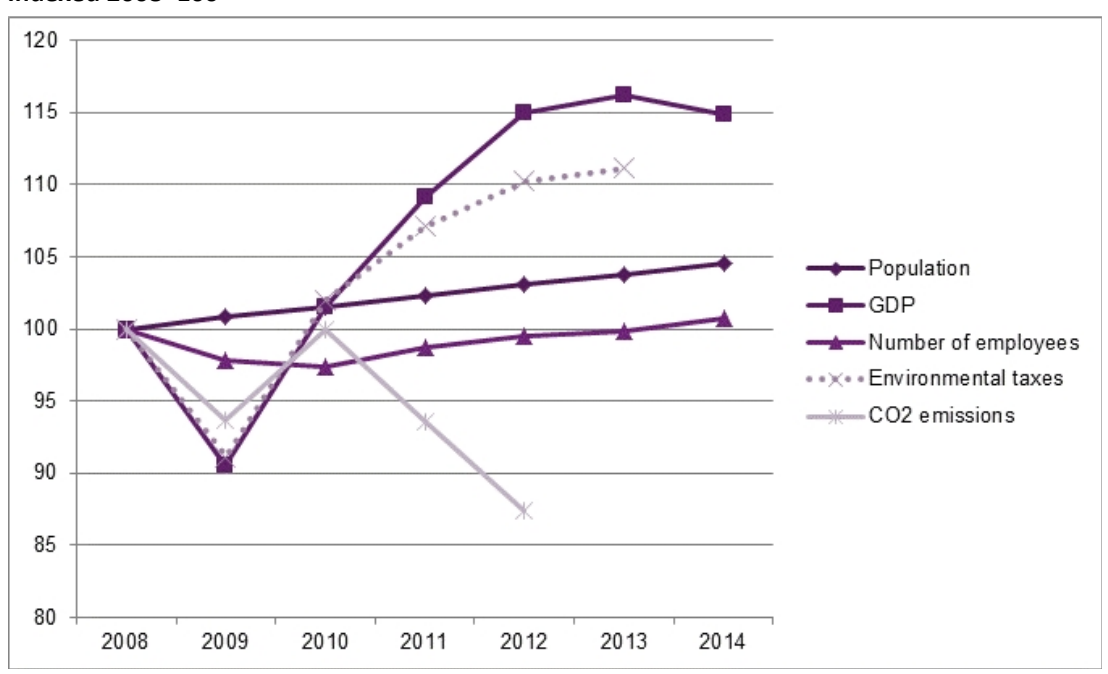

Note: To add the Nordic countries, GDP at current prices has been used.

Source: Eurostat and Statistics Iceland. 
The Nordic countries contribute to the European Economic Area (EEA) in many ways. For our joint population (Denmark, Finland, Iceland and Sweden), we account for $5 \%$ of the EU and EFTA population and $6 \%$ of carbon dioxide emissions.

In 2013, our joint contribution to the EEA GDP is just below 10\%. This can be considered a large share in view of our small share of the EEA population. The same thinking can be applied to the considerable share of environmental tax revenues the Nordic countries have within the EU and EFTA region.

Figure 4: Contributions of environmental, economic and social components from the Nordic countries to the EU28+NO+IS, 2013. Environmental taxes, CO2 emissions, number of employees, GDP and population, per cent

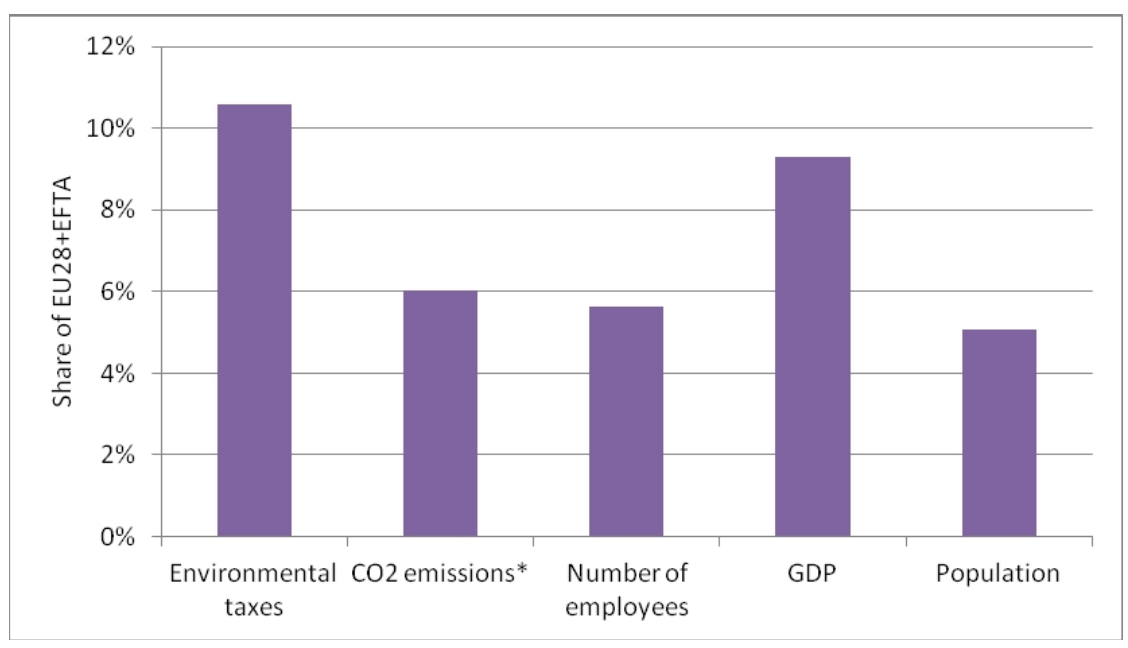

Note: CO2 emissions year 2012. Data for Iceland follow UNFCCC definitions.

Source: Eurostat and Statistics Iceland.

There are differences between the Nordic countries in population size, energy systems, industrial structure and environmental policies. And following on figure 4 a country breakdown can be made to visualise how each of the Nordic countries looks like.

Denmark and Sweden account for just below $60 \%$ of the environmental taxes paid to governments in the Nordic countries. The emissions of carbon dioxides from Denmark are dominated by the shipping industry, and the production of electricity is heavily dependent on coal-fired power plants but the energy system is changing due to large investments in wind turbines and biofuels. Norway's emissions of carbon dioxide are mainly 
coming from the petroleum industry, which is also a very important contributor to the GDP, while the national energy system is almost entirely using hydro power for the production of electricity.

Figure 5: Country contributions to selected environmental economic components in the Nordic region, by country, 2013, environmental taxes, CO2 emissions, number of employees, GDP and population, per cent of Nordic total

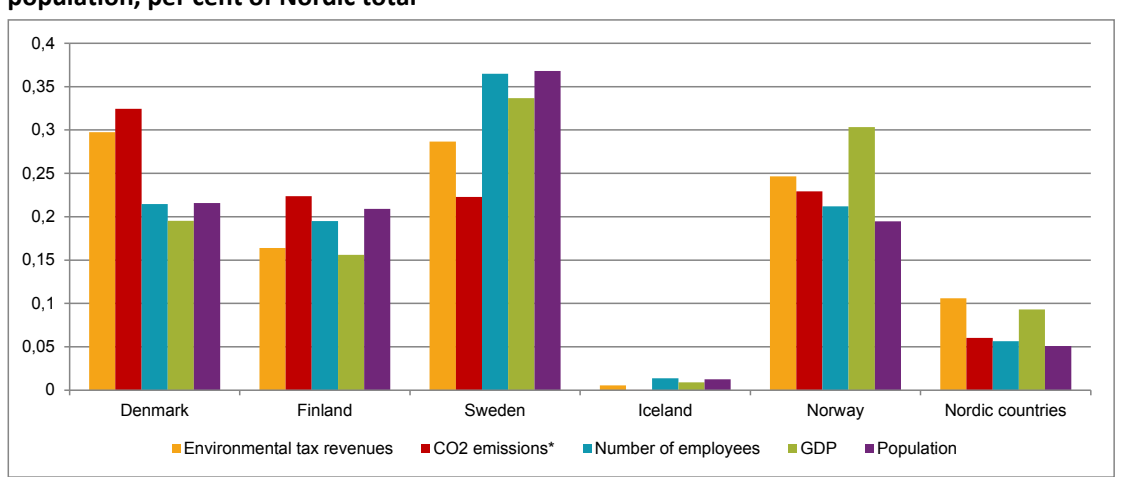

Note: CO2 emissions year 2012. Data for Iceland follow UNFCCC definition.

Source: Eurostat and Statistics Iceland.

Table resources are an important base of the economy. The Nordic countries are richly endowed with natural resources and these have been the base for industries such as the pulp and paper industry, the steel industry, petroleum industry and for agriculture.

Compared to the EU average, and put in relation to the GDP, Finland, Sweden and Norway have a larger domestic extraction and production of biomass and other natural resources from their natural endowments. In contrast to the EU and to the other Nordic countries, Denmark extracted fewer natural resources. For EU28 the yearly extraction and production of biomass employed to produce EUR 1 of GDP was 0.43 kilos in 2013. Denmark, Finland, Sweden and Norway were at $0.38,0.81,0.52$ and 0.81 kilos per Euro GDP, respectively. The high numbers for Finland and Norway are due to the structure of their economies which are largely based on the extraction of non-metallic minerals and biomass from forestry, and natural gas and crude oil, respectively. 


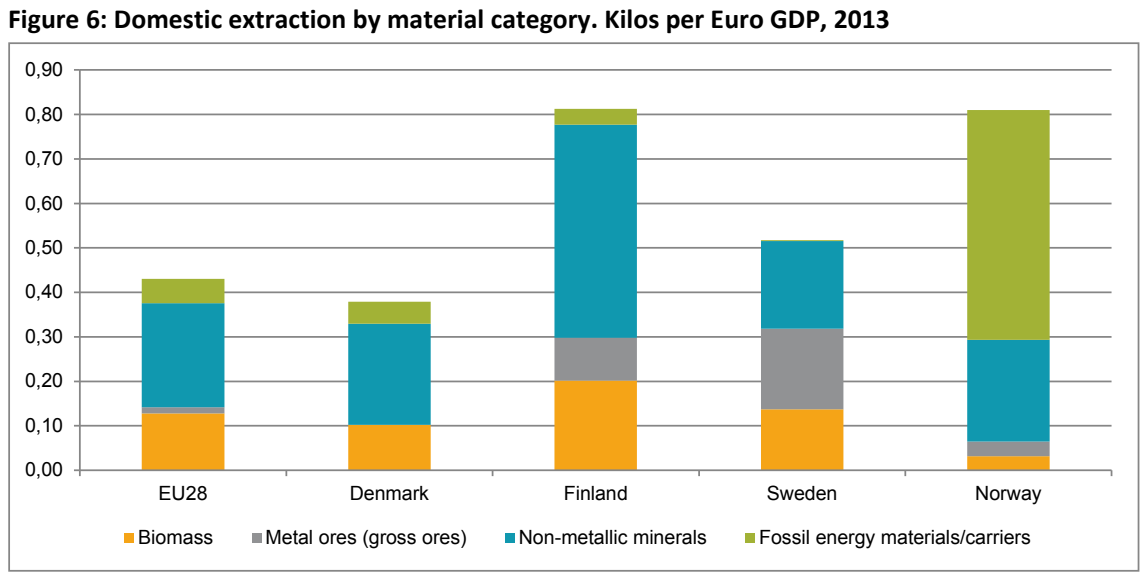

Source: Eurostat.

In Denmark the production of biomass relates first of all to crop production, while wood accounts for a bigger part of the biomass in Finland and Sweden.

All Nordic countries, and especially Finland, had substantial levels of extraction of non-metallic minerals, which are predominantly used for construction activities. Sweden, and to some extent Finland, also had high levels of extraction of metal ores, including iron, copper and precious metals.

In addition to domestic extraction are the imports of products, measured as their mass weight, when crossing the border. All Nordic countries had substantial material inputs from abroad. Denmark and Finland are the two Nordic countries with the highest level of per Euro GDP imports at 0.23 and 0.29 in kilos per Euro GDP, while the imports to Sweden and Norway were at 0.18 and 0.10 kilos per Euro GDP, respectively. Denmark and Finland are both importing substantial quantities of fossil fuel, while especially Norway had lower levels of imports of these products. 
Figure 7: Imports of products. Kilos per Euro GDP, 2013

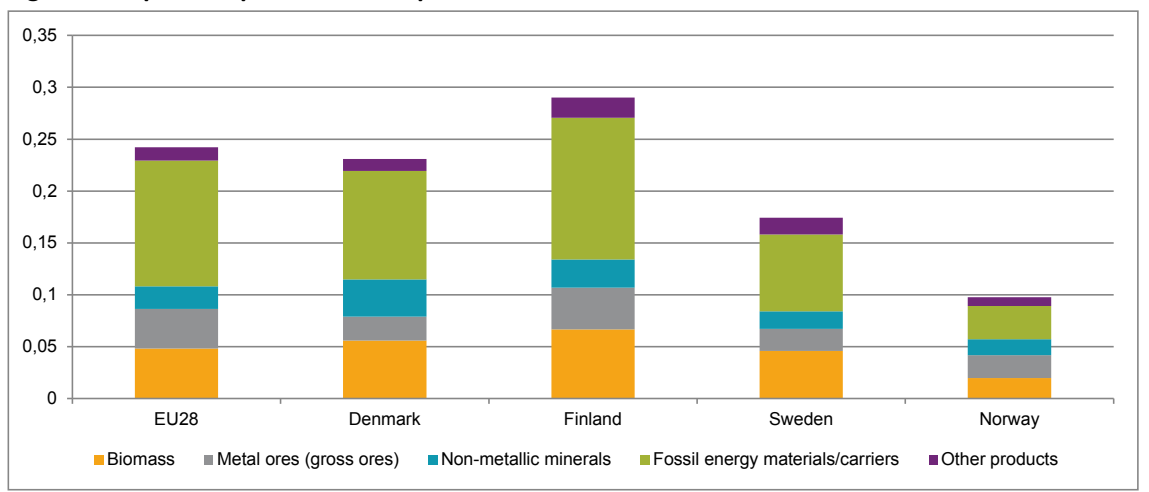

Note: "Other products" are mostly products that are highly processed and consist of a complex mix of materials for which it is not possible to determine a main material component (Eurostat 2013a).

Source: Eurostat.

The most prominent source of climate change related greenhouse gas emissions is the burning of fossil fuels. The Nordic countries are working extensively on combating the emission levels, through taxation, capand trade systems and other policy measures as well as technological advancements.

In the Nordic region, the largest users of fossil fuels are the transport industry in all countries, the electricity and gas producers in some countries and the manufacturing industry in other countries. All of these industries are becoming more and more efficient in their use of fossil fuels. The largest reduction of energy intensities comes from the electricity, gas, steam and air conditioning supply industry and within the manufacturing industry in Denmark and Finland. 
Figure 8: Energy fossil fuel use intensity, TJ per million Euro value added, by industry, NACE 20082011, Nordic countries total, excluding Iceland

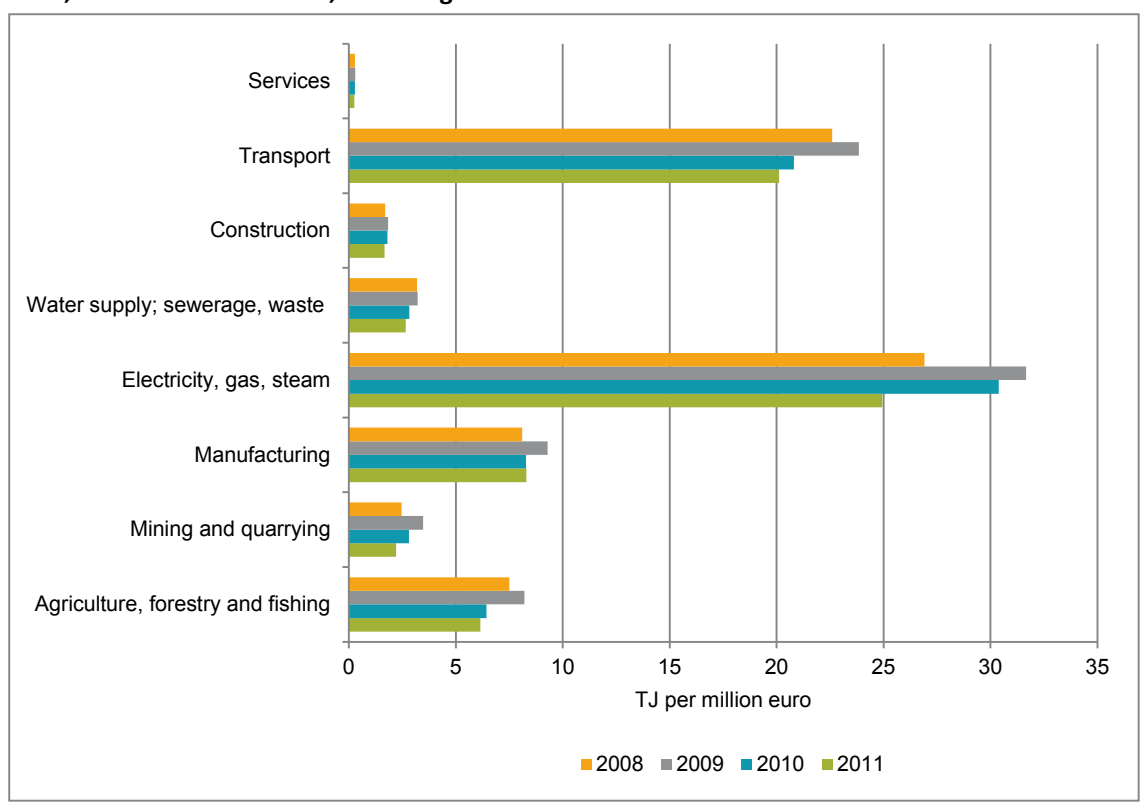

Source: The Nordic statistical offices and Eurostat, data for Iceland are not available.

It is also possible to view the emissions by group of activities. Figure 9 shows that overall in the Nordic countries, the direct emissions from heating homes for households together with household emissions from transportation are relatively small, and that the emissions are relatively even between the production of goods and production of services. The exception is Denmark where the shipping industry is noticeable in the production of services. 
Figure 9: Greenhouse gases emissions, 2012, tonnes per capita, Nordic countries (excluding Iceland), NACE aggregates and Households

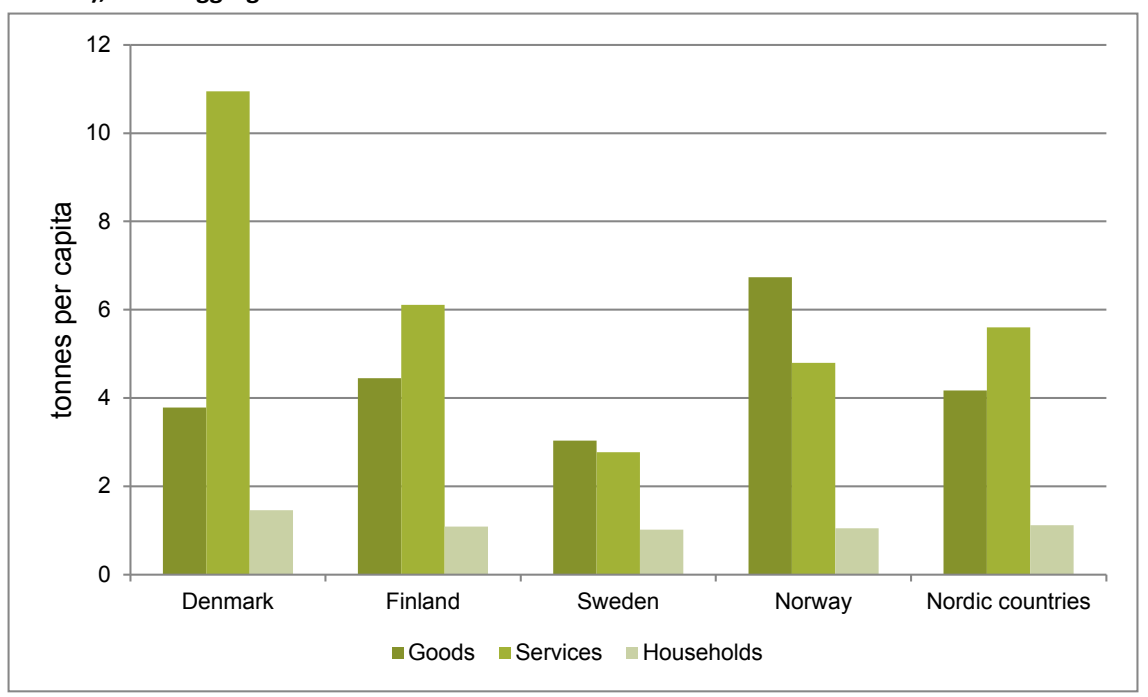

Note: Goods=includes NACE Agriculture, forestry, fishery, mining, quarrying, manufacturing and construction. Services= includes NACE electricity, gas, heating, waste water and waste management, financial services, transport, health and education. Households= direct emissions from household activities, e.g. vehicles, heating and other activities. Data for Iceland is not available.

Source: Eurostat. 


\section{Driving forces - from the economy and society}

\subsection{Summary}

Important driving forces that determine the size of the environmental pressure is the size of the production and consumption activities in a region. Of importance and closely connected to the environmental pressure from the economy is also the energy system infrastructure, i.e. how electricity and heat are generated, and the use of fossil fuels. The analytical starting point is the national accounts - where we find the basis for calculating the macroeconomic indicator, GDP. The description of the economy needs to be "opened up" so that the structure of production and consumption can be seen, since the environmental pressure is very different depending on the type of economic activity analysed. The Nordic countries differ in their economic structure but they all have developed electricity and heat systems that have relatively little fossil fuel input. Whereas, the extractive industries in the Nordic countries make the material flows from the region unusually high as compared to the mean of the EU countries.

The Ad Hoc Group recommends an annual publication of below visualised indicators by the Nordic Council of Ministers:

- Real GDP growth rate - volume, percentage change from the previous year. See Figure 10 below.

- Growth rate of the population, indexed. See Figure 11 below.

- Energy intensity, kilos of oil equivalents per EUR 1,000. See Figure 12 below.

- Share of renewable energy in gross final energy consumption. Per cent. See Figure 13 below.

- Share of biofuel use in total fuel use. Per cent. See Figure 14 below.

- Domestic extraction, by material category. Kilos per Euro GDP. See Figure 15 below.

- Imports of products, by material category. Kilos per Euro GDP. See Figure 16 below. 
- Exports of products, by material category. Kilos per Euro GDP. See Figure 17 below.

- Domestic Material Consumption, by material category, DMC. Tonnes per Euro GDP. See Figure 18 below.

It should be emphasised, that these indicators are aggregate indicators, which can cover up more diversified developments seen at more detailed levels. For instance, the GDP growth rate focuses on the overall economic activity, but tells nothing about the structural development of the economy and the development in income or wealth distribution, etc. Similarly, the aggregates for natural resource extractions and foreign trade of products sum up the weight of different resources and types of products with no regard for environmental pressures. As with the example of the material consumption, a measure that contains fossil fuels as well as sand and gravel, the environmental pressures need to be assessed separately. As such the indicators should be interpreted with care and always be put into a specific context.

The indicators on energy intensities and share of renewable energy in gross final energy consumption should, like others, be revisited in a couple of years to establish a changeover to indicators that follow the framework and definitions of environmental accounts. It is important that the indicators align to the same framework for a full and comprehensive analysis to be made.

Mandatory annual data reporting of energy accounts to Eurostat, the European statistical office, starting in 2017, means that this data will be readily available soon. All Nordic statistical offices are currently working to establish regular routines to produce and disseminate these statistics.

The present work of the Ad Hoc Group links to the work in the StiglitzSen-Fitoussi report (2008) and the OECD report (2011) on measurements of green GDP. Rather than to dig deep into the intricacies of a green GDP, the thrust of the effort is on developing a Nordic set of already existing indicators and measures, which relate to the SEEA Central Framework. This can be used besides GDP, as a satellite environmental account, that could be combined with traditional SNA national accounts and provide input for thorough, transparent and reliable analysis of the interplay between economy and environment. A common Nordic effort in this field would be a path-breaking contribution to the follow-up of the new UN sustainable development goals. 


\subsection{The economy and our population}

\subsubsection{Introduction}

Economic growth and development has led to and still lead to severe and critical environmental pressures. They are seen as drivers to environmental degradation. Breaking the link between growth and environmental degradation, by "delinking" or "decoupling", has become a central element in environmental and green growth policies internationally. ${ }^{18}$ Ecosystem thresholds, critical loads, carrying capacities and planetary boundaries mean that in many cases even this may not be sufficient to reach environmental targets, ${ }^{19}$ but indicators of decoupling, relative or absolute, are very useful to track trends and demonstrate progress.

Further, our use of materials has economic, social and environmental consequences, which extends beyond our Nordic borders. Thus, our imports of products from other countries do not only create income and jobs around the world, but also affects resource extraction and environmental pressures in the exporting countries. Likewise, exports by the Nordic countries contribute to our economic welfare but serve at the same time as a driver for environmental degradation and depletion in the Nordic area.

Useful indicators include resource use intensities and efficiencies, which are also linked to the concept of "eco-efficiency" at the product and company level. The most recent trends, at least for most OECD countries, are that energy and materials intensities show relative decoupling, some countries have achieved absolute decoupling while most countries still are a long a way from goals based on planetary boundaries, such as the two-degree target. ${ }^{20}$ It should be underlined that decreasing intensities or decoupling on national or sectoral levels do not necessarily constitute necessary conditions for a resource efficient or cost effective development at a global level and therefore should be interpreted with due caution Actually, in some instances even increasing national intensities could signal improvements in global resource efficiency.

There is an increasingly global nature of economic activities, where natural resources are more and more mobile and where national econo-

\footnotetext{
${ }^{18}$ Relative decoupling implies reduced environmental pressure (e.g. energy/resource use or emissions) per unit of production or Gross Domestic Product (GDP), while absolute decoupling means that the total volumes or amounts of resource use or emissions are reduced, even with economic growth.

19 On "planetary boundaries" a recent report, from the Stockholm Resilience Centre, was published in "Science" in January 2015.

${ }^{20} \mathrm{~A} 2 \mathrm{C}^{\circ}$ increase in temperature, measured against pre-industrial temperature levels.
} 
mies rely more and more on international trade cooperation. Comparative advantages of production are exploited through expanding world trade generally resulting in a more over all efficient use and allocation of scarce resources.

The aftermath of the financial crisis of 2009 is still visible as the growth in gross domestic product (GDP) is not yet stabilised across the EU nor in the OECD. The EU has seen the potential of increasing the notion of a "green economy" and promoting manufacturing in the EU towards more efficient production processes leading to a reduced environmental burden. ${ }^{21}$ In turn the OECD launched the "Green Growth Strategy" where the OECD put emphasis on improving resource productivity and ensuring a sustainable resource and materials management. ${ }^{22}$

\subsubsection{The Nordic situation}

Each of the Nordic countries felt the effect of the financial crisis in 2009 and Finland is still experiencing economic contraction with a negative GDP growth rate. The indicator "Real GDP growth rate" allows for comparisons of the dynamics of economic development both over time and between economies of different sizes.

Figure 10: Real GDP growth rate - volume, percentage change from previous year

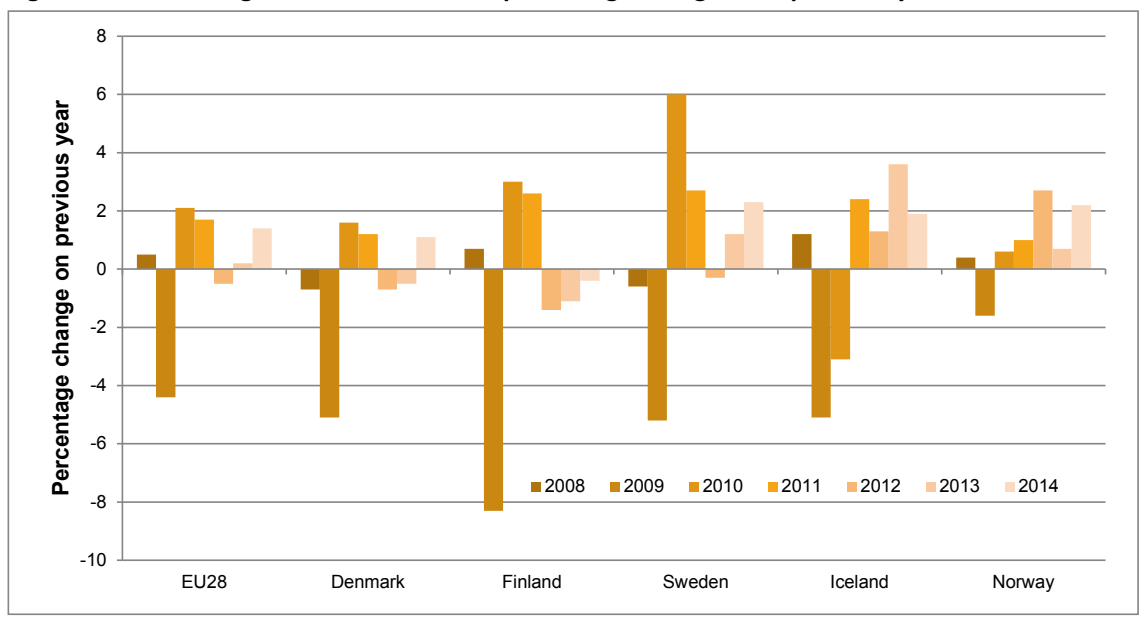

Source: Eurostat.

21 The 7th environment action programme to 2020 .

${ }^{22}$ For a discussion of the GDP concept see appendix 1. 
As the population increases so may also the labour force. A growing population also increases the potential for growing national income and/or further environmental damage depending on economic and political development. In all Nordic countries populations are growing, with the highest rate seen in Iceland.

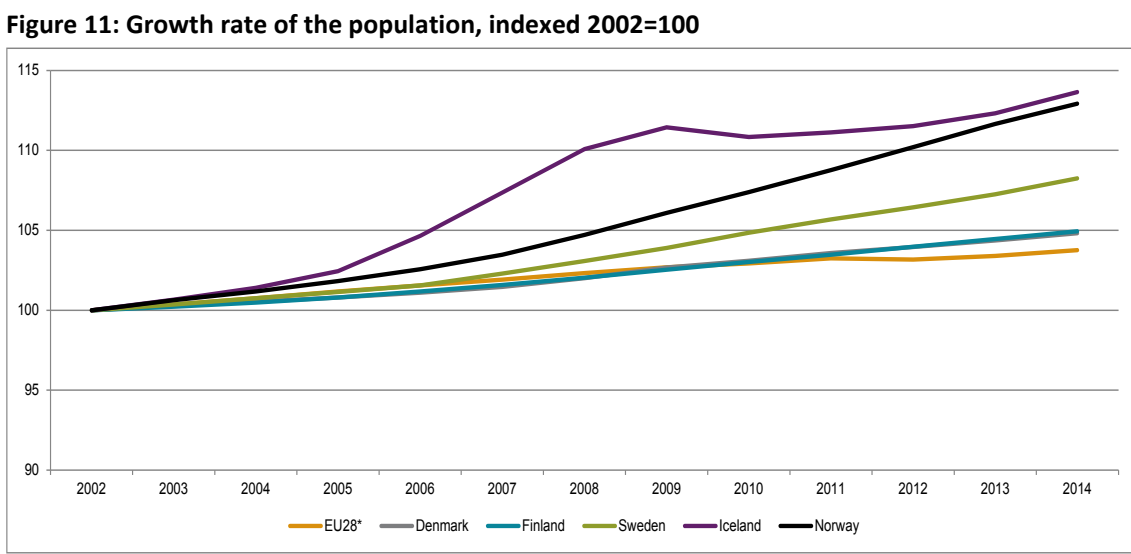

Note: EU28*: break in times series in 2007, 2011 due to the succession of a pre and post census reference year. EU28 2013-2014 are provisional.

Source: Eurostat.

\subsection{Use of energy}

\subsubsection{Introduction}

In modern economies, energy is an essential input factor. However, energy production, use of fuel in transportation and in production processes has consequences irrespective of the energy source. These include air pollution and climate change, water pollution, solid waste problems and impacts on landscape and biodiversity. Efficient use of energy is particularly important in the context of sustainability.

The EU is aiming for an EU-wide reduction in energy use, setting the targets at $20 \%$ energy savings by 2020 - the EU compare the target to the amount generated by 400 power stations. ${ }^{23}$ Contributions to these targets are implemented through policies and measures in the Nordic countries.

23 Directive 2009/28/EC of the European Parliament and of the Council of 23 April 2009 on the promotion of the use of energy from renewable sources (2009/28/EF) http://ec.europa.eu/energy/en/topics/ energy-efficiency 
Monitoring and managing the use of energy resources are important from various perspectives. Firstly, the continued uses of fossil energy resources are important to monitor as these are still the main energy sources as inputs into production and consumption processes. Important international trade flows of energy products have placed a focus on the risk of supply disruptions and on price volatilities. Secondly, the link between burning fossil fuels and climate change requires a far reaching and extensive effort from society to limit emissions and avoid effects of climate change. Thirdly, good energy resource management and increased energy productivity are important for companies to strengthen their competitiveness.

When it comes to monitoring countries' overall energy use, statisticians have developed the so-called physical energy accounts, which measure the total supply and use of energy during a year. ${ }^{24}$ This differs from the established framework on energy balances and more information about the differences in these two approaches is described in Annex 1. The accounts have more disaggregated data by industry when compared to the energy balances. The energy balances are designed to show the national amount of energy produced and how it links to the energy used, with the losses that occur in the transformation and has been developed to answer questions from of the energy sector. The accounts are aligning this data with the industries, e.g. the transportations sector is more detailed and the transports are connected to the industries that use them. This makes it possible to measure energy intensity or energy productivity of the economic activities. The intensity measures, e.g. the fossil fuel use per value added, shows the amount of fossil fuels used to produce the value added. The productivity indicator measure value added to fossil fuel use, i.e. how much value added does $\mathrm{X}$ amount of fossil fuels bring to the economy.

\subsubsection{The Nordic situation}

The Nordic countries keep increasing their energy consumption in absolute terms. One driving factor of the increase of final energy consumption in Iceland is due to an increase in the production of non-ferrous metals (e.g. aluminium). Although total energy use keeps increasing, all Nordic countries are becoming more and more efficient in their use of energy. In the Nordic countries, except Iceland, and in the EU28, the energy intensity is decreasing. The energy intensity, measured as energy consumption per unit GDP in Euros, is shown in Figure 12.

24 The UN is about to publish the handbook on energy accounts - SEEA-Energy. 
The energy intensity has decreased the most in Sweden, Denmark and Finland, while it has increased by about $40 \%$ in Iceland compared to the 2001 level. The intensity measure shows how much energy is needed to produce the value added to the economy, the GDP. The lower the intensity, the less amount of energy is required for input to the economy.

Figure 12: Energy intensity, Kilos of oil equivalents per 1,000 Euro GDP Nordic countries and EU28. 2001-2012

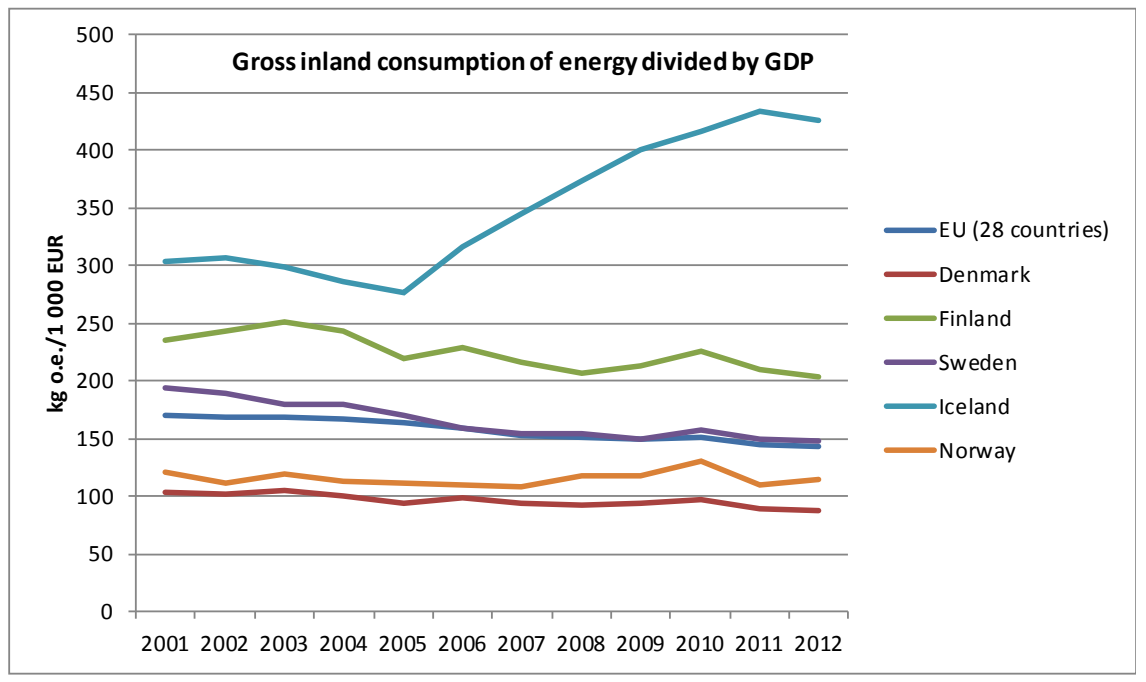

Note: Gross inland consumption of energy divided by GDP.

Source: Eurostat.

While it is an important indicator, the viewpoint of gross energy consumption and the need we have for a secure and stable electricity supply can be supplemented with knowledge about what type of energy sources we are drawing from. Statistics show that the share of renewable energy in the energy consumption has increased in all the Nordic countries and in EU (Figure 13). The share of renewables has become an increasingly explicit policy targets in the Nordic and EU countries. This has been motivated by the EU as a mean to combat climate change in Europe. However when looking at energy from a climate change policy point of view it should be also taken into account that nuclear power while not falling under the definition of renewables still is a low or zero greenhouse gas emissions energy source alternative. The drawback of radioactive waste is the on the other hand also to be considered. 
The highest shares for energy produced from renewable sources are found in Norway and Sweden, two countries with a lot of electricity produced using hydropower. The EU has established the overall target of a $20 \%$ share of renewable energy in the European Union by 2020, but all the EU countries also have individual targets concerning the increase in the share of renewable energy. Norway and Iceland, as members of the European Economic Area (EEA) agreement, also have targets for 2020 (the targets are indicated in Figure 13).

Figure 13: Share of renewable energy in gross final energy consumption, Nordic countries and EU28. 2004-2012. Per cent

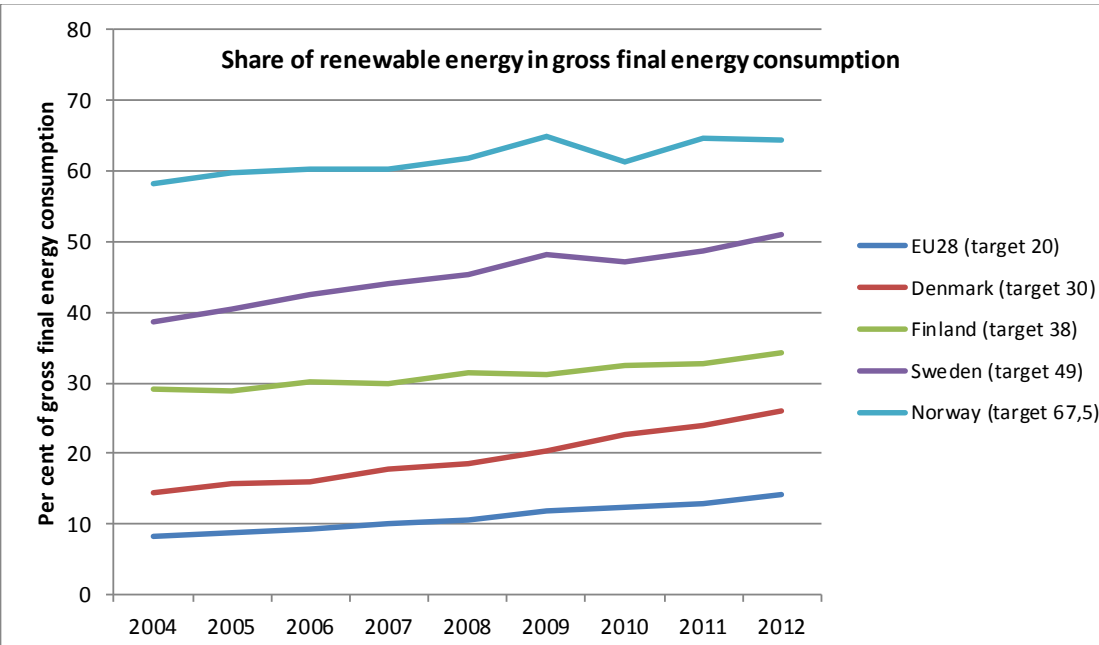

Note: This indicator is calculated on the basis of Directive 2009/28/EC on the promotion of the use of energy from renewable sources. Data for Iceland is not available.

Source: Eurostat.

The use of fossil fuels is still a major driving force for emissions of greenhouse gases, but more and more alternative energy sources are becoming available on the market, to industries and to households.

In the Nordic countries the share of biofuels used is increasing and is often replacing the use of fossil fuels. Between 2008 and 2011 households were steadily replacing fossil fuels with biofuels, as were most of the industries of the Nordic economies. The electricity, gas and steam suppliers are increasing the share of biofuels mostly along with the water and waste management, construction and transport industries. However, agriculture and the manufacturing industry have not yet been able to substantially replace their use of fossil fuels. 
Figure 14: Share of biofuel use of total fuel use. The Nordic countries (combined), 2008-2011. Per cent

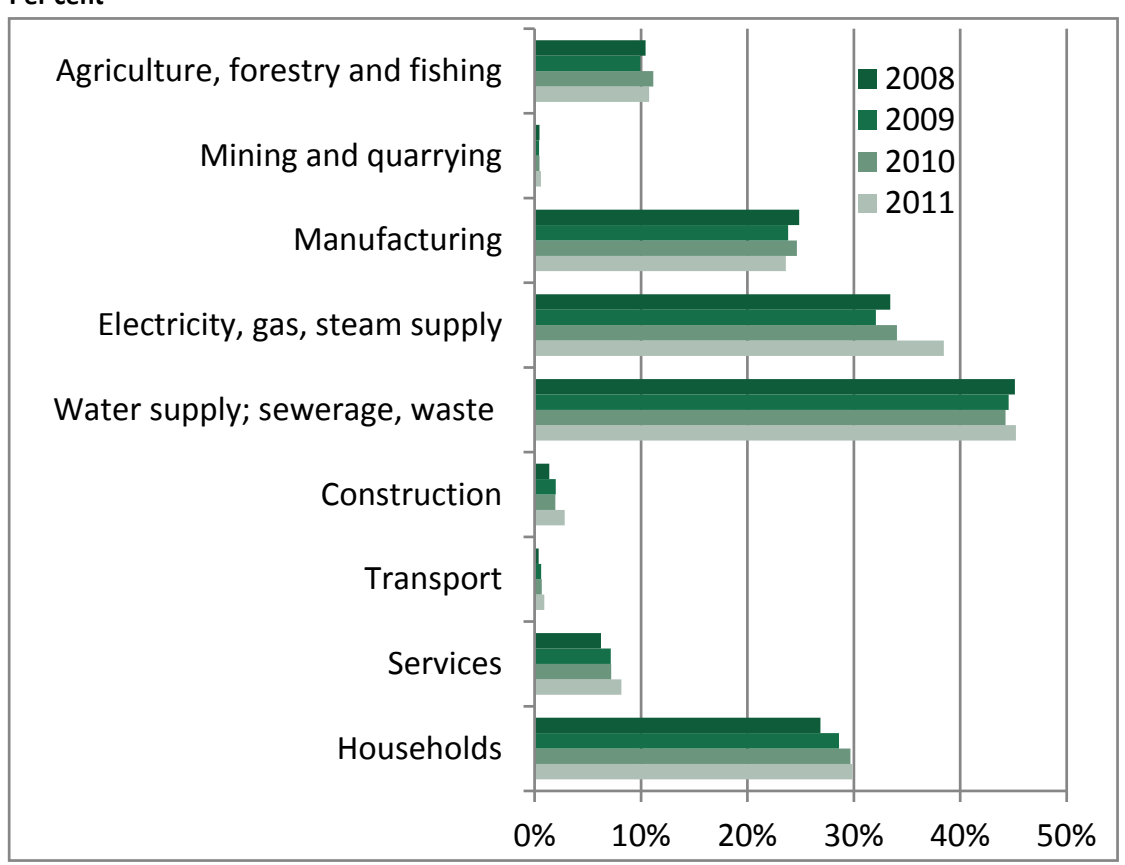

Source: Nordic statistical offices, data from Iceland not available.

\subsection{The need for materials}

\subsubsection{Introduction}

Human activities cannot persist without the use of materials in one form or another. It is the use of millions of tonnes of raw materials, energy, food, water, etc. that provides the foundation our economies and well-being.

While natural resources and material supplies to some extent are still regarded by many as being available in abundance it is increasingly recognized that there is a need to ensure good management of the natural resources and the use of materials in order for economies to develop successfully and fulfil the goals of society, regardless of whether these goals are formulated in terms of economic growth, green growth, sustainable development, or development of welfare. Concerns regarding the supply of exhaustible resources are increasing but so is the potential for finding substitutions for these types of resources. 
Monitoring and managing the use of materials is important from various perspectives. Firstly, the continued availability of natural resources and materials are obviously important to ensure inputs for production and consumption. Increasing international trade flows of commodities has placed a focus on the risk of disruptions in supplies and increasing raw material prices. Secondly, it is recognised that there is a close relationship between the use of materials and the generation of waste and other residuals (pollution). These residuals can have a harmful effect on the environment or, alternatively, requires an expensive effort from society to avoid these harmful effects. Thirdly, good materials management and increased resource productivity are important for companies to increase their competitiveness.

At the policy level natural resource and material use management is addressed in various national sustainable development strategies and environmental policies, including initiatives for waste prevention and integrated product policies. Companies address it by highlighting material use in green accounts, investing in research and development and ecodesign leading to reduced resource intensity and quality of production.

When it comes to monitoring countries' overall material use, statisticians have developed the so-called economy-wide material flow accounts (part of the SEEA CF), which measure the total use of materials during a year. The statements that can be made based on these accounts correspond, for instance, to the familiar statements about the total national energy use during the year, but now focusing on natural resources and materials instead.

The supply of materials to the economy consists of domestic resource extraction, changes in inventories and imported products. Domestic extraction and imports are the two main sources of material inputs to a national economy. The economy-wide material flow accounts indicator, direct material input, DMI, is the sum of all domestic resources extracted plus the imports. If the exports of materials are subtracted, the indicator called domestic material consumption, DMC, is obtained. The latter can be seen as an indicator of the total amount of materials, which have been used by the economy during that time period and remains on the national territory. In that sense, it can also be considered as an indicator of the amount of waste and other residuals, which the economy at some point in time needs to take care of. 
More information about the statistical methodology used is available in Appenidx 1. And similarly to the measurement of energy intensity or energy productivity it is possible to measure materials intensity or material productivity of the economic activities, for example as GDP to domestic material consumption.

\subsubsection{The Nordic situation}

Compared to the EU, and put in relation to the GDP, Finland, Sweden and Norway had a larger domestic extraction of biomass and other natural resources from their natural endowments. In contrast, Denmark extracted fewer natural resources. For EU the yearly extraction and production of biomass employed to produce EUR 1 of GDP was 0.43 kilos in 2013. Denmark, Finland, Sweden and Norway had a total extraction and production of biomass per Euro GDP at $0.38,0.81,0.52$ and 0.81 kilos, respectively. The higher intensities for Finland and Norway are due to the extraction of non-metallic minerals, natural gas and crude oil, respectively.

Figure 15: Domestic extraction, by material category, Kilos per Euro GDP. Nordic countries and EU 2013

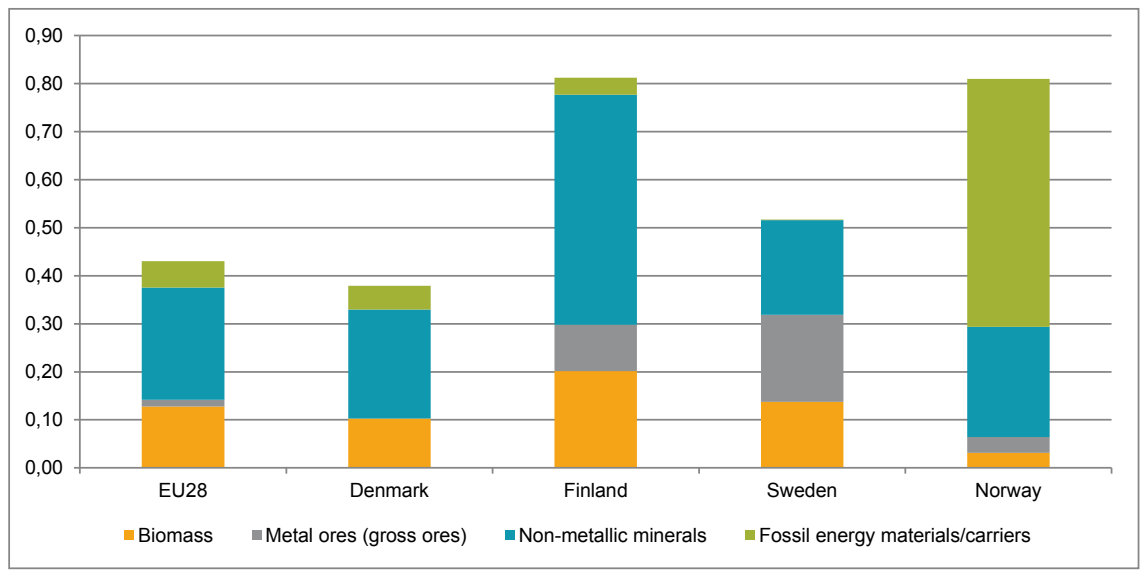

Source: Eurostat.

Finland and Sweden had per Euro GDP production of biomass above the EU level, while Denmark produced less biomass than the average EU level. In Denmark the biomass relates first of all to crop production, while wood accounts for a bigger part of the biomass extraction in Finland and Sweden. 
All Nordic countries, and especially Finland and Norway, had a substantial extraction of non-metallic minerals, which are predominantly used for construction activities. In contrast to the EU and the other Nordic countries Sweden had a large extraction of metal ores, including especially iron, copper and precious metals.

The domestic extraction is augmented by the import of products measured as their mass weight when crossing the border. All Nordic countries had substantial material inputs from abroad. Denmark and Finland are the two Nordic countries with the largest per Euro GDP imports at 0.23 and 0.29 kilos per Euro GDP, while the imports to Sweden and Norway were at 0.18 and 0.10 kilos per Euro GDP. The main difference between these two groupings of Nordic countries (Denmark and Finland; Sweden and Norway) can best be explained by the degree of dependency of imported fossil fuels. Denmark and Finland are both importing substantial quantities of fossil fuels, while especially Norway had lower imports of these products.

Figure 16: Imports of products, by material category, Kilos per Euro GDP. The Nordic countries and EU, 2013

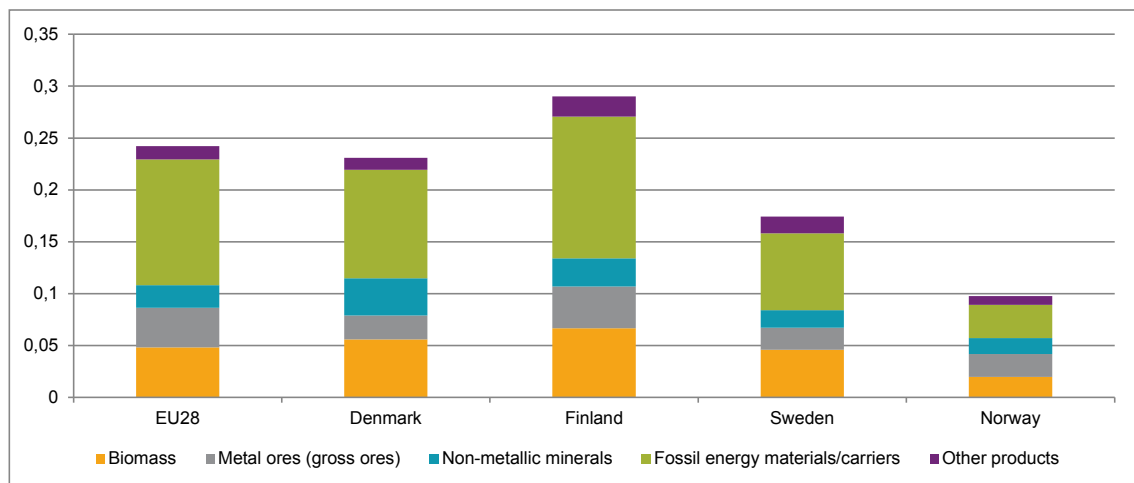

Note: "Other products" are mostly products that are highly processed and consist of a complex mix of materials for which it is not possible to determine a main material component (Eurostat 2013a).

Source: Eurostat.

The imports of products of the EU were 0.24 kilos per Euro GDP, i.e. at a level almost the same as in Denmark but significantly higher than the imports of Norway. However, the EU28 number includes the intra EU imports (i.e. imports from one EU country to another). If intra-EU imports are excluded so the area EU28 is treated more like a "country" when counting, the imports per Euro GDP of the EU28 were 0.13 kilos. 
Imports together with the domestic extraction form the direct material input (DMI), i.e. the amount of materials that is actually available to the country as a physical basis for all economic activities. In 2013 the DMI was 0.67 kilos per Euro GDP for the aggregated EU economy. For Denmark, Finland, Sweden and Norway the DMI per Euro GDP was 0.61, 1.10, 0.69 and 0.91 , respectively.

Figure 17: Exports of products, by material category, Kilo per Euro GDP, Nordic countries and EU 2013

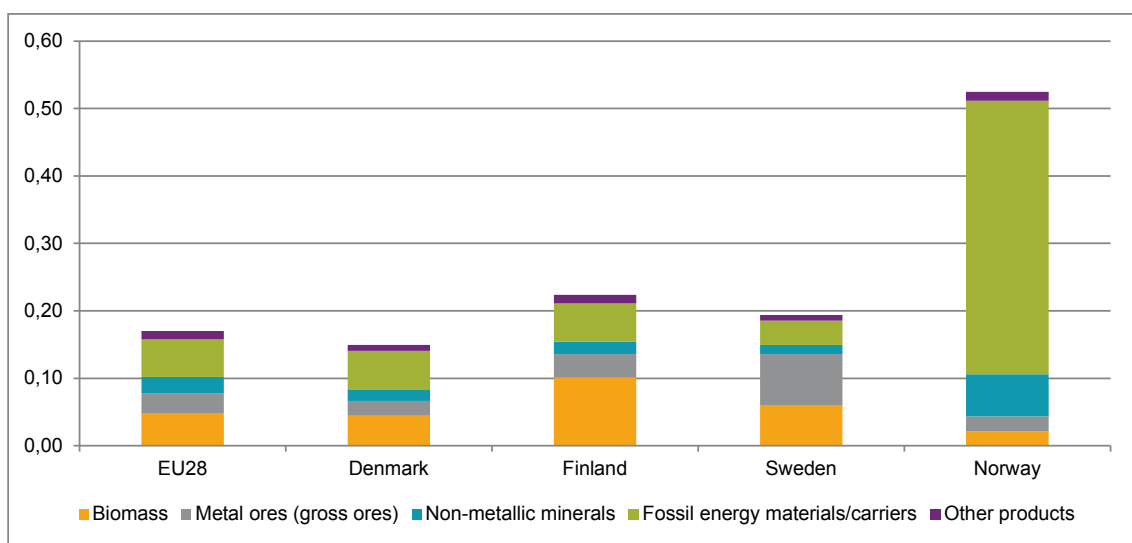

Note: "Other products" are mostly products that are highly processed and consist of a complex mix of materials for which it is not possible to determine a main material component (Eurostat 2013a).

Source: Eurostat.

Compared to EU28 and the other Nordic countries, Norway had a huge export of products, and especially fossil energy products. If the export of oil and natural gas is excluded the Norwegian exports measured at kilos per Euro GDP would be closer to the other Nordic countries. The exports without fossil energy products were $0.09,0.17,0.16$ and 0.12 kilos per Euro GDP for Denmark, Finland, Sweden and Norway, respectively. If fossil energy products are included, the corresponding numbers are 0.15 , $0.22,0.19$ and 0.53 kilos per Euro GDP. Sweden had the highest exports of metal ores and concentrates at 0.08 kilos per Euro GDP, while Norway exported non-metallic minerals (mainly sand and gravel) corresponding to 0.06 kilos per Euro GDP.

One main aggregate indicator derivable from this type of statistics is the indicator Domestic Material Consumption (DMC). By adding domestic extraction and imports and subtracting exports, the indicator can provide information on how much material a specific country uses for production and consumption during one year when the exports of products from the 
country are excluded. The DMC is in no way a precise indicator of the natural resources used, especially if the country in question has a large export of the natural resources. The indicator should rather be seen as a pointer towards the amounts of waste and other residuals that will result sometime in the future

The magnitude of this indicator is very much influenced by the use of construction minerals like sand and gravel, and other non-metallic minerals. In fact, for most countries, the main driver of the change in DMC from one year to another is the fluctuations in the construction activities and subsequent use of construction minerals.

In 2013, Denmark, Sweden and Norway had DMC's at more or less the same level, at 0.4-0.5 kilos per Euro GDP, although the compositions were different. Denmark had, in contrast to Finland and Sweden, no DMC of metal ores, while Finland and Denmark's DMC of fossil energy carriers were much bigger than Sweden's. Norway's domestic consumption of fossil energy was the highest at 0.14 kilos per Euro GDP.

The DMC of Finland was much higher than in the other countries, 0.88 kilos per Euro GDP. This high number was mostly due to the use of nonmetallic minerals, 0.49 kilos per Euro GDP.

Figure 18: Domestic Material Consumption (DMC), by material category. Kilo per Euro GDP, Nordic countries and EU 2013

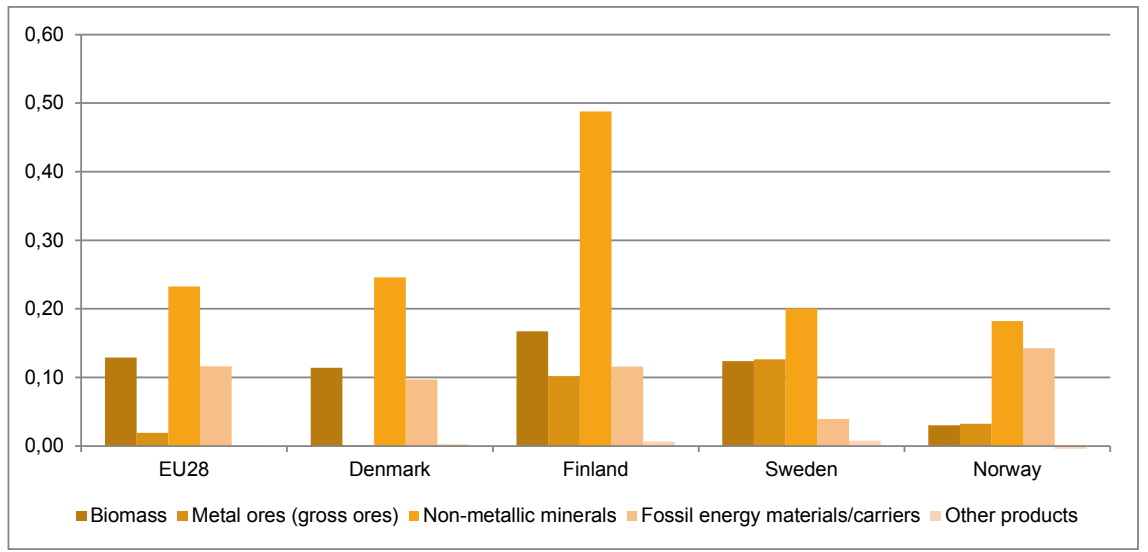

Note: "Other products" are mostly products that are highly processed and consist of a complex mix of materials for which it is not possible to determine a main material component (Eurostat 2013a).

Source: Eurostat. 


\subsection{Other drivers of environmental pressures}

The indicators shown in this chapter cover several different types of drivers of environmental degradation and depletion. With examples of energy use and the growth of the economy itself the drivers of environmental degradation has been viewed from different angles as has depletion with aspects such as consumption and trade of materials. However, the world is not oneor two-facetted; it is complex. Aspects that have not been touched upon here can be, for example, how our culture is affecting our behaviour, or how the geography can enhance or dampen the impact of drivers.

Culture as a driver of environmental issues requires research and is difficult to respond to from national statistical offices. However, other aspects are easier to map through statistics.

The consumption of water, land use statistics and the development of the accounts in these areas are one step towards providing additional information about drivers. For abstraction and use of water resources, many OECD countries have achieved impressive absolute decoupling and reductions. Australia and the Slovak Republic increased efficiency the most in the OECD community in terms of abstractions of freshwater resources per capita (OECD 2013). Even though the Nordic countries are generally considered well-endowed with water resources a couple of Nordic countries have followed the OECD average of 5\% reduction since the mid-1990s and reduced water abstractions per capita. ${ }^{25}$ In Denmark the statistical office developing what is called water accounts. This type of account focuses on water use and water supply within the economy and is part of the SEEA. ${ }^{26}$ The results will bring the statistics of water use and abstraction in line with the national accounts.

The land we occupy is central to us. Land is also a component in the assessment of national and institutional sector wealth. Land (property) is traded along with the natural resources attached. In the Nordic countries, land accounts within the framework of environmental accounts have been tested (SCB 2003, SCB 2002) but it has so far created little interest within policy or research institutes. However, in the frame of ecosystem services land accounts have come into focus again. Statistics Sweden and the Swedish University of Agriculture Science (SLU) tested an experimental methodology to look at land important for biodiversity and who the owners are. The results showed that there is a viable methodology for bringing together data on

\footnotetext{
25 Denmark reducing water abstraction per capita by $29 \%$, Sweden by $7 \%$. Finland increased the water abstraction per capita by $146 \%$ and Norway increased by $16 \%$ since the mid-1990s (OECD 2013).

${ }^{26}$ SEEA Water http://unstats.un.org/unsd/envaccounting/seeaw/seeawaterwebversion.pdf
} 
land inventories with economic information through Geographical Information System (GIS) tools (SCB 2015b).

Other drivers of environmental pressures not described in this chapter relate to our consumption patterns. Detailed statistics are available on expenditure from household consumption and also through the national accounts on final demand. A consumption perspective is highly relevant with the increase in globalisation. The environmental pressures are dependent on where goods and services are bought and how they are used. In chapter 6 there is an example of how consumption related emissions of greenhouse gases can be visualised based on an analysis combing the national accounts input-output models and environmental accounts. The analysis examines a pressure indicator but the drivers could be explained through the underlying information in the input-output tables.

Data about consumption in monetary terms are defined by the system of national accounts and could easily be incorporated into the structure of the Nordic environmental economic accounts. It would however require additional time and knowledge to bring them together.

\subsection{Recommendations and future use}

The national accounts, being mature and readily available include the Gross Domestic Product (GDP) as an indicator of the overall economic activity. Gross Domestic Product (GDP) reflects the value (measured in market prices) of the national production of goods and services during a time period (see Appendix I). GDP summarizes a myriad of results from the production activities of a national economy in one single number. From the very beginning it has been clear that GDP has weaknesses as a measure of welfare. It does not account for e.g. leisure, natural resource depletion, environmental degradation or household production. Other topics such as income distribution and wealth and also not evident from the GDP figure, but it was never intended for these purposes.

Instead one can look towards complementary measurements that are adapted to provide a broader picture. When it comes to use of natural resources and environmental pressures, energy and material flows are relevant drivers to include. To follow the flow of energy through our economy and monitor the changes in the composition of the different energy carriers are important in order to answer questions about policy implementation, e.g. are policy strategies to reduce fossil fuel use being implemented fast enough by the users addressed. 
Another measure to follow relates to the overall flows and uses of materials. The material flow accounts do not reflect the economic value of natural resources or show the flows of specific hazardous materials. But they do show the form of the natural resource basis and corresponding extractions in a country and they show the material dependencies on imports from other countries. The accounts are instrumental for the analysis of how much material the economy needs in order to be able to support the functioning of the economy. It also points at how much waste that eventually needs to be reused or redirected back to the environment. It should be emphasized, however, that the aggregate indicators, which sum up the weight of different resources and types of products, should be interpreted with care. As an aggregate of very heterogeneous materials they do not indicate what the environmental pressures or impacts are.

At best the aggregated indicators serve as signals, which may indicate a need for further analysis of the development in material uses and natural resource extraction. Thus, a steadily growing material use per capita or per GDP may be a sign of economies which becomes more dependent on materials, and the reasons for this need to be analysed in more detail. Does it, for instance, reflect that more fossil fuels or metallic minerals are used, or does it reflect that construction activities are increasing? Depending on the results of such analysis appropriate policy measures can be considered.

As a step towards a policy oriented use of the accounts, the so-called material resource productivity indicator is often presented. This indicator, which is defined as GDP/DMC indicates how much GDP that is generated per tonne of total domestic material consumption, DMC. The indicator has gained quite a lot of attention at the policy level, and is, for instance, used as an EU sustainable development indicator for policy evaluation and it is linked to the so-called Flagship initiative on a resource-efficient Europe as part of the Europe 2020 Strategy.

An increase in the resource productivity is often interpreted as a sign of a more efficient use of resources and as an indicator of environmental sustainability in the sense that we can have economic growth while reducing the resource use and environmental pressures. There is a need to be very sceptical about such interpretations and uses of the resource productivity indicator since increases can also be due to the reduction of extraction on the national territory with materials being replaced by imports. In addition, it is not entirely clear why it is the DMC and not the so-called direct material inputs (DMI), which include exported materials, that is used as the denominator when the indicator is calculated. 
Since it is hard to discard the criticism of the aggregate indicators for material consumption and resource productivity it is recommended that in a Nordic context (and also generally) that most emphasis is put on disaggregated accounts and indicators highlighting more homogenous groups of materials. At the same time, care should be taken not to assume that there is a one-to-one relationship between material flows as drivers and environmental pressures or impacts.

The standard EW-MFA, which are published on a regular basis by the Nordic countries and reported by European statistical system members to Eurostat do include the necessary details for making interesting analyses of the domestic extraction of various natural resources and the imports and exports of various product types. Currently there is research focusing on how the foreign trade flows of products can be converted into the underlying natural resources that have been used in order to produce the traded products. Also, work on more detailed material flow accounts which make it possible to follow the physical flows through the economy is being carried out. As these further developments of the material flows accounts advance the possibilities of doing analysis of the physical and material basis of our economy increase. 


\section{Pressures on the environment}

\subsection{Summary}

Pressures on the environment such as greenhouse gas emissions or air pollution are among the most developed in the SEEA where economic activities are visualised.

Useful indicators include carbon and pollution intensities and efficiencies at the national level, industries and product groups. The most recent trends are that most countries are still a long way from goals that together would fully take account of planetary boundaries, such as the 1.5 degree target.

Within the environmental accounts there are still developments in the area of producing and publishing data on pressure indicators. As such this chapter focuses on climate change and air pollution indicators, for which there are harmonized data available.

Areas that measure other pressures, such as statistics on waste generation or emissions to water are still being developed both nationally and internationally. The EU regulation on waste statistics is only now attaining stable data collection processes where definitions and scope no longer change. With regards to water statistics it is recognised that there are large data gaps in the reporting instrument that the OECD and Eurostat jointly uses. The Nordic statistical offices encounter different levels of interest in water statistics and accounts from policy makers. In Sweden the statistical office assists in the reporting of data to the Water Framework Directive and has done so since the early 2000s, while in Denmark a renewed interest in water accounts have brought forward new developments in the field.

The Ad Hoc Group therefore thinks that it would benefit the set of accounts that the areas of water and waste accounts to be revisited in a couple of years to establish new indicators on a Nordic level if they are available. Such periodic re-evaluations are recommended by the group. 
The Ad Hoc Group recommends an annual publication of the following indicators by the Nordic Council of Ministers:

- Greenhouse gas emission intensities. $\mathrm{CO}_{2}$-equivalents in kilos per Euro GDP. See Figure 19.

- Share of total greenhouse gas emissions, by industry (NACE) and households. See Figure 20.

- Acidifying emissions ( $\mathrm{SO}_{2}$ equivalents), in Kilos per Euro GDP. See Figure 21.

- Acidifying emissions ( $\mathrm{SO}_{2}$ equivalents) tonnes per capita, by industry (NACE). See Figure 22.

- Emissions of particulate matter, $<2.5 \mu \mathrm{m}$, per cent of total $\mathrm{PM}_{2.5}$ emissions, by industry (NACE) and households. See Figure 23.

\subsection{Preconditions for climate change policy in the Nordic countries}

\subsubsection{Introduction}

The starting points for the climate policy are very different for Nordic countries: Norway and Denmark have significant production of fossil fuels (oil and natural gas). Norway and Sweden have large scale hydroelectric power production. Sweden and Finland also produce nuclear energy and Finland is currently building a new nuclear plant and has plans for another one and thus increases the nuclear power based electricity production significantly. Finland and Sweden have large production of bioenergy and a big technical potential to increase production and use of energy from renewables. Denmark and Sweden have a considerable share of wind power in their electricity sectors. Iceland has heating systems largely based on GHG emissions free geothermal energy sources.

As was noted in the previous chapter, fossil fuels are still a dominant source of energy in several economic sectors, such as e.g. in the transportation sector, construction and mining and quarrying industries. 


\subsubsection{The Nordic situation}

Greenhouse gas emissions in the Nordic economies have decreased the last few years. ${ }^{27}$ Between 2008 and 2012 the decrease amounted to $12 \%$ or just above 39 thousand tonnes of $\mathrm{CO}_{2}$-equivalents measured as its global warming potential. This can be compared to an $8 \%$ decrease in the EU area as a whole. Denmark has seen the largest decrease of the Nordic countries. The emissions of greenhouse gases have decreased by $16 \%$ from 2008 to 2012. For most Nordic countries an increase in emissions was seen in 2010, which was largely due to higher economic activities compared with 2008 and 2009 but also weather variations. Annex 1 describes the data sources and the relevant delimitations of them.

In 2012, when examining the Nordic countries, greenhouse gas emissions were highest in Denmark with just above 90 million tonnes $\mathrm{CO}_{2}$ equivalent, or $32 \%$ of all Nordic greenhouse gas emissions in 2012. Norway had the lowest greenhouse gas emissions in the Nordic region with 62 million tonnes or $22 \%$ of the Nordic share.

Compared with GDP and the economic development for the period 2008-2012, the greenhouse gas emissions per GDP have decreased in the region. The largest decrease can be seen for Norway with a reduction of 26\% for the period 2008-2012, followed by Denmark (-22\%) and Sweden (-20\%).

Transportation and storage accounted for the majority of greenhouse gas emissions in 2012, by $30 \%$ in the Nordic region. Next to follow are manufacturing, electricity, gas, steam and air conditioning and households. In EU as a whole, larger shares of the emissions can be ascribed to production of electricity, gas, steam and air conditioning, manufacturing industries as well as for activities of households.

\footnotetext{
27 The study object of GHG emissions follow the SEEA CF and includes total economy and households, for more information, read Appendix 1.
} 
Figure 19: Greenhouse gas emission intensities. Nordic countries and EU, CO2-equivalents in kilos per Euro GDP, 2008-2012

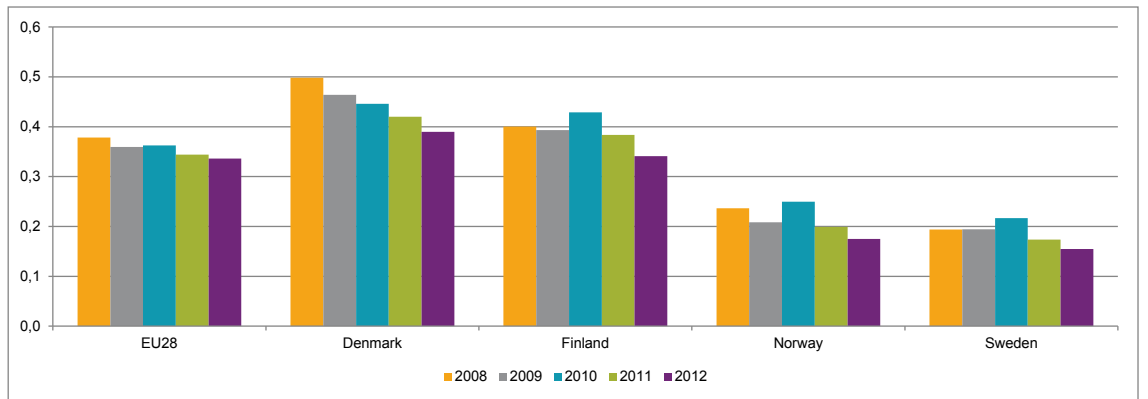

Note: Includes carbon dioxides, methane and nitrous oxides. Data for Iceland is not available. Excludes GHG emissions from households. Euro GDP in current prices is used to calculate the ratio for each year.

Source: Eurostat.

Figure 20: Share of total greenhouse gas emissions, by industry (NACE) and households, in EU28 and Nordic countries, 2012

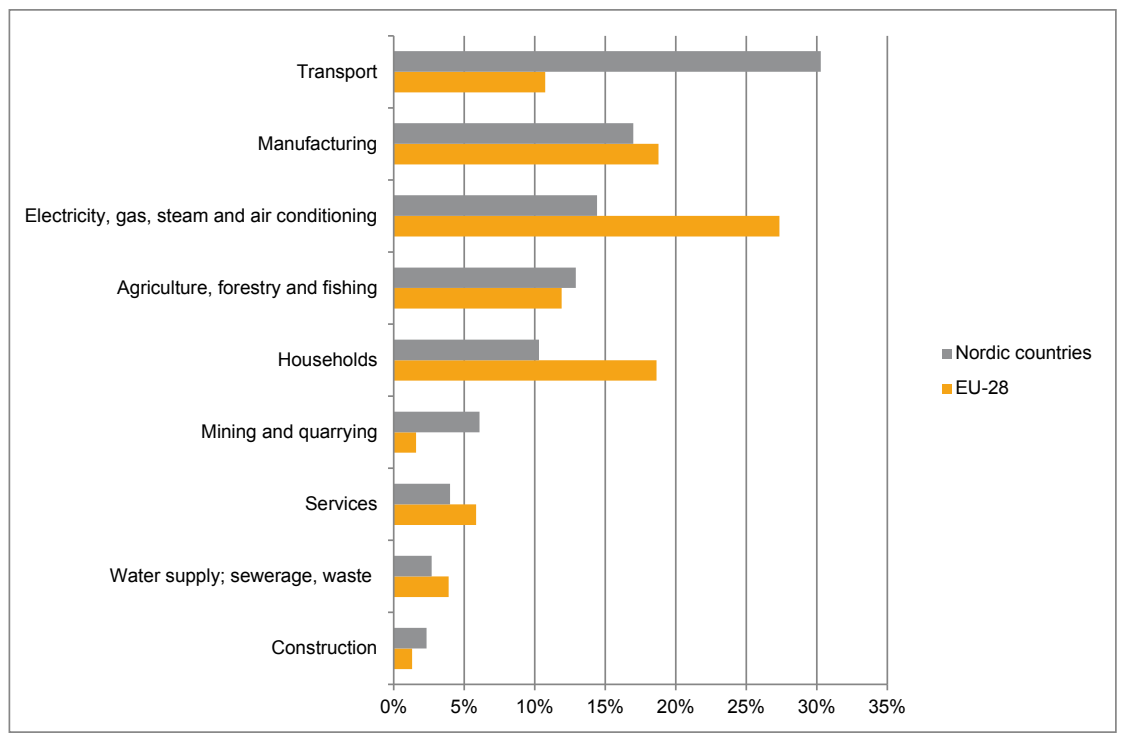

Note: Includes carbon dioxides, methane and nitrous oxides. Iceland is excluded

Source: Eurostat. 
The Nordic region, as a whole, has a relatively small share of fossil fuels in their heating and electricity systems compared to other countries within the EU. The policies have been geared towards using hydro power, biofuels, geothermal and wind power as well as nuclear power and to phase out fossil fuels.

The fossil fuels are still important in the transportation sector, in land, sea and air transports as well as in the mining and extraction industry, as was indicated above in Figure 14, that the share of biofuels is still low.

\subsection{Acidifying emissions in the Nordic countries}

\subsubsection{Introduction}

Acidification of the environment is caused by inputs of acidifying substances with rain and snow or direct deposition of gases or particles on vegetation (dry deposition). Both of these processes are normally included in the definition of acid rain. Acid rain is caused mainly by emissions of sulphur dioxide $\left(\mathrm{SO}_{2}\right)$ and nitrogen oxides $\left(\mathrm{NO}_{\mathrm{x}}\right)$ from the combustion of fossil fuels. In addition, ammonia and ammonium ions $\left(\mathrm{NH}_{\mathrm{x}}\right)$ contribute to acidification through various chemical processes that take place in soil and water.

The agriculture sector is an important emission source for ammonia. Air pollutants are often transported for long distances, for example from central Europe, Russia or Britain, before ending up as acid rain in the Nordic countries.

Acidification of soils results in leaching of nutrients and metals (especially aluminium). Fresh-water organisms, e.g. fish, may suffer serious damage. In addition to its impact on the flora and fauna, acid rain results in corrosion damage to buildings and cultural monuments.

Acidifying emissions have been estimated to still have very serious health effects in Europe. The largest source of $\mathrm{NO}_{\mathrm{x}}$-emissions is transport and heat and power production.

The most important sources of $\mathrm{SO}_{\mathrm{x}}$-emissions are transport and industry. Ammonia is also an acidifying gas; its most important source is animal production. While other pollution sources have decreased acidifying emissions, focus has moved to the sulphur emissions from shipping. The new EU sulphur directive came into force in the beginning of 2015 in 
the (Nordic and) Baltic Sea area. ${ }^{28}$ The new directive aims at further reductions of sulphur dioxide emissions from ships. This will mostly affect northern Europe.

For acidifying emissions, the difference between emissions and deposition must be recognized. The acidification of Nordic land is dependent on the rate of downfall of acidifying substance largely stemming from sources abroad and only partly on indigenous Nordic emissions which, on the other hand also cause acidification outside the Nordic area. In the Nordic countries the highest concentrations of nitrogen oxides in 2011 were in the big city-areas and for sulphur dioxide in the Oslo region. The only area where the nitrogen dioxide concentrations increased from 20022011 was the border between Finland and Russia (EEA 2013).

Nowadays the acidifying emissions from stationary sources are less significant for the concentrations than from moving sources, because the emissions from manufacturing and power production have decreased. It is also important to note that much of the downfall originates from stationary sources outside the Nordic region.

\subsubsection{The Nordic situation}

In Denmark, soil and water contains lime that naturally neutralises the effects of acidification, much more than in any other Nordic country. The critical load is not exceeded anywhere in Iceland, and acidification is not a problem there. The Swedish and Norwegian areas, which are lime-deficient, are more vulnerable to acidification of soil, lakes and watercourses. (Nordic Council of Ministers 2014).

Measured with accounting data, the emission intensities of acidifying substances are decreasing in the Nordic countries. Between 2008 and 2012 the acidifying gases were cut with just shy of $22 \%$ in absolute terms, the intensity has come down from 2.5 to 1.7 kilos acidifying emissions per Euro GDP. This indicates that fewer emissions are required to produce the same amount of goods and services within the economy, i.e. the production is more efficient. The EU reduced the acidifying emissions during the same period, in absolute terms by $17 \%$, but has had a lower intensity during the whole period, below that of the Nordic countries. Observe that the high intensity of Denmark is due to a very high international sea transport activity and that a substantial part of this activity is carried out outside the Danish territory.

${ }^{28}$ EU Sulphur Directive 2012/33. 
Acidifying gases comprise of sulphur, nitrogen oxides and ammonia. Out of the three, nitrogen oxides which are a combination of several gases contribute the most to acidification. Nitrogen dioxide is toxic also by inhalation. The sources of these pollutions are often internal combustion engines, thermal power stations and pulp and paper manufacturing.

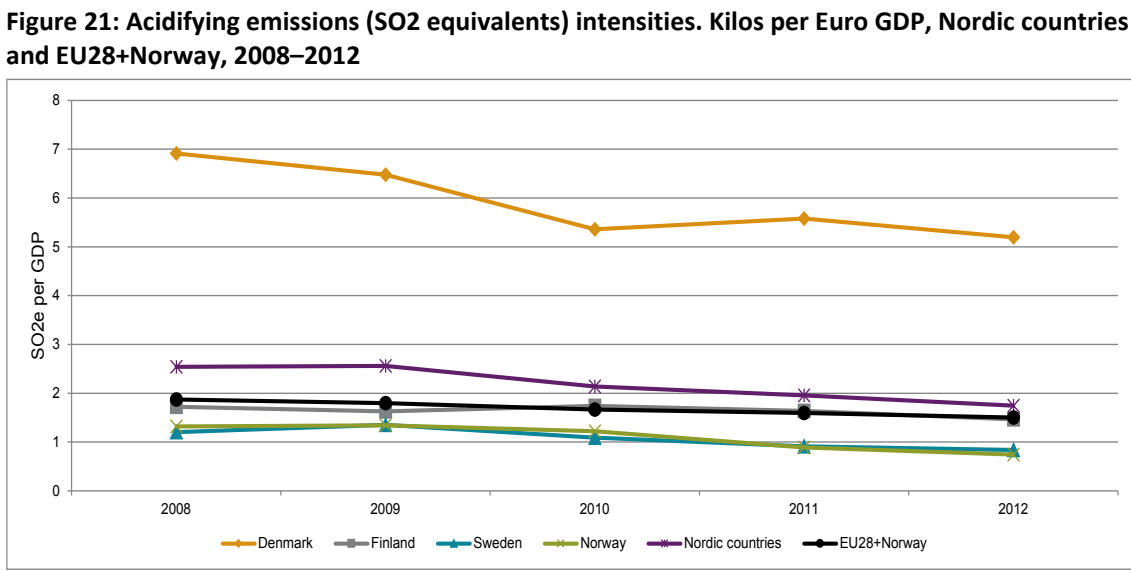

Note: Sulphur oxides, Nitrogen oxides and Ammonia. Data for Iceland is not available.

Source: Eurostat.

Figure 22 provides information about the type of industries that are producing acidifying emissions, divided by the population to normalise that data. The group "services" which contain economic activities such as shipping, trade, and financial activities are most prominently visible in the figure. Almost all of the acidifying emissions in the services can be attributed to the shipping industry where the fuel used is highly acidic. New rules for shipping in the Baltic Sea requires the shipping industry to reduce the acidifying content of the fuels or use flue gas desulphurisation and the result is reduced amounts of acidifying gases.

Households contribute very little to the acidifying emissions; it is mainly from their use of lawn movers and other vehicles. As oil based heating systems become less common the emissions of acidifying gases are reduced.

Concerning the emissions of ammonia $\left(\mathrm{NH}_{3}\right)$, agriculture is by far the most important emission source in all the Nordic countries and EU28. The emissions stem from livestock, the management of manure and the use of fertilisers. 
Figure 22: Acidifying emissions (SO2 equivalents), tonnes per capita, Nordic countries, 2012, NACE aggregates and households

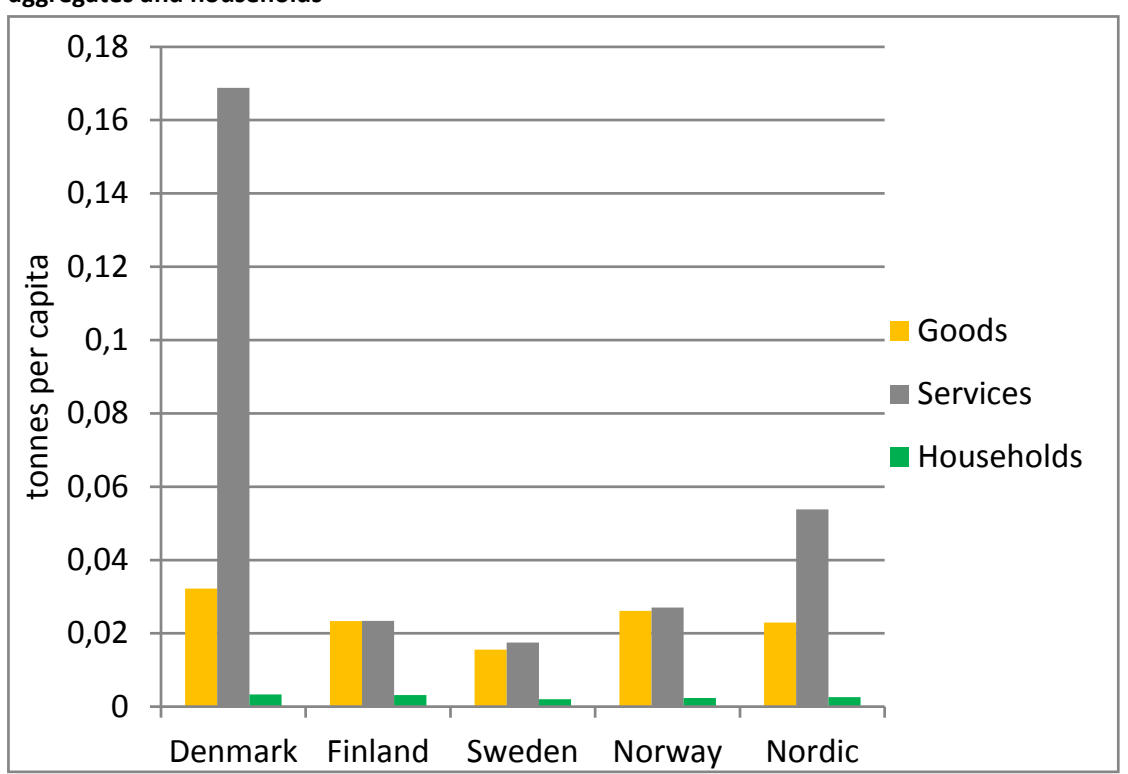

Note: Sulphur oxides, Nitrogen oxides and Ammonia. Data for Iceland is not available.

Source: Eurostat.

\subsection{Emissions of particles to our atmosphere}

\subsubsection{Introduction}

Pollution of particles in our atmosphere is a source of health problems for people. As such the Nordic countries and the EU have agreed to set a limit to the levels of emissions of particles. However, the sources of the pollution are from both the nature and from human activities. Particulate matter from the nature comes from forest and grassland fires, living vegetation and even from the sea. Human-made pollution stem from road abrasion, wear and tear from tyres, and burning of fossil fuels.

Known human health effects are decreased lung capacities and the effect on normal development of lung capacities in children. Studies have also shown that people with heart or lung diseases, as well as children and older adults are more vulnerable to the exposure of particle pollution. ${ }^{29}$

29 US EPA: http://www.epa.gov/pm/health.html, Swedish EPA: http://www.miljomal.se/Miljomalen/ Alla-indikatorer/Indikatorsida/?iid=105\&pl=1 


\subsubsection{The Nordic situation}

The statistics on particulate matter show that in 2012 the households were the group contributing the most to particulate matter below 2.5 microgram per cubic meter. Use of fossil fuels, such as diesel, as well as wood and other biomass for heating explains the large emissions by households. In the EU28 households contribute with over $50 \%$ of total $\mathrm{PM}_{2.5}$ emissions, while in the Nordic region the share is a little lower, about $47 \%$.

The transport sector in the Nordic region emits more $\mathrm{PM}_{2.5}$ than in the EU28 average. This is mainly due to the fact that in the Nordic region the use of studded winter tyres are more common than in Europe.

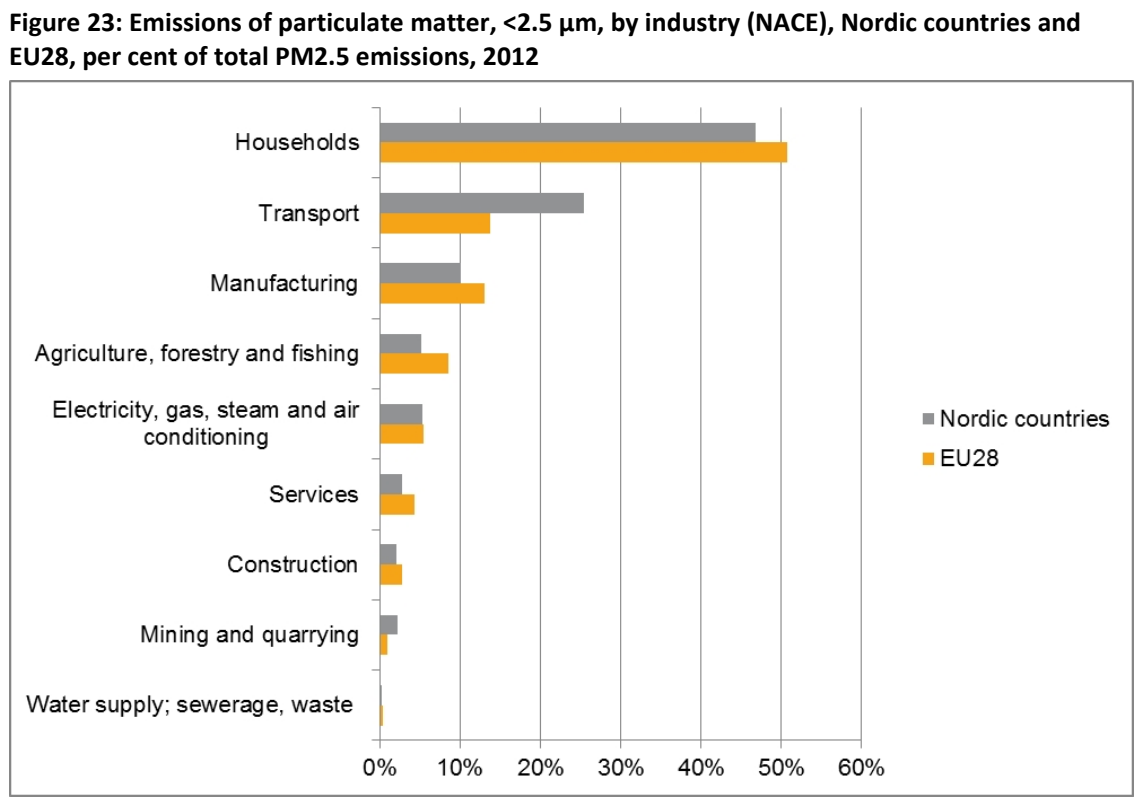

Note: Data for Iceland is not available.

Source: Eurostat. 


\subsection{Other environmental pressures}

The indicators shown in this chapter cover three different types of pressures on the environment. With the examples of greenhouse gas emissions, acidifying emissions and particulate matter by industry a picture emerges. It has shown who the emitter is (by industry and households) and how emission levels change over time in relation to their economic contributions.

However, there are many more pressures on the environment, besides air emissions but the reason for these pressures not to be included in this report is that the data are not yet available in an environmental accounting context. Pressure indicators that are missing are for example waste generation, water pollution and land degradation.

The Nordic statistical offices are however aiming at increasing the availability of pressure indicators within the environmental accounting context.

As mentioned in the previous chapter, Denmark has embarked on new developments of both water and waste accounts, and these accounts will be published before the end of 2016. It is expected that a yearly update will be carried out in Denmark.

Statistics Sweden has produced water accounts in the past on commission; the most recent study available is from 2012.

With time, additional accounts measuring pressure on the environment will be available. Increasing policy applications of the data visualising the economy and household pressure on the environment increases the demand for these types of integrated statistics.

\subsection{Recommendation and future use}

In this chapter we have shown a few indicators that can show some of the pressures the economies in the Nordic countries put on our atmosphere. It has been limited to air pollution and greenhouse gases because this is where most data are currently available.

We recommend that a Nordic Environmental Account will use the pressure indicators that are already reported to Eurostat with the support of legislation as they are harmonised and regularly collected. The greenhouse gases are very closely related to the economic activity and with the accounts it is possible to distinguish the production and household consumption details and how they may be linked to environmental and economic policy. Air pollution from transportation and heating is also 
a problem that can be informed by the environmental accounts. The issue of particulate matter by industry is vital to understand how to protect the population in the Nordic countries and our environment alike.

Other types of pressures, like waste and emissions to water do not have a legal reporting obligation to Eurostat in the accounts. Waste statistics are slowly coming to a stage where times series can be built although they are not yet fully ready to be included in the accounting framework on a Nordic basis.

Water statistics, and especially water pollution statistics, are covered by international agreements such as the Baltic Marine Environment Protection Commission (HELCOM) and The Convention for the Protection of the Marine Environment of the North-East Atlantic (OSPAR). The international community, with the UN, the OECD and Eurostat, is driving the interest towards the compilation of water accounts. In progress now in the Nordic countries is the development of water accounts in Denmark.

While useful in relation to giving an overall view of the economies' dependence on water and the economics of water supply and use, it should also be mentioned that much interest lies in information on the local management of water and institutions managing the water. Thus the water accounts cannot stand alone. An interesting aspect in relation to bridging the water accounts with more detailed information at the local and regional level is the development of regional water accounts, which highlights the supply and use of water and the economics of water at a regional level. Also for other types of environmental accounts (both for drivers and pressures) the regional aspect is interesting and deserves more research also in a Nordic context.

The institutional set-up of environmental statistics is similar across the Nordic countries. The main responsible institution is generally Ministries of the Environment and/or national environmental protection agencies. Many pressure data are not sourced from within the statistical office. Thus, it is recommended that further developments of the pressure data within an environmental-economic accounting context are furthered through a close cooperation between different institutions and that the obstacles of limited financial resources for the work are addressed. 



\section{Responses - environmental economic instruments}

\subsection{Summary}

Environmental economic policy responses that a government can use to change consumption and production patterns range from pollution taxes and tradable permits, to administrative and legal initiatives.

International evaluations have shown that environmental economic instruments such as taxes and subsidies can accomplish important changes in market dynamics (e.g. UNEP 2004, NCM 2014). For example, taxation has the possibility to price all units of pollution, while laws restricts and allows pollution below a certain threshold.

To monitor and follow the development of environmental economic instruments, the Ad Hoc Group recommends an annual publication of the following indicators by the Nordic Council of Ministers:

- Environmental taxes, percentage of total revenues from taxes and social contributions. See Figure 24.

- Energy taxes, paid, by industry and households, per capita. See Figure 25.

The Ad Hoc Group recommends that the following indicators should be reviewed in about three years to have a new evaluation regarding their incorporation into the set of indicators to be recommended for the annual publication by the Nordic Council of Ministers on Environmental Accounts:

- Value added and employment in Environmental Goods and Services Sector, (EGSS), and total GDP, EU, indexed. See Figure 26.

- Contributions to the EU of production values from market activities within EGSS, share of total EU EGSS. See Figure 27.

- Environmental protection expenditures by industry by GDP. See Figure 28. 
- Type of environmental area of investing by the industry. See Figure 29.

- Type of environmental investment by the industry: Pollution prevention investments as share of total environmental protection investments. See Figure 30.

Market-based or related instruments, such as cap-and trade, taxes and subsidies are in most cases implemented by national governments as a means to respond to the pressures that arise on the environment. These instruments can also simply be a way to increase government revenues.

There are also other ways to respond to the pressures on the environment, such as through means of technological and innovative advancements and investments in these technologies.

Response indicators to environment degradation such as the trends and developments of the environmental goods and services sector (the green sectors of the economy) are under development within the environmental accounts in the Nordic countries. In Europe, the EU regulation on environmental accounts expects well developed statistics to be reported by 2017 when the first required reporting cycle begins.

On the other hand, response indicators such as environmental taxes have been established for some time now and are regularly published in all Nordic countries, except Iceland.

\subsection{Environmental taxes}

\subsubsection{Introduction}

Taxing the use of environmentally harmful products is one way for a government to change the purchasing behaviour of consumers or use of products for intermediate consumption by businesses.

The use of environmental taxes, which include so-called pollution, transport, energy and transport taxes, has been recognized as an efficient means to limit the use of harmful substances; in particular the tax on $\mathrm{CO}_{2}$ has had an impact on the use of fossil fuels (OECD 2014). However, issues such as business competitiveness in a globalized world economy, a need for governments to balance state budgets and general public opinion influences the decisions taken to implement such measures.

The statistics on environmental taxes provide information on the revenues collected by the government and on who pays the tax. It should be underlined that environmental tax revenues do not necessarily reflect a 
measure of the state of the environment or the level of ambition of environmental policy, e.g. the Swedish tax on gravel is not an expression of the environmental impact gravel has but is a means to enhance the sustainable extraction of the gravel. In other cases the environmental taxes, especially energy and transport taxes, are in fact introduced or increased at least partly in order to raise revenues for governments.

Detailed information about environmental economic instruments used in the Nordic countries as well as the methodology for the data production is presented in Annex 1.

\subsubsection{The Nordic situation}

A recent report from the Nordic Council of Ministers on environmental economic instruments (Bragadóttir et al., 2014) The Use of Economic Instruments - In Nordic Environmental Policy 2010-2013 presented the Nordic region insights into the use and implementation of environmental economic instruments. For example, almost all Nordic countries have implemented taxes on energy and air pollution, ranging from excise taxes to taxes on products such as fuel oil. Exceptions are Iceland and Finland, which do not have taxes on sulphur dioxide and nitrogen dioxide emissions. With regard to taxes on waste, the Nordic countries have applied different approaches. Norway and Denmark are the only two countries in the Nordic region that apply taxes on incinerated waste (Bragadóttir et al., 2014).

The overall trend in the EU on the topic of environmental taxes is that they have been declining as revenues for the governments both in relation to GDP and to the revenues from other taxes and social contributions. Such a decline does of course not necessarily indicate weakening environmental ambitions.

There are far more taxes on energy than any other source of environmental pressure, e.g. than on transport, resources or pollution in the EU and in the Nordic countries (Eurostat 2015).

This reflects the multitude of aims for energy taxation, including fiscal revenues, security of energy supply, climate change mitigation and environmental improvement. 
Figure 24: Environmental taxes as a share of total revenues from taxes and social contributions, Nordic countries and EU28, Per cent. 2008-2012

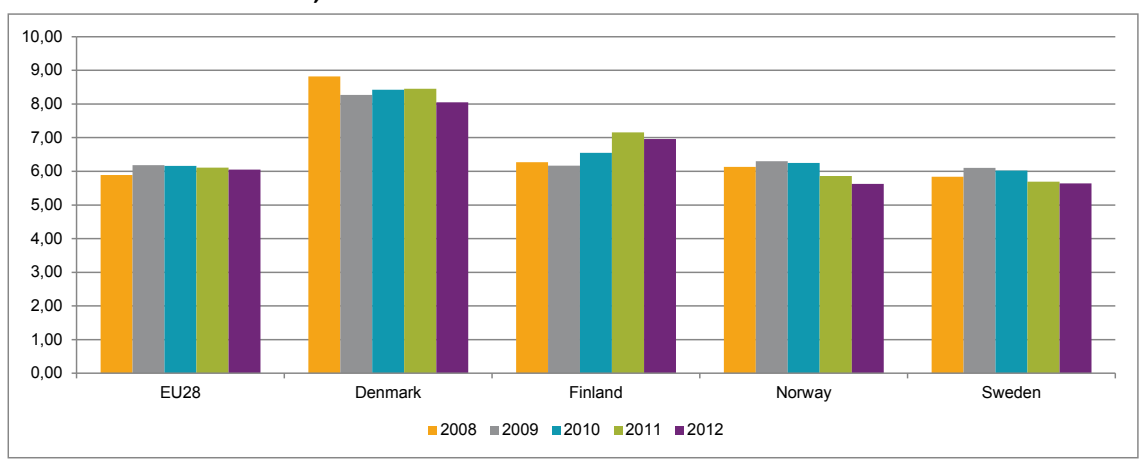

Source: Eurostat.

The main contribution to energy taxes stem from businesses that contribute to the tax revenues through their purchase of fuels, but households are almost equal in their contributions. In Denmark the total revenue from environmental taxes paid by households exceeds even the revenues paid by businesses. Interestingly the businesses in the Nordic countries contribute almost equally, EUR 0.5 per capita, or EUR 0.01 per million Euro GDP.

Figure 25: Energy taxes, paid, by industry (all NACE) and households per capita, Nordic countries, 2012

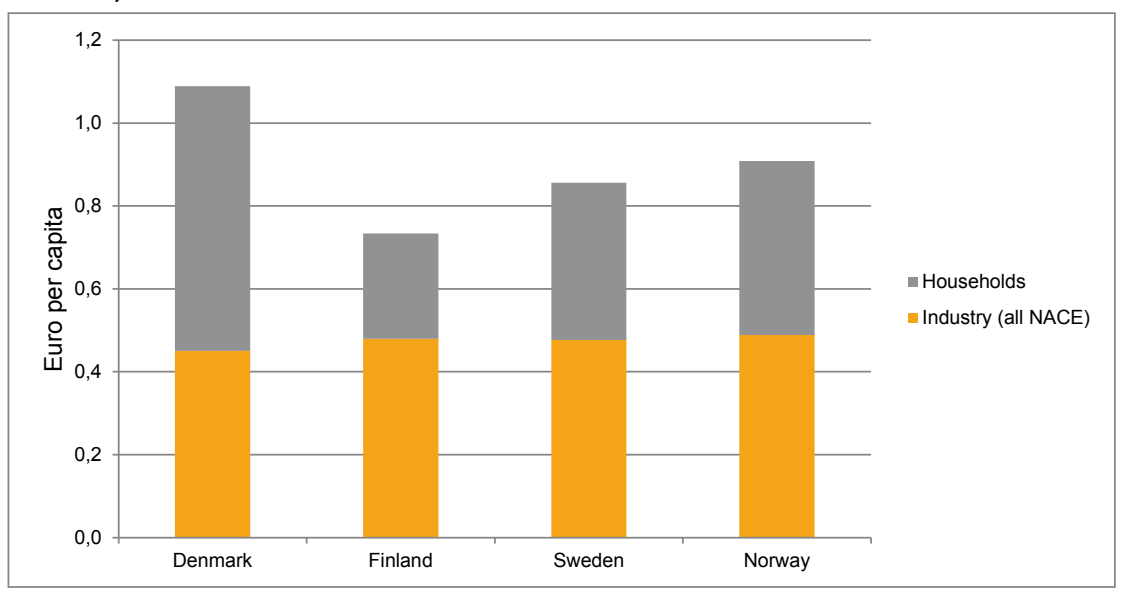

Note: Data for Iceland is not available.

Source: Eurostat. 
In Denmark and Norway transportation taxes have a prominent place among environmental taxes; this group of taxes are second after energy taxes in terms of revenues. Transport taxes mainly include taxes related to the ownership and use of motor vehicles.

Pollution and resource taxes cover different types of taxes such as taxes on the extraction of raw materials; on measured or estimated emissions to air (e.g. nitrogen oxides $\left(\mathrm{NO}_{\mathrm{x}}\right)$ and sulphur dioxides $\left(\mathrm{SO}_{2}\right)$ and water; on noise and on the management of waste. However, these taxes have not been used much and in 2012, only 3\% of the Nordic countries' total environmental tax revenue was raised by pollution and resource taxes.

\subsection{The EU Emissions trading system (EU ETS)}

\subsubsection{Introduction}

The EU Emission Trading Scheme or the European Union Greenhouse Gas Emissions Trading System started operating in January 2005. Since then there has been continued development of the trading system and expansion of its scope. It now covers around half of Europe's emissions of mainly $\mathrm{CO}_{2}$ but also other greenhouse gases (e.g. nitrous oxides and perfluorocarbons) are covered by the trading system. The system includes emissions from combustion plants, oil refineries, coke ovens, iron and steel plants, and factories making cement, glass, lime, brick, ceramics, pulp and paper. Aviation was included in 2012 into the trading system. ${ }^{30}$

A fundamental feature of the EU ETS is that the system works on a supranational level where the developments of the emission under the whole EU cap is what matters when it comes to climate mitigation. The possibility to trade emission permits means that reductions are distributed in a cost effective way among countries and businesses. The development when it comes to specific industries of the economy and countries should be seen in this light.

The economic crisis 2008 and a lax common EU emissions ceiling has led to a persistent surplus of allowances (permits to emit) in relation to actual emissions. This situation has resulted in permit prices being lower than

30 The legislation was adopted in 2008. To allow time for negotiations on a global market-based measure applying to aviation emissions, the EU ETS requirements were suspended for flights in 2012 to and from nonEuropean countries. For the period 2013-2016 the legislation has also been amended so that only emissions from flights within the EEA fall under the EU ETS. Exemptions for operators with low emissions have also been introduced. DG Clima: http://ec.europa.eu/clima/policies/transport/aviation/index_en.htm 
originally expected. The EU ETS is, however, still considered to be the cornerstone of EU climate policy covering more than half of the GHG emissions of the EU. Measures have however been decided to address the surplus.

Recently it has been decided that the ceiling - the yearly distribution of allowances - should be reduced from minus $1.74 \%$ per year to minus $2.2 \%$ per year meaning a total reduction by $40 \%$ by 2030 . Part of the current surplus will also be withheld from the market in a so called market stability reserve and further structural reform is under way (DG Clima 2015).

\subsubsection{The trading aspects}

Within the cap, companies receive or buy emission allowances which they can use themselves or trade with one another. Until 2020 they can also acquire and use limited amounts of international emission reduction credits from emissions-saving projects around the world that have been certified in accordance with a thorough and meticulous UN process. The limit on the total number of allowances available ensures that they have a value and that a price is established by supply and demand for emission allowances in the market. The market value of the permit is independent of whether it is acquired through purchase or distributed free of charge. The share distributed through auctioning will be increased over time.

Due to the economic crisis of 2008 emissions particularly in the energy intensive branches, fell more than expected which resulted in a persistent surplus of allowances and prices lower than expected. The EU ETS, however, still functioned in accordance with its aim to distribute emission reduction in a cost effective way but low prices also meant that less action was taken to prepare for a long term low emission path. Thus the system has been reformed by the introduction of a market stability reserve which will hold back part of the allocation of new allowances from the market and increase scarcity of supply of allowances and support prices.

Additional structural reforms within the EU ETS are under way with the aim to strengthen the system to secure its function as a central part of the EU climate policy. 


\subsubsection{The statistical aspect}

Since 2011 Statistics Norway are publishing data on how the industries are trading emission permits. ${ }^{31}$ In Sweden, the Environmental Protection Agency is publishing a list of entities showing their allocated emission permits and if there has been a surplus of emissions or not. The Finnish Energy Authority is publishing data on the amount of emissions of entities and enterprises of the trading scheme.

The UN has through the SEEA established a theoretical framework for incorporating the ETS in the accounts. One aspect is that the use of emission permits is regarded as a payment of a tax according to the national accounts. In addition, accounts can be made for the number of emissions permits available and the surrender of these permits. Denmark tested the suggested approach in 2006 and concluded that including a description of the flow of permits in the Environmental-Economic Accounting framework provides useful insights and creates further possibilities for a thorough analysis of the relationship between the use of energy, resulting air emissions, emission allowances as well as energy related taxes, carbon taxes and other similar taxes. Also, Statistics Norway has included the revenues of emission permits as taxes, both in the National Accounts and as part of their annual statistics on environmental taxes. ${ }^{32}$ In Sweden there is currently a project testing data from the trade on emission permits to see what can be done with the data in a statistical way that can be incorporated in the environmental accounts. In Finland, the auction revenues of emission permits have been recorded as tax revenues in the national accounts from 2014.

\subsubsection{The Nordic situation}

From 2013 and onwards the free distribution of allowances is partly based on benchmarks reflecting relative carbon effectiveness (emissions per produced unit), a distribution key which has so far been advantageous to carbon efficient Nordic companies. Plants and companies that are more efficient than the average receive an allocation of that is more generous than that of less carbon efficient plants. Thus the distribution of allowances serves as an incentive and a driver for companies to become more carbon effective in a way that the current prices on the market do not. This price introduces a cost for emissions and incomes

\footnotetext{
31 www.ssb.no/natur-og-miljo/artikler-og-publikasjoner/industrien-har-klimakvoter-til-overs 32 www.ssb.no/miljovirk
} 
related to reductions that make it possible to sell resulting surplus allowances. It is intended that the benchmark distribution system should be replaced by a gradually increasing share that is auctioned to plant owners presently with the target that all allowances should be distributed by auctioning in 2027 .

\subsection{Producers of environmental goods and services (EGSS)}

\subsubsection{Introduction}

The production of goods and services results in pressures on our environment. The consumption of goods and services also results in environmental impacts. The choices made before purchasing an item, be it a pair of socks or a complex production system installation, affect the environment. If consumers choose alternatives which have lower environmental impacts, it is better for societies and the earth.

The statistics on environmental goods and services aim at measuring the activities of the economic units, private enterprises or government actors that produce goods and services in order to combat pollution and provide tools for a better management of natural resources. This area of statistics are defined as follows:

The purpose of environmental goods and services is to prevent, reduce and eliminate pollution and any other form of environmental degradation (environmental protection) and to conserve and maintain the stock of natural resources, hence safeguarding against depletion (resource management)

(Eurostat 2009).

More information about the statistical methodology is available in Annex 1.

With globalization, the production of goods and services from the Nordic countries can contribute to making a difference worldwide. Statistics to track the trends of these activities are becoming more widely available, at least at the European level.

According to Eurostat's estimates for the EU28, the output of environmental goods and services per unit of gross domestic product (GDP) has grown by more than $50 \%$ over the last decade. The employment linked to this production has risen to more than 4 million employees (full-time equivalents). 
The activities are measured by companies' output/value added of environmental goods and services and the employment engaged in these activities.

Figure 26: Value added and employment in EGSS, GDP. EU28, indexed to 2003=100

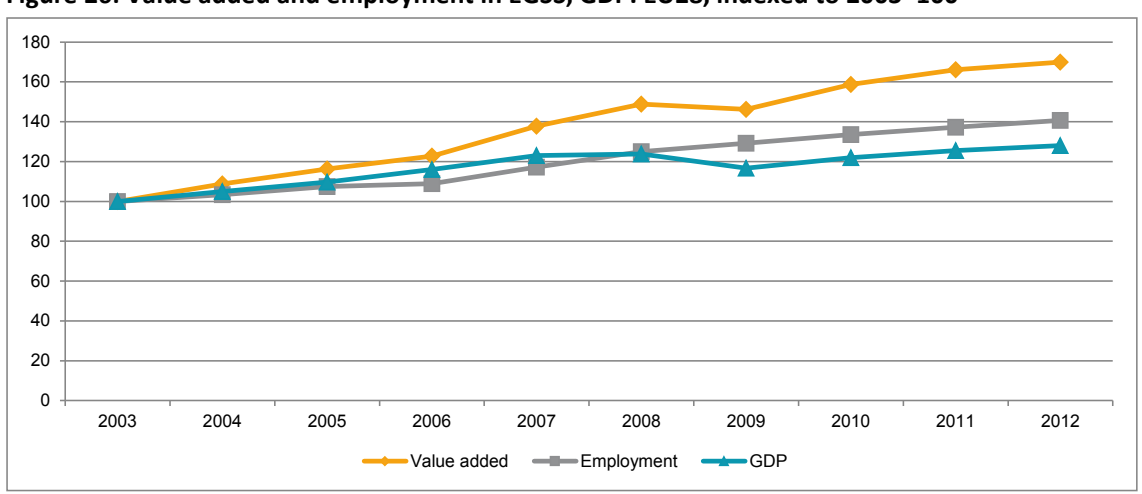

Note: Value added includes the value from market and non-market activities (i.e. private and government owned companies), in current prices.

Source: Eurostat estimate.

\subsubsection{The Nordic situation}

The Nordic Council of Ministers has identified green growth as a key priority for Nordic co-operation in the coming years. ${ }^{33}$

The statistics showing the trends and developments of enterprises that produce the goods and services to reduce the environmental impact and the use of natural resources are still under development in the Nordic countries and around the world. One needs to be careful when comparing the EGSS statistics between countries due to different measurement methods used. The example shown in Figure 27 can however be used to indicate the contribution of environmental goods and services sector from the Nordic EU members' economies to the EU.

${ }^{33} \mathrm{http}: / /$ www.norden.org/en/theme/green-growth 
Figure 27: Contributions to the EU of production values from market activities within EGSS, 2012, share of total EU28 EGSS

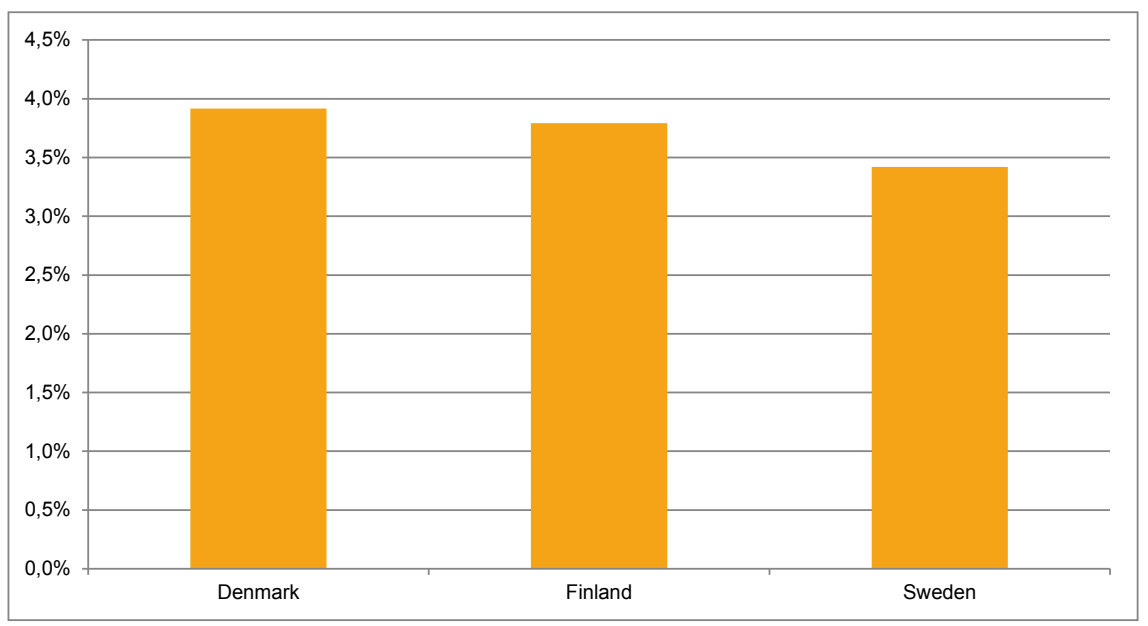

Source: Eurostat, data for Norway and Iceland not available.

It is challenging to statistically define and delineate which sectors and products can be called "green". Although a special focus on EGSS can be useful, even more important for green growth and greening the economy is to figure out to what degree the whole economy is turning greener. A frequent recommendation is therefore that data on the degree of "greenness", that is, the absolute and relative environmental impacts, from all sectors, is a necessary supplement and in some ways more relevant and important than the relatively small, if growing, percentage of value added and employment in the specifically "green" (EGSS) sectors. Reductions in impact from the "black" or "brown" sectors may, overall, be much more important than any growth in "green" sectors.

Disaggregated data from the environmental accounts are particularly well suited to such tracking and analysis of how green all economic sectors are, and how they are changing. Such recommendations are found, inter alia, also in two earlier NCM reports (Hass \& Palm, 2012 and Bruvoll et al., 2012). Important messages from these reports, that the Ad Hoc Group adheres to, are that the interpretation of the statistics on EGSS should be drawn with care. For instance, it is not necessary that a high share of production values in Denmark within the EU in relation to EGSS is a result of a higher awareness and priority of a greener economy in Denmark than in the rest of the EU. It does however indicate that more enterprises are specializing their business activities within EGSS than in many other countries. Therefore the indicator can be viewed as an oppor- 
tunity for Denmark to enhance the policies that can encourage these industries to grow and expand, both nationally and internationally. Danish enterprises can then assist other countries in receiving relevant technology and services to reduce their environmental pressures and become more resource efficient.

The Ad Hoc Group also sees the importance of developing and improving the statistics on EGSS. The analytical value using the currently available statistics on a Nordic level is limited, especially due to problems of comparability of the statistics between countries. But by enhancing the level of detail in the statistics, such as the industries involved (the NACE breakdown), type of activity the EGSS are involved with (e.g. air, waste, renewable energy and sustainable tourism) much more can be said about the sector at large in terms of value added, employment and export.

With the new EU regulation on environmental accounts also encompassing the environmental goods and services sector it is anticipated that the data will improve in terms of comparability and coverage become fuller in the short time span.

The Ad Hoc Group also recognises that the communication of these types of statistics needs to improve. The report on measuring green jobs (Bruvoll et al., 2012) identifies several important gaps in the statistics but also some misconceptions. One example is that the EGSS ought to cover also household activities. However, as the EGSS measure those entities (enterprises) who are producing the equipment or the services required to combat environmental pressures, the households are by default not included. Households are of course contributing to the reduction of for example greenhouse gases by switching their energy sources from fossil to renewable energy sources.

\subsection{Environmental protection expenditure}

\subsubsection{Introduction}

Opportunities arise from the production of goods and services but they also arise due to the deterioration of the local environment. Many enterprises have, either via government regulations or as company policies, to reduce their natural resource use and their environmental pressures with can lead to degradation of the environment.

Environmental protection expenditure (EPE) statistics is a measurement or assessment of how much money, enterprises and government, are spending to protect the environment. It includes both large 
and small investments in green technologies and current expenditure for running costs related to the environment. The EPE statistics measure how much has been invested and spent on environmental technology and equipment. These statistics also show the demand for these products and services. Since these statistics also cover government expenditures, they provide a platform to compare expenditures allocated to the environment.

This measure does not necessarily reflect the impact of policy on the state of the environment or the social cost of environmental policy, but it does indicate the measures taken by private and public actors to reduce their environmental impacts. It also provides an indication as to what type of technology they are relying on, whether it may be conventional technologies that clean already produced emissions such as pollution treatment equipment (end-of-pipe) or more process oriented technologies that look to prevent pollution from arising in the first place (pollution prevention or integrated technologies).

The data collection on environmental protection expenditure has been made by Eurostat and the OECD through a joint reporting arrangement since the early 1990s. In Europe, the regulation on environmental accounts will replace this extra reporting procedure. In the European Statistical System it will become mandatory to report EPE for a selected number of economic actors. The figures collected will include their investments (gross), current expenditures, subsidies and other transfers on environmental protection. The sectors covered in the new regulation are: the government sector, mining and quarrying, manufacturing, electricity, gas and water supply, waste management and waste water management.

\subsubsection{The Nordic situation}

The statistics in the Nordic countries for environmental protection expenditure varies in coverage and depth. Denmark has so far focused on covering the public sector while Sweden has focused on the mining, quarrying, manufacturing and electricity and water supply industry. Norway and Finland have covered both industries and the government sector. Iceland does not report any data to Eurostat and the OECD. This means that the chosen indicators in this section lack one or more countries from the Nordic region.

It has also been seen in evaluations that the coverage of environmental protection expenditures in the public sector varies between the Nordic countries (SSB 2013, SCB 2014). 
The main trend in EU28 regarding EPE in industries (defined as: mining, quarrying, manufacturing and electricity, gas and water supply) is that it is stable and accounts for $0.4 \%$ of GDP.

In the Nordic countries the situation is different. Norway shows a sharp decline of EPE by GDP, while Finland shows an increase and had in 2012 the highest share of EPE by GDP of the Nordic countries.

Figure 28: Environmental protection expenditures by industry, as share of GDP, 2008-2013

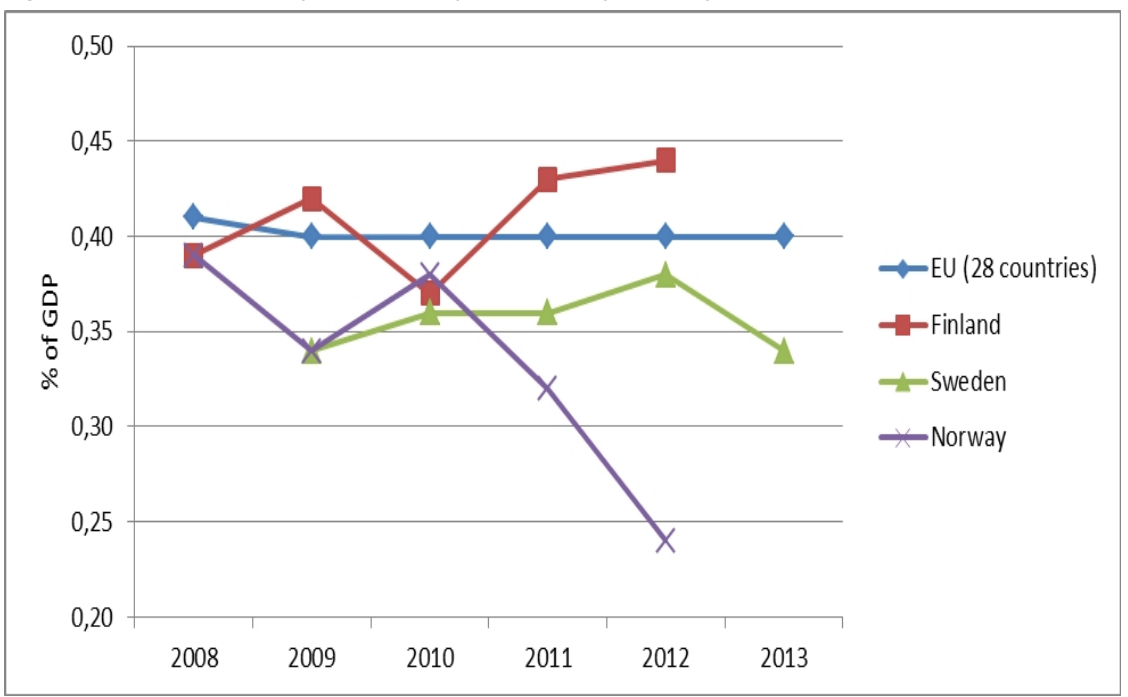

Note: Data for Denmark and Iceland are not available, in current prices. "Industry" includes: mining and quarrying, manufacturing, and electricity, gas and water supply.

Source: Eurostat.

The Nordic countries show a similar pattern regarding the environmental domains that are the focus of the investments in green technology, with the exception of Norway.

Figure 29 show that the Nordic industries are focussing up to $50 \%$ of their investments for environmental protection to reduce and manage emissions to air and climate protection. The second highest investment area involves waste water management including minimising, monitoring and preventing pollutants to reach water sources. 
Figure 29: Total EPE investments, by environmental domains, by industry, (NACE) 2012, EU28 and the Nordic countries

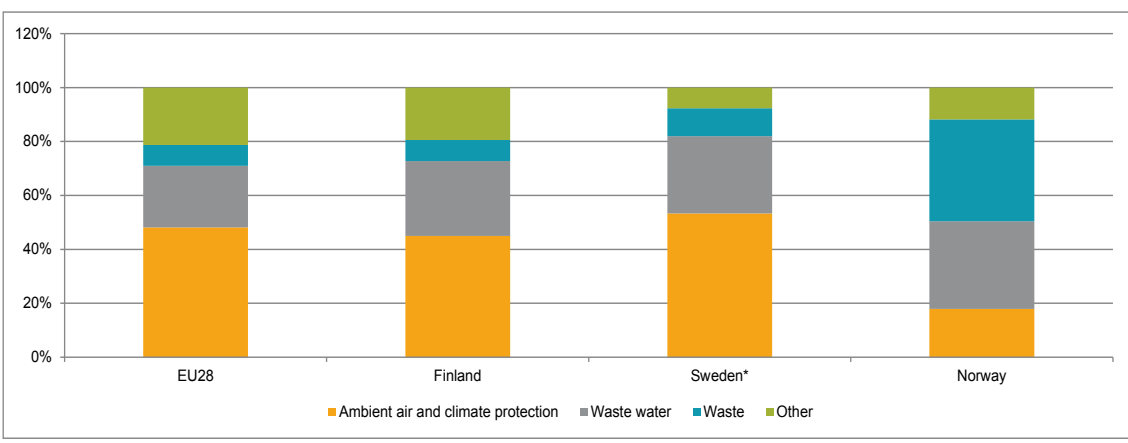

Note: * * Sweden 2013, data for Denmark and Iceland are not available, in current prices. "Industry" includes: mining and quarrying, manufacturing, and electricity, gas and water supply.

Source: Eurostat.

Examining the types of investments in more detail, Figure 30 shows how much the manufacturing, mining and extraction, and energy producing industries in the Nordic countries Norway, Finland and Sweden are using their investments to technology and equipment that reduces emissions from occurring in the first place. The figure shows that in the mining and quarrying industries in Finland, Norway and Sweden, the focus is on investments that treat already proven emissions and pollutions rather than on investing in pollution prevention technology.

In 2012, the share of pollution prevention technologies in relation to total environmental protection investments ranges from $20 \%$ in Norway, to $12 \%$ in Finland, to 3\% in Sweden. In the electricity, gas and water supply industry in the countries, there is a higher focus on preventing pollution from arising in the first place. The share of pollution prevention investment to the total EPE amount invested ranges from $78 \%$ in Finland, 62\% in Norway and 41\% in Sweden. 
Figure 30: Share of pollution prevention investments of total environmental protection investments, 2012, the Nordic countries, by some industries (NACE)

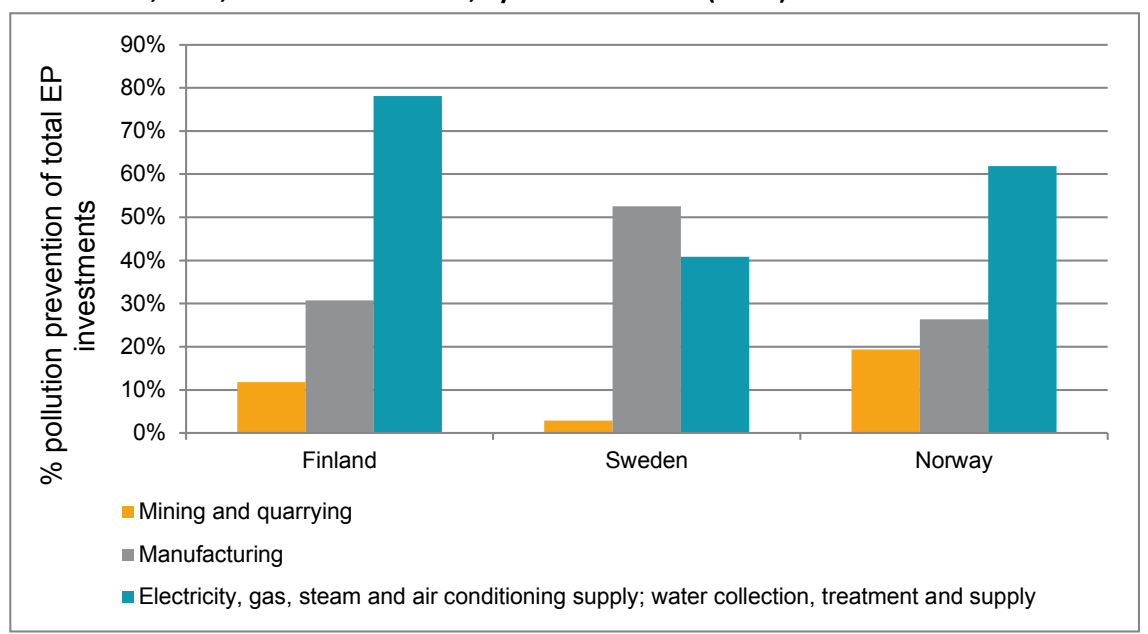

Note: Data for Denmark and Iceland are not available. Denmark expect to have data available by the end of 2016.

Source: Eurostat.

\subsection{Other environmental policy responses}

Other statistics on environmental policy responses are most notably subsidies related to environment. These subsidies can be subsidies that are aimed at bettering the environmental situation, such as economic support to farming methods to maintain biodiversity in the farming landscape, or for demonstration projects for environmentally beneficial technology.

There can also be economic support aimed at non-environmental purposes but which have an unwanted environmental effect, such as the wide-spread subsidies for fossil fuel production and consumption.

Sweden publishes statistics on environmentally motivated subsidies yearly. Denmark has also started to publish data on environmentally motivated subsidies on a yearly basis. Over the years Statistics Sweden has made a number of studies showing how environmentally damaging subsidies can be measured. Development on the definition and identification methodology for these types of subsidies is needed before statistics can be produced in an internationally harmonised and comparable way. 


\subsection{Recommendation and future use}

Statistics on environmental taxes are defined in the SEEA-CF and included in the EU environmental accounts regulation. Regular reporting and publication of environmental taxes occurs for the countries within the European Economic Area. The basic statistics stem from the national accounts and can be used within the context of environmental economic accounts easily, with the benefits that go with a globally accepted set of statistics. In this report it has been described both the strength of the indicators related to environmental tax revenues and the limitations. The recommendation from the Ad Hoc Group is to annually follow the indicators on environmental tax revenues as presented earlier.

The statistics for environmental goods and services basically measures the supply of products and services that reduce environmental pressures that can lead to environmental degradation and reduces the rate of depletion of natural resources. This statistical area is still under development but with the help of the EU regulation on environmental accounts the data for developing these statistics will soon become more readily available in Europe. It is recommended by the Ad Hoc Group to revisit this area in the short term. As these EGSS statistics are developed further, additional value added will be brought to the community.

It is possible to also look at the demand for environmental technologies and services. The statistics on environmental protection expenditure look at the demand side and measure how much companies have invested and used as intermediate consumption goods and services to reduce their own environmental pressures. Although these statistics have been under development a number of years, not all Nordic countries have implemented them. Since this is the case, it is recommended by the Ad Hoc Group to revisit this area in the short term. A driving force for full Nordic coverage of environmental protection expenditures comes from the new reporting requirements under the EU regulation on environmental accounts.

Additional statistics on other environmental economic instruments such as subsidies and the EU emission trading scheme are still in the development stage. The Ad Hoc Group recommends revisiting the area in the medium term to evaluate the possibility to include these areas in a Nordic environmental account. 


\section{Extensions and analysis - options for data and policy use}

\subsection{Summary}

This chapter focuses on the uses of data from the environmental accounts that extend beyond straight forward indicators. The Nordic statistical offices have tested the approaches of using national accounts input-output analyses to identify structural changes or to examine consumption related emissions.

The Ad Hoc Group recommends that the Nordic Council of Ministers revisit the area of analysis of decomposition and consumption as was suggested in Bruvoll (2007) as data are readily available. The lack of resources has hampered the progress of analysis of impacts abroad derived from Nordic consumption, imports and exports, but also looking into the aspects of drivers of pollution within a country.

With regards to environmental and economic modeling, these exercises are largely performed on an ad hoc basis on occasions when a specific question has been posed. It is now simply recommended that basic data from the environmental accounting framework are used to ensure and assist consistent environmental and economic modeling.

For several decades, macroeconomic models have included energy and air-pollution (including greenhouse gases) modules or sub-models in forward-looking analysis and scenario evaluations. Analyses to identify which factors were most important quantitatively behind the trends for various emissions or for the changes observed in the energy mix of the economy are made using decomposition analysis techniques. A major advantage and strength of environmental accounts is that they are well suited for being linked directly to and being integrated with both national accounts and such macroeconomic models and analysis techniques. 
Such modelling is useful for policy analysis, development and discussions. These approaches can serve as a common framework for different ministries, including finance or treasury ministries and integration with economic policies. Mostly the modelling and calculations have been one-way, from economics to environmental effects, but some attempts, including most recently the OECD's project, Consequences for Long-term Economic growth (CIRCLE), have been performed to model economic effects of human-induced or anthropogenic environmental change, e.g. climate change.

\subsection{Consumption - or demand-related environmental impacts}

\subsubsection{Introduction}

Environmental "footprinting", estimating the global impacts of a nation's consumption, including imports (and disregarding exports for consistency), has been increasingly proposed and much discussed in recent years. "Footprint" type indicators are gaining in popularity in spite of the uncertainties inherent in the calculation methodologies. The OECD, the EU and the UN Sustainable Development Goal indicators are all including these types of indicators in their various indicator sets. The OECD's suggested set of Green Growth indicators and for the indicators envisaged for the EU Roadmap on Resource Efficiency and the circular economy include footprint indicators. It must be strongly emphasized that such calculations ideally requires detailed data both on energy use, resource use and emissions in individual sectors from all exporting countries, and preferably recent import/export data for the whole supply chain, not just (traditional) bilateral trade data.

Ecological footprints, where use of resources for consumption is weighted by and converted to the assessed acreage needed to maintain and renew natural resources that are used for consumption, have received a lot of attention but has also met severe and well-founded criticism from the statistical and scientific communities. In particular weighting methods are often highly questionable.

In the context of this report, it is worth noting that environmental accounts data at disaggregated level (or similar data) are required for such estimates, or, positively put, that environmental accounts data are both very useful and also necessary for such analyses of footprints and global impacts. 


\subsubsection{The Nordic situation}

A Nordic Council of Minister's report on carbon footprints demonstrates some of these methodological requirements (multiregional input-output modelling), including the need for sectorally disaggregated data of exactly the type offered by the environmental accounts (Peters \& Solli, 2010). This means, that if national accounts type input-output tables are used, then the data on e.g. air emissions that should ideally be used for calculating footprints can come from the environmental accounts. The reason for this is that the air emission accounts follow the same definitions and scope as the national accounts. The above mentioned report (Peters \& Solli, 2010) recommended that future studies in the field of demand based environmental impacts should be benchmarked against multiregional input-output modelling. This is highly commendable in order to reach a global balanced input-output model. The issue is that all global databases available, may it be Exiopol, ${ }^{34}$ Eora $^{35}$ or any other model including environmental extensions in their global work, are research driven and the long term aspect and regular updating of the models are uncertain.

A new NCM report under preparation will look more closely on requirements, challenges and opportunities for footprinting, for carbon and greenhouse gases and for other resources and issues such as materials, land and water. It is anticipated that the results will be available in 2016 or 2017.

Also in the Nordic context, a much larger and more comprehensive Swedish project, led by Statistics Sweden with strong participation from world-leading experts in this field of research, including the Norwegian University of Science and Technology (NTNU) in Trondheim, has recently started the PRINCE project (Policy-Relevant Indicators for National Consumption and Environment). ${ }^{36}$ The project aims to develop a sound and repeatable methodology to monitor the environmental impacts of Swedish consumption, both inside and outside Sweden's borders, using the latest modelling and statistical techniques. Results will become available during the course of the project, which finishes in 2018.

In 2016 Statistics Denmark will start a project aiming at analysing Danish footprints abroad by using available multi-country input-output models. The project follows up on a similar project carries out some years ago.

\footnotetext{
${ }^{34}$ Exiopol: multiregional environmentally extended (EE) Input-Output (I-O) framework, with links to other socio-economic models: http://www.feem-project.net/exiopol/

35 Eora: a multi-region IO database provides a time series of high resolution input-output (IO) tables with matching environmental and social satellite accounts http://worldmrio.com/

${ }^{36} \mathrm{http}: / /$ www.sei-international.org/projects?prid=2170
} 
Emissions in Nordic countries are not the whole story of how the production and consumption pattern are drivers of environmental pressure. To calculate the total impact of Nordic final use, we need to look outside the Nordic area and study what and how much we import, and what environmental impact that production has in other countries. Impact on climate change is a global phenomenon and effect of emissions reductions remains the same regardless of where the emissions occur geographically.

The negotiations on reductions of climate gases have so far been largely based on a national geographical perspective, calculating the emissions within each party's national border. This perspective has advantages in the sense that the legislation and the responsibility for the economy within the national borders are within the jurisdiction of the nations. However the insight that global warming is a true global externality where the impact of emissions and emissions reductions on climate change is independent of in which country's territory it occurs has somewhat changed the national perspective of climate policies.

The UN climate convention is based on the principle of cost effectiveness, which seeks to achieve emissions reductions in the most cost effective manner by opening for international cooperation and joint implementation of measures to curb climate change. Based on this marketbased approach, the EU has, through its ETS system, established a common EU target - or cap - for the sectors and companies covered by the system. The UNFCCC and the Kyoto protocol also provides for the possibility of taking responsibility through action beyond national borders.

The consumption perspective has the advantage of illustrating, in broad terms, how patterns of our consumption behaviour can be seen as a driving force.

The following figure is an assessment of the greenhouse gases that could be linked to Swedish consumption, both within Sweden's borders and the emissions produced in the countries where the imported goods were made. It should be emphasized that such an assessment is based on simplifying assumptions and the emissions connected to the imported products are especially uncertain. 
Figure 31: Greenhouse gas emissions that could be linked to Swedish consumption, 1993-2012, million tonnes CO2-equivalents

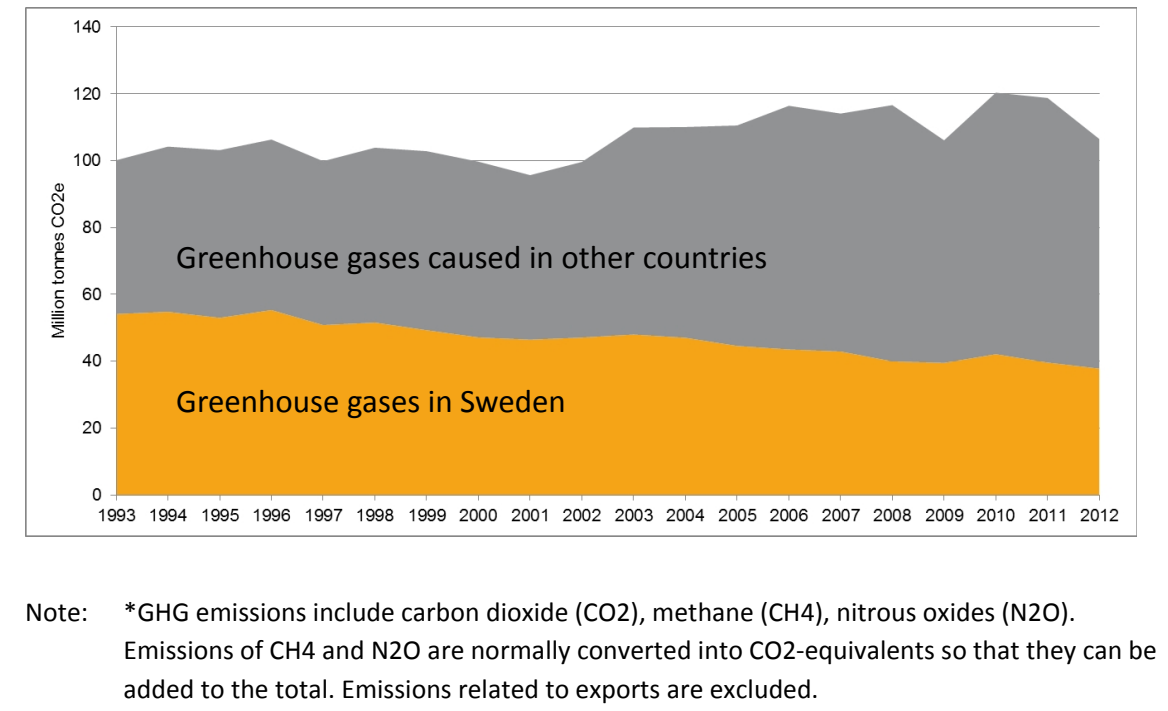

Source: Statistics Sweden and the Swedish EPA, SCB 2015a.

\subsection{Analysing drivers of greenhouse gas emissions}

\subsubsection{Introduction}

In trying to green our economies by decoupling environmental pressures from economic growth, both at national aggregate level and at the level of individual economic sectors, it is necessary to analyse the different factors, including policy instruments, behind the evolution and trends in environmental impacts for different emissions and for different sectors. Such decomposition analysis, looking at the relative weight or contribution, e.g. to changing emission patterns, from population growth, economic growth, changes in the structure of the economy, changes in the use of energy products and natural resources, technological changes, and other factors, also require SEEA-type data.

An earlier report by the Nordic Council of Ministers (Bruvoll, 2007) provided an overview and introduction to some of the work done in the Nordic countries at that time. Their recommendations were that the methodology and data availability would make the analysis practical to implement. Other work presented the work done by the statistical agencies in the Nordic countries at that time, particularly in Norway (Bruvoll, 
A. \& H. Medin (2003), Denmark (Jensen, P.R. \& T. Olsen (2003) and Sweden (Wadeskog, A. \& V. Palm (2003).

\subsubsection{The Nordic situation}

\section{A Swedish example}

From an economic production perspective (the environmental accounts), carbon dioxide emissions are influenced by the type of goods and services produced, e.g. real estate services and transport. The figure below shows that the manufacture of less emission-intensive products is on the increase (distribution between goods and services) and that the fuel mix has been changed (the emissions intensity). We have gone from using fossil fuels to using e.g. biofuel, wind power and geothermal energy instead.

Another factor that is helping to reduce climate impact is that producers are starting to change the types of input materials they use in production (e.g. plastic, steel and wood) and also from where they buy them (domestically or abroad). These factors, the purchase of input goods, are shown in the figure as trade in production. The reduction in the frequency of input goods may have something to do with the goods being imported instead of being purchased in Sweden. This is something that must be considered separately in the analysis.

Despite the fact that several of the factors, such as increased production in services and lower carbon content in fuels, should lead to reductions of carbon dioxide emissions, total emissions are not changing to any great degree.

This is because the driving forces of the emissions are cancelling each other out on the national level. A growing population and greater production of goods and services, measured as GDP, are factors that have an impact in the opposite direction, towards increased emissions.

The figure below shows the change in actual carbon emissions in production 1993-2012 and how contributory factors have developed during the same period. 
Figure 32: Factors affecting carbon dioxide emissions in Sweden - a decomposition analysis, per cent, 1993-2012

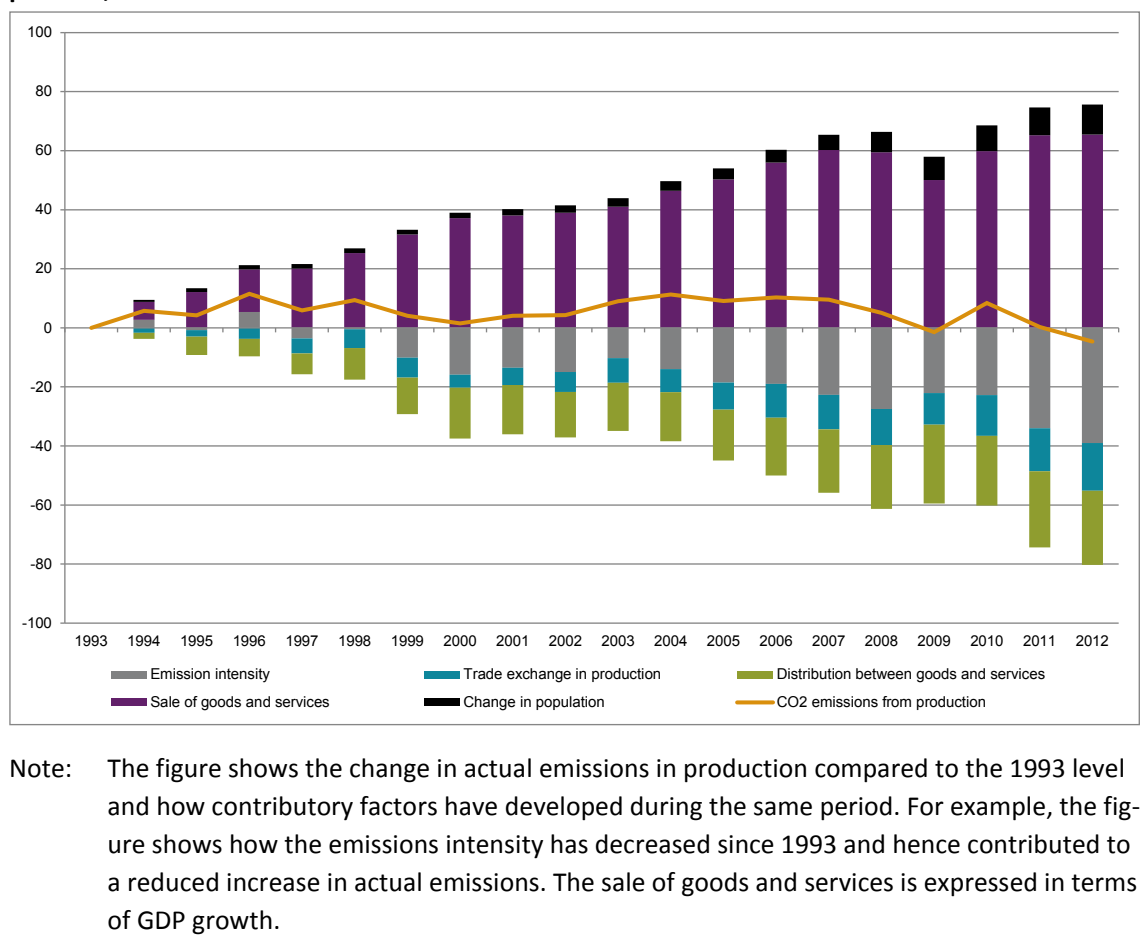

Source: Statistics Sweden, SCB 2015a.

\subsection{Environmental economic instruments - the price of $\mathrm{CO}_{2}$ emissions}

\subsubsection{Introduction}

The same system boundaries and definitions are used throughout most of the environmental accounts. This enables different modules, like air emissions and environmental taxes, to be used together. An interesting example combines emissions of $\mathrm{CO}_{2}$ and tax revenue from the $\mathrm{CO}_{2}$ tax. Using these two together creates an implicit average tax rate, Euros per tonnes of $\mathrm{CO}_{2}$ emissions, which is also a type of price for $\mathrm{CO}_{2}$ emissions that can be compared between countries. This measure should however not be confused with a reflection of damage costs of emissions.

There is also another instrument with the purpose of decreasing $\mathrm{CO}_{2}$ emissions, the EU ETS. For a more comprehensive price of $\mathrm{CO}_{2}$ emissions, regard should also be given to emission permits. However there is at the 
moment no NACE industry allocation of emission trading for the Nordic countries combined.

All the Nordic countries have a tax on $\mathrm{CO}_{2}$ emissions; it is actually a tax on the carbon content of different fuels. It is levied on top of the price of the fuel when it is bought by the end consumer.

In the Nordic region as well as in the EU, where the tax on carbon exist, both the $\mathrm{CO}_{2}$ emissions and $\mathrm{CO}_{2}$ tax revenue statistics are allocated to different NACE industries. This enables calculation of not only a type of price of $\mathrm{CO}_{2}$ in the country but also within different industries and sectors.

\subsubsection{The Nordic situation}

A pilot study was made in 2014 and the results are presented in figure 33. The figure depicts $\mathrm{CO}_{2}$-taxes paid by the industries and by the households, and their respective $\mathrm{CO}_{2}$ emissions. As a comparison the maximum price of an emission permit for 2011 has been added to the figure.

As can be seen, there exists clear differences between the industries and also between the countries in terms of Euros per ton $\mathrm{CO}_{2}$ emissions. At the country level the average tax per ton of $\mathrm{CO}_{2}$ is highest in Sweden, then Norway and lowest in Denmark.

Households and service industries appears to be paying more for $\mathrm{CO}_{2}$ emissions in all three countries. From a damage cost point of view it does not matter from where the emissions origin. Therefore an optimal policy should imply that the cost to emit should be the same regardless of from where it occurs within and between countries. An optimal international carbon tax is obviously difficult to agree upon and establish. Other aspects than an optimal policy design might affect national carbon tax levels and the differentiation of these levels.

It should be noted that the $\mathrm{CO}_{2}$ emissions cover both industries within the EU-ETS and beyond. In the future a distinction of each instrument and the related emissions will be possible to show. 
Figure 33: Average tax (implicit price) on carbon dioxide emissions, Nordic countries, by industry (NACE) and spot price of emission permit. 2011

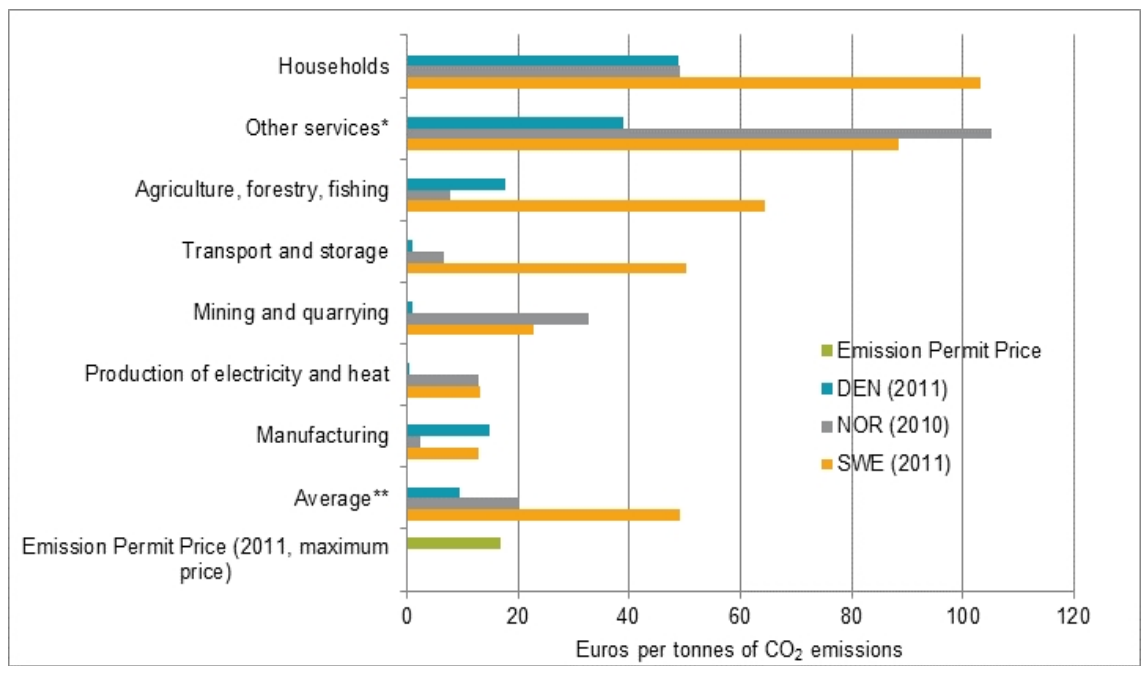

Note: *Other services consists of industries such as construction, waste and waste water management, wholesale and retail, public administration and financial institutes.

**Average of $\mathrm{CO} 2$ tax paid per tonnes of $\mathrm{CO} 2$ emission.

Source: The statistical office in the Nordic region. Data for Finland and Iceland are not available.

Manufacturing industries are paying less than households for their emissions of $\mathrm{CO}_{2}$. Some of these are included in the EU Emission Trading Scheme and as a comparison; the maximum price of an emission permit has also been placed at the bottom of the figure. The industries that have lower implicit tax rates for $\mathrm{CO}_{2}$ emission differ somewhat across the countries. In Denmark; transport, mining and energy production are the industries paying the least. In Sweden it is manufacturing and energy production. In Norway it is agriculture, forestry, fishing, manufacturing and transport that have the lowest implicit tax rates.

New methods for industry allocation of tax revenue and air emission statistics is constantly being developed by the statistical offices. In time these type of implicit tax rates can be produced more regularly and hopefully also include Finland and Iceland. 


\subsection{Environmental economic modelling}

\subsubsection{Introduction}

For several decades, macroeconomic models have been combined with energy and air pollution (including greenhouse gases) modules or submodels, used for forward-looking analysis as well as for backward-looking analysis. A major advantage and strength of environmental accounts is that they are well suited for direct linking to and integration with both national accounts and such macroeconomic modelling.

Modelling environmental pressures have generally proved easier to do for energy, air emissions and pollution, and partly for waste and material production, including toxic materials, than it has been for water, land use and biodiversity, where geographically disaggregated and spatially explicit models are often required. Biodiversity has proved among the more challenging environmental issues to link to macroeconomic models.

\subsubsection{The Nordic situation}

\section{Norway}

In Norway there is a long tradition of linking environmental accounts and national-accounting-based macroeconomic models to make projections, first for energy demand and particularly electricity, as a basis for planning further hydropower development. From the 1980's this was also done for air pollution (the SIMEN project), and since the 1990's also, and with increasing emphasis, for greenhouse gases (starting with the KLØKT project). In Norway, macroeconomic models have been developed and used for economic policy-making at least since 1960 , both short- and medium-term models (for demand management): KVARTS-MODIS-MODAG, ${ }^{37}$ and the many longer-term, general equilibrium models in the MSG family (MultiSectoral Growth), also from around 1960. New models have now been developed to replace MSG: SNoW (Statistics Norway World model, in two main versions, SNoW-No (rest of the world exogenous) and SNoW-W (World). These models build on the economic structure of the MSG models and are much easier to use, update, compare and link with other national and international models. The SNoW models also link to GTAP (Global Trade Analysis Project) data, i.e. for analysis of trade-climate-environment issues, and possibly also for environmental "footprints".

${ }^{37}$ Quarterly model - MOdel of DISaggregated type, 1960 - MODel of AGgregated type, from 1980. 


\subsubsection{Denmark}

The three main economic (but not including environment and energy) models that are used in Denmark are ADAM from Statistics Denmark, ${ }^{38}$ DREAM which is financed by the Ministry of Finance ${ }^{39}$ and SMEC from the economic council. 40

However there are also a number of other environmental economic related models that are based on these models (Miljøstyrelsen 2013).

EMMA is an energy and environmental macroeconomic model coupled to ADAM. It is used mainly by the energy agency to calculate the energy use and to quantify the effect on the environment of financial plans for the climate and energy policy.

IntERACT is used to investigate new policies for climate and energy and their consequences for the energy system and the economy. The IntERACTmodel has two parts. One is an economic model and the other is a detailed technical energy model. similar to the international TIMES-model.

MUSE (MUlti SEctor model of the Economic Councils) is a CGE-model that has been used to analyse green fees and its distributional consequences in 2009. In 2010 it was used to analyse the agricultural sector and the environmental pressure from the agriculture.

\subsubsection{Finland}

ENVIMATscen is an environmentally extended long-term simulation model. The base year is 2010 and the model is solved to the chosen terminal year assuming that the relevant variables develop along steady growth paths from the base year to the terminal year. The principal terminal years are 2030 and 2050.

The model is very detailed. It has 147 industries, 230 product groups, 61 household consumption commodities, 7 institutional sectors, 21 kinds of income flows, 57 types of energy, 34 types of raw-materials from the nature and 39 types of emissions into air and waters. Besides domestic raw-material use and emissions, the model contains estimates of the life cycle or upstream resource use and emissions abroad of the 174 imported products.

\footnotetext{
38 http://www.dst.dk/da/TilSalg/ADAM.aspx

$39 \mathrm{http}: / /$ www.dreammodel.dk

${ }^{40} \mathrm{http}: / /$ www.dors.dk/sw354.asp
} 
The ENVIMATscen core model is constructed in conformity with the structure of the national accounts.

According to a study by Statistics Finland and then Thule Institute using the ENVIMAT model, interesting results were seen in the case of greenhouse gas emissions. The theorem around the commonly accepted opinion that living in city centre causes fewer environmental pressures than living in suburbs or at countryside was tested. The results showed that this seems not to be the case in Finland. The results of the study show that there is no difference between the emissions of households living in cities or countryside.

Table 3: Greenhouse gas emissions of households 2012, Finland, kilos of $\mathrm{CO}$ eq

\begin{tabular}{lrrr} 
Type of region & GHG per household & $\begin{array}{l}\text { GHG per } \\
\text { consumption unit }\end{array}$ & $\begin{array}{l}\text { GHG per } \\
\text { consumption of EUR 1 }\end{array}$ \\
Inner urban area & 17,104 & 12,662 & 0.549 \\
Outer urban area & 20,381 & 12,959 & 0.554 \\
Peri-urban area & 21,361 & 13,183 & 0.538 \\
Local centres in rural areas & 16,210 & 11,652 & 0.560 \\
Rural areas close to urban areas & 19,612 & 12,558 & 0.526 \\
Rural heartland areas & 17,274 & 11,458 & 0.026 \\
Sparsely populated rural areas & 18,263 & 11,460 & 0.534 \\
\hline
\end{tabular}

Source: Nurmela and Mäenpää (2014).

Interesting result is that the GHG-emissions of households for housing and energy are highest in urban areas. The reason for this is that in Finland most of the households in urban areas are connected to district heating. Most of the district heat in urban areas is produced by fossil fuels or peat. In rural areas, much fuel wood is used and electricity, which today has much lower greenhouse gas content. The average GHG-emissions for housing and energy of the households in rural heartland areas and sparsely populated rural areas are the lowest. On the other hand, traffic emissions are highest of the households in rural areas close to urban areas.

The study was done by using input-output tables of National Accounts; it was possible to estimate the greenhouse gas emissions of different commodity groups of consumption. From Statistics Finland's Household Budget Survey it was possibly to collect the consumption data of different kinds of households by a disaggregated breakdown. By using the coefficients available from the input-output tables, the consumption of household in Euros was transformed into emissions. Coefficients were calculated by the ENVIMAT-model. In addition, data on the use of raw materials exists and could be analysed as well. 


\subsubsection{Sweden}

The National Institute of Economic Research has developed a Computable general equilibrium model, EMEC, ${ }^{41}$ which is used for analysis by the Ministry of Finance and is using environmental account data. It is used by the finance ministry to assess environmental economic issues. It has been used in the long term planning and informed the environmental tax investigations.

Statistics Sweden and the Swedish Environmental Protection Agency has also been using the Cambridge Econometrics model E3ME. This is an econometric model that is also using environmental accounts data and was used to assess the emission allowance trading schemes in $2004 .^{42}$

The Swedish Energy Agency is also using models that have more technical content such as the international optimization model MARKAL and then align them with economic information in their projections. ${ }^{43}$

\subsection{Recommendations and future use}

The Ad Hoc Group recommends that the Nordic Council of Ministers revisit the area of decomposition analysis and consumption models as was already suggested in already in 2007 (Bruvoll, 2007) since the data needed for these exercises are readily available.

With regards to environmental and economic modeling, it appears that they are performed mostly on an ad hoc basis. The Ad Hoc Group makes the recommendation that whenever the question is right for an environmental economic model to be used then the input data should be based on data from the environmental accounting framework to ensure consistent results from environmental and economic modeling.

\footnotetext{
${ }^{41} \mathrm{http}: / /$ konj.se/download/18.1734e80814bc5f7dc5b55b/EMEC-en-popularvetenskaplig-beskrivning.pdf, http://konj.se/download/18.768d17ac139d0d0248f1ee4/Fordjupnings-pm-15-Fragor-rorande-EMECs-tillganglighet-och-forbattringsmojligheter.pdf and http://www.scb.se/statistik/MI/MI1202/ 2003M00/MI710P0301.pdf

42 http://www.scb.se/statistik/MI/MI1202/2004A01/MI1202_2004A01_BR_MIFT0401.pdf

${ }^{43}$ http://www.scb.se/statistik/MI/MI1202/2004A01/MI1202_2004A01_BR_MIFT0402.pdf
} 



\section{Social indicators}

\subsection{Summary}

The Ad Hoc Group finds that the existing work and follow-up of the European sustainable development policy has helped clarify the types of statistics that are necessary to be able to follow the trends of the social pillar of sustainable development. With the work of establishing a new post2015 sustainable development agenda there is now a push to truly integrate the analyses. How to integrate social aspects with economic and environmental aspects is the next substantial step to take. The accounting framework that is used to integrate environment and economic statistics could be a possible framework for such integration. The Nordic countries would be well placed to take such a step. In sustainable development indicators sets there are some commonly chosen social indicators that could also be part of an integrated statistical framework for policy analysis. Including general social indicators in an accounting framework is possible, but not a standard practice in the SEEA.

With detailed enough data and using the framework of SEEA it is possible to calculate some environmental pressures arising from household consumption by different types of households. This is an established type of analysis that involves environment, economic and social aspects. Analysis of the so-called green jobs is another established analysis that has aspects of all three areas (environmental jobs, employment by sex and region as well as investments or trade data) assuming that all of these data parameters are collected and kept with the primary data.

In economic models the inclusion of data about the employed per industry is common and some Swedish pilot studies show that many other social statistics can also be added as long as some additional categories of people are added. In order to cover the whole population, the people outside of the workforce were represented as not employed, children and elderly in the studies made.

We suggest that this area needs to be further developed. Statisticians with expertise in social statistics are needed. One way to assist in this development would be to hold a workshop inviting people from NMR's Committees to initiate such cooperation. 
The following areas would be of interest to develop in order to make an integrated sustainability account:

- Social-economic aspects.

To analyse in detail data that can be easily incorporated into the SEEA: e.g. number of employed persons, consumption patterns of types of households by gender or income, education.

- Social-environmental aspects.

Integrate health and other relevant data (or model through research) and relate this to environmental pressures such as emissions, noise exposure, smoking, work environment, traffic accidents, access to nature, etc. Some type of geographical referencing of the data may be needed to make sense of the analyses.

- Other social aspects.

Social issues identified as important for sustainable development. For example poverty, self-reported health, threats of violence, unemployment and political influence.

\subsection{Introduction}

The mandate of the Ad Hoc Group stated that social issues that belong to sustainable development should also be considered. There has been little international work on including social issues in the SEEA framework, but Sweden has been interested in exploring this path and some pilot studies have been made.

In 2004 Statistics Sweden made an inventory of social studies within the context of the SEEA. This review was presented at the London Group meeting and it showed that there are some different approaches to doing this. ${ }^{44}$ The inventory divided the studies into three different types, economy-social, environment-social and social-social.

The first type makes a link between the economy and households, such as when the accounts are used to calculate the environmental pressure from consumption. Different types of households consume different types of products and therefore different types of households are possible to distinguish. The second type makes the link between environment and health, and can show the health dimensions of the persons employed in different

44 The London Group is a UN City group with SEEA practitioners that meet yearly to harmonise and cooperate to develop the SEEA system. 
industries or in the development of a given population's health in heavily polluted areas. The third type relates to purely social issues such as loneliness or smoking habits but reported by industry.

\subsection{Sustainable development indicators (SDI)}

A number of social indicators are part of the SDI sets. For some systems they are ranked, so that there are different levels of indicators, in order to facilitate the communication. The headline indicators are then indicating the general trends whilst the underlying indicators are dealing with important trends that can explain differences between countries or over time. Developing and developed countries have focussed on different issues and the new post-2015 indicator system is now designed to address issues that are high on the agenda in all countries.

The headline indicators for the social aspects of sustainable development in most SD indicators sets are typically healthy life years, where life expectancy at birth is weighted with data on how many of those years are estimated to be healthy.

Also the subjective indicator on how many people consider their life to be ok is often incorporated in the indicator sets. Other important explanatory indicators are employment, education, income and health-related indicators that can be regarded as important factors that can determine the trend on healthy lives.

The EU sustainable development indicator set is divided into ten themes of which three are very clearly social in their focus; namely Public Health, Social Inclusion and Demographic Changes. These three themes have one headline indicator each.

The EU social headline indicators: 45

- Healthy life years and life expectancy at birth, by sex.

- People at-risk-of-poverty or social exclusion.

- Employment rate of older workers.

There are also other types of indicators that follow the operational policy goals of the EU and some other indicators that are contextual so do not have a particular goal (such as public expenditure of education).

${ }^{45} \mathrm{http}$ ://ec.europa.eu/eurostat/web/sdi/indicators/public-health 


\subsubsection{Nordic Council of Ministers' social indicators ${ }^{46}$}

Nordic Sustainable Development Indicators show long-term trends in the following focus areas: the Nordic welfare model; viable ecosystems; changing climate; sustainable use of the earth's resources; and education, research and innovation. Most social indicators are presented under the Nordic welfare model focus area, and one (exposure to air emissions) under viable ecosystems. The social indicators on the website for the Nordic countries present some important facts about the trends of the populations in the Nordic countries, such as Life expectancy at birth, by sex.

Other topics that are covered in the NCM SDI-set concern populations development since 1990, urbanisation, risk of poverty for families with children, gender differences in salaries and percentage of employed and unemployed of the population 15-64.

\subsubsection{Sweden}

The statistical office in Sweden has investigated if the social issues can be included in the accounts in a similar way as is done in Corporate Social Responsibility reporting. By going to the social statistics data sources it was possible to distribute the social data by industry. ${ }^{47}$

The project chose indicators from most of the dimensions that make up the social statistics. In order to cover the whole population some new categories were added such as unemployed, children and retired people. The work shows that it is possible to include many different aspects of the social field in the environmental accounts. This is demonstrated by presenting data distributed by industry from the Living Conditions Survey (ULF) in Sweden, surveys which have industry as a background variable for those employed. Including this social dimension in the environmental accounts also makes it possible to analyse the social data together with the system's economic and environmental data. This can be done using methods frequently used in the environmental accounts, such as different kinds of industry profiles and decoupling diagrams, in which social data are treated in the same way as economic and environmental data. Adding social data on industry level to the environmental accounts also adds the social dimension of sustainable development to the environmental accounts, which makes it possible to make industry level analyses. The por-

\footnotetext{
${ }^{46} \mathrm{http}: / /$ www.norden.org/en/nordic-council-of-ministers/ministers-for-co-operation-mr-sam/ sustainable-development/indicators-for-sustainable-development-1

${ }^{47}$ http://www.scb.se/statistik/_publikationer/MI1202_1988I02_BR_MI710P0401.pdf
} 
tion of the population that are not connected to an industry, such as children, non-employed and unemployed persons, the elderly, etc. would not be part of the analysis.

\subsubsection{Finland}

In the Finnish indicator set for sustainable development, there is a wide spectrum of indicators featuring social sustainability. ${ }^{48}$ Social sustainability is mainly reflected in such social goals as equal opportunities for wellbeing, society of participating citizens, sustainable work and sustainable communities and local communities. In addition to indicators commonly used in international indicator sets, such indicators are also included like subjective well-being, voting turnover, corruption, work absences due to sickness and average commuting distance.

\subsubsection{Norway}

Norway has since 2005 reported annually on a national set of indicators for sustainable development, proposed by a national commission (NOU 2005:5), and further developed since then. Out of 17 indicators for sustainable development reported on in Norway's National Budget 2014, there are four social indicators, on Income distribution, Education level, Social exclusion (e.g. percentage of the population 16-66 years receiving disability pensions), and Life expectancy at birth.

\subsubsection{Denmark}

In Denmark a research project explicitly aimed at combining environmental accounts with socioeconomic and social data in order to analyse the environmental performance of various household or family types. The analysis showed that that families living in urban flats and especially young and elderly families had the most environmentally friendly consumption pattern, while middle income families living in houses have the least environmentally friendly consumption pattern. The analysis was carried by combining family budget statistics, input-output tables and environmental accounts (energy, material flows, and various types of air emissions). (Wier et al., 2005).

${ }^{48} \mathrm{http}: / /$ www.findicator.fi/en/kestavakehitys 
Out of Denmark's 23 sustainable development indicators launched in 2014, there are 10 social indicators. These focus on Education, Crime rates, Homeless people and Drug uses.

\subsection{Recommendations and future use}

Further systematic development of this area is needed before data can be interlinked to environmental and economic statistics and accounts, in reliable and consistent ways. As the Ad Hoc Group have limited knowledge of the social sphere it can see a couple of potential ideas to further the area in an accounting context.

The development could be started with a workshop to which other committees of the NCM can be invited to discuss what types of integrated analyses would be of greatest policy value.

Another suggestion is to include as a regular indicator, employment for men and women by industry. There is also a possibility to develop indicators with levels of education by industry. 


\section{Ecosystem services}

\subsection{Summary}

Work on describing ecosystem services has been under development for some time now. The Convention on Biological Diversity (CBD) and the Millennium Ecosystem Assessment (MEA) have driven the area forward considerably. However, work on developing indicators is still experimental and depend on data availability. The Nordic national statistical offices are divided as to the role of the statistical community in the further development of this area.

The Ad Hoc Group recommends that the Nordic countries make pilot studies and experiments to further the information needs in this area. These pilot studies could be organized in a multidisciplinary way and may include several government agencies as well as research institutes.

The ideas of SEEA experimental ecosystem accounts should be further developed and integrated with the ecosystem assessment approach. The aim of the pilots and experiments should be to find methods to link the ecosystems and their services to economic and social considerations.

In the Nordic countries national biodiversity strategies are in place to follow the CBD and European strategies. The Nordic countries take different approaches in monitoring and assessing the strategies. Finland has come far in measuring ecosystem services through indicators to monitor the development of the services. Sweden has for many years held on to the environmental quality objectives which include a specific target to maintain and stop loss of biodiversity. One problem, however, is that ecosystem services are not being measured on a regular basis. Norway monitors the development through the Nature Index. ${ }^{49}$ In Denmark two of the key areas of ecosystems are the protection and increase of forest areas and the reduction of invasive species. Iceland has sharpened its strategy to focus on invasive species, restoration of degraded habitats and conservation measures (Mazza et al., 2013).

${ }^{49} \mathrm{http}$ ///www.nina.no/english/Environmental-monitoring/The-Norwegian-Nature-Index 
The statistical community has until now been involved to a limited extent in the provision of data for the national strategies and the development of indicators related to ecosystem services. Agriculture and tourism statistics, water and fishery related statistics have been used in assessments. It is common to use research related studies for the monitoring and assessment of ecosystem services. The availability of data from the various research studies helps the assessments. However, research on small areas is difficult to aggregate to macro scale and it is also not possible to use the studies as a basis for establishing a time series.

The UN has developed a tool within the environmental accounts to facilitate a comprehensive data production that can link the ecosystems with the economy at large. Tests have been undertaken through pilot studies around the world, including Australia and Sweden to see how the environmental accounts can respond to the increased need for more data on ecosystems.

There is a great potential to use the large amounts of data and understanding available at the statistical offices to increase the knowledgebase on ecosystem services. However, as this is a new area there is little room for experimental work and developments within the operating budgets of the statistical offices. In order to continue to follow the work on the Economics of Ecosystems and Biodiversity (TEEB), indicators that are reliable and of sound quality have to be incorporated.

Issues that are still debated concerns the weight put on valuation of ecosystem services and the lack of internationally agreed standards on how to measure them in monetary terms. The fact that data on the physical attributes come a long way when used appropriately and should not be under estimated in the discussion. The physical attributes (hectares, amounts and tonnes) are what they are while a value of recreation or particular services depends highly on the tool of measurement and the weights applied.

\subsection{Introduction}

In recent years increased attention and policy priority has been given to analysing, mapping and monitoring ecosystems and biological diversity, perhaps most importantly related to the Convention on Biological Diversity at the Rio Summit in 1992. The UN Millennium Ecosystem Assessment (MEA) in 2005, and the work on TEEB, The Economics of Ecosystems and Biodiversity, since 2007, has led to a large amount of work and research on these issues, focusing on the concept of ecosystem services. 
However, when it comes to constructing accounting systems and linking such accounts or even indicators to national accounts, ecosystems and biodiversity have proved to be particularly challenging, compared to other environmental issues and resources, such as energy use and air pollution.

The OECD has produced projections of biodiversity loss by 2030 and 2050 in its two most recent Environmental Outlooks (OECD 2008 and OECD 2012) using the indicator Mean Species Abundance (MSA). This indicator was linked to OECD's economic model ENV-Linkages with the IMAGE model (Integrated Model to Assess the Global Environment).

Based on the modelling results, mean species abundance at the global level is projected to decline by a further $10 \%$ between 2010 and 2050 , with the majority of loss occurring before 2030 . The steepest decline in MSA is in scrubland and savannah (19\%), temperate forests (19\%) and tropical forests (14\%) (OECD, 2012).

In the Nordic countries national biodiversity strategies are in place to follow the CBD and European strategies. The Nordic countries are taking different approaches in monitoring and assessing the strategies. Finland has come far in measuring ecosystem services through indicators to monitor the development of the services. Sweden has for many years used the environmental quality objectives which include a specific target to maintain and stop loss of biodiversity. The main problem is that ecosystem services are not being measured on a regular basis. Norway monitors the development through the Nature Index. In Denmark one of the key areas of ecosystems are the protection and increase of forest areas and the reduction of invasive species. Iceland has sharpened their strategy to focus on invasive species, restoration of degraded habitats and conservation measures (Mazza et al., 2013).

\subsection{UN SEEA experimental ecosystem accounts}

SEEA - Experimental Ecosystem Accounting (EEA) is an integrated statistical framework for organizing biophysical data, measuring ecosystem services, tracking changes in ecosystem assets and linking this information to economic and other human activity. SEEA EEA provides a complementary perspective to the accounting approaches described in the SEEA Central Framework (CF) but does not have the status of an international statistical standard. It provides a synthesis of current knowledge in this area and is a starting point for the development of ecosystem accounting at national and sub-national level. 
The SEEA - Experimental Ecosystem Accounting was presented to the UN Statistical Commission in 2013.50 The Commission welcomed it as an important first step in the development of a statistical framework for ecosystem accounting, and encouraged its use by international and regional agencies and countries wishing to experiment in this new area.

In the SEEA CF environmental assets and natural resources are measured from the perspective of "individual" environmental assets, such as timber resources, land, mineral and energy resources, and water resources. In SEEA EEA environmental assets are measured from the perspective of ecosystems. SEEA EEA assesses how different individual environmental assets interact as part of natural processes within a spatial area to provide a range of services for economic and other human activities.

In the development of the SEEA - Experimental Ecosystem Accounting, several organisations and institutions were involved. The UN Statistical Division, UNEP, the CBD secretariat, the European Commission and a number of interested countries, also from the Nordic region, developed experimental pilot accounts using the SEEA EEA.

The Nordic countries both participate in and follow this work closely, and it may be possible to develop common Nordic work also on this issue in the future. Norway has contributed with funding to the UN work. Statistics Sweden made a study where wetlands, grasslands and taiga that are reported as important for biodiversity were being mapped and related to the sector that owns the land. ${ }^{51}$

Figure 34 shows that the majority of land important for biodiversity is owned by the agriculture and forestry industry. As such the land is not protected. Interesting to note is the absence of the ownership of the government.

50 The UN statistical commission comprises of the world's general directors of national statistical offices.

${ }^{51}$ http://www.scb.se/Statistik/_Publikationer/MI1301_2014A01_BR_MI71BR1503.pdf 
Figure 34: The four largest landowners of the habitats Grass- and pasture, Western taiga and Wetlands. Hectares, industry NACE/ISIC 2007

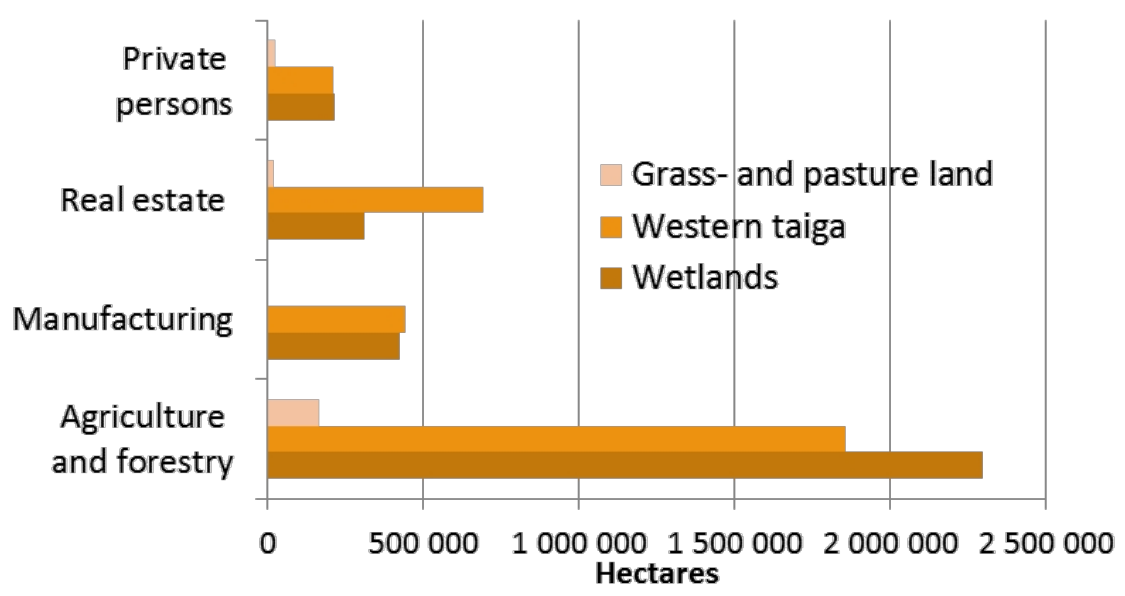

Source: SCB 2015b.

Statistical units are the entities about which information is sought and about which statistics is ultimately compiled. The statistical units of ecosystem accounting are spatial areas about which information is collected and statistics are compiled. Examples of methods include remote sensing, on-ground assessment, surveys of landowners and administrative data. Geo-coded data that can be used for ecosystem accounting is accumulating rapidly as so-called big data in various Information and communications technology-applications, administration and by environmental monitoring.

A debate on the focus of valuing ecosystem service is occurring from time to time, statisticians are not in favour due to the difficulties of measuring experiences, while policy makers often see the valuation as key to monitoring and change decision making processes. Eurostat has put in a word in the debate on valuation and sees that what the economic theory can provide is not enough to monitor sustainable development. Evidence based decision making requires real life applications otherwise it has no relevance (Eurostat 2014). Eurostat proposes that statisticians have the capacity to further develop integrated systems about the state and conditions which can easily feed into environmental accounting. 


\subsection{TEEB - Economics of Ecosystems and Biodiversity}

The international study on the Economics of Ecosystems and Biodiversity - known as TEEB - reviewed the status of biodiversity and ecosystem services and emphasized the need to both incorporate natural capital in standard national accounting as well as developing a broader set of economic and development indicators integrating biodiversity and ecosystem concerns. An extensive synthesis and analysis of existing information on the socio-economic importance and value of nature in the Nordic countries was released 2013.

Key conclusions of the Nordic TEEB was that policy response should not be limited to environmental policies, but should also be part and mainstreamed into sectoral policies, to be integrated. The study also highlighted that one way of doing this would be to develop a set of national ecosystem services indicators. In Finland the work on developing indicators measuring ecosystem services has come a long way along.

\subsubsection{TEEB in Finland}

The ecosystem indicator project of Finnish Environment Institute, SYKE, has developed a framework for monitoring the state and trends of ecosystem services in Finland. The aim has been to increase awareness of the sustainable use of ecosystems by identifying important ecosystem services nationally and developing indicators for them.

The idea is that by identifying the ecosystem services additional information becomes available in a user friendly format. The results can be used for

- framing and clarifying the big picture of ecosystem services nationally

- monitoring the state and trends of ecosystem services

- evaluating policies affecting ecosystems and their services

- after further development: environmental impact assessment and land use planning. 
Indicators were developed for 28 ecosystem services (10 provisioning, 12 regulating and maintenance, and 6 cultural services), a set of four indicators for every stage of the cascade model; altogether 112 indicators in cooperation with stakeholders and experts.

Results of the project were published in 2015 on www.biodiversity.fi/ ecosystemservices

The indicators are based on two international frameworks. CICES 52 classification was used as a starting point in classifying ecosystem services. In order to achieve a balance between the ecological and social perspectives involved, the Cascade model was applied in developing indicators. Four indicators were defined which highlight the structure and functions of ecosystems as well as benefits and values of ecosystem services for the people.

Figure 35: Cascade model with integrated ecosystem service indicators

\section{Ecosystem service}

Ecosystem and biodiversity

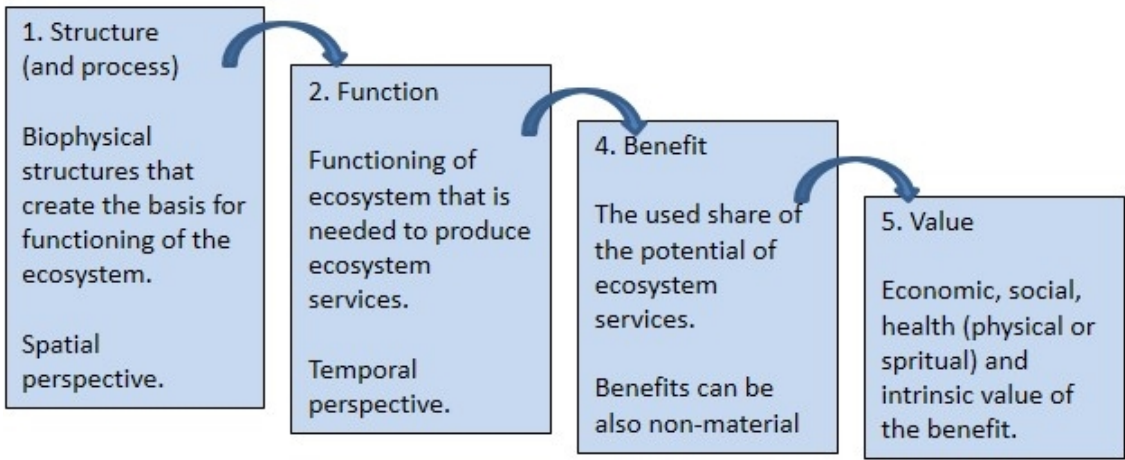

Extensive work on breaking down the indicators resulted in 5 main groups: structure, function, ecosystem service, benefit and value. In the cascade model the ecosystem service is seen as the overarching group with the rest following beneath. The indicators are therefore grouped accordingly. 
Below follow three examples of groups of indicators measured under Provisioning services, Regulating services and Cultural services:

Figure 36: Example1: Provisioning services: Berries and mushrooms

\begin{tabular}{|l|l|l|l|}
\hline \multicolumn{3}{|c|}{ Berries and mushrooms } \\
\hline $\begin{array}{l}\text { Structure: } \\
\text { Berry and mushroom } \\
\text { habitats (ha) }\end{array}$ & $\begin{array}{l}\text { Function: } \\
\text { Average annual } \\
\text { production (total } \\
\text { kg/A or kg/ha/A) }\end{array}$ & $\begin{array}{l}\text { Benefit: } \\
\text { Harvest (kg) }\end{array}$ & $\begin{array}{l}\text { Value: } \\
\text { Value of berries and } \\
\text { mushrooms }\end{array}$ \\
- area of suitable berry and \\
$\begin{array}{l}\text { mushroom habitats in mires } \\
\text { and forests }\end{array}$ & $\begin{array}{l}\text { - change in } \\
\text { annual } \\
\text { production, trend }\end{array}$ & $\begin{array}{l}\text { - amount of berry } \\
\text { and mushroom } \\
\text { harvest entering } \\
\text { the markets and } \\
\text { domestic use }\end{array}$ & $\begin{array}{l}\text { - sales, picking } \\
\text { income (€) } \\
\text { - berry and } \\
\text { mushroom pickers, } \\
\text { (n,\%), health and } \\
\text { intrinsic values }\end{array}$ \\
\hline
\end{tabular}

Figure 37: Example 2: Regulating services: Climate regulation

\begin{tabular}{|c|c|c|c|}
\hline \multicolumn{4}{|c|}{ Climate regulation } \\
\hline $\begin{array}{l}\text { Structure: } \\
\text { Carbon storing habitats } \\
\text { (ha) } \\
\text { - area of carbon storing } \\
\text { forests, mires, Baltic Sea } \\
\text { and inland water }\end{array}$ & $\begin{array}{l}\text { Function: } \\
\text { Carbon balance, } \\
\text { sequestration } \\
\text { rate } \\
\text { - the balance of } \\
\text { sequestered (to } \\
\text { plants) and } \\
\text { released (to } \\
\text { atmosphere) } \\
\text { carbon }\end{array}$ & $\begin{array}{l}\text { Benefit: } \\
\text { Climate } \\
\text { regulation, stable } \\
\text { climate } \\
\text { - stability helps } \\
\text { foreseeing and } \\
\text { preparing for the } \\
\text { future } \\
\text { - increases } \\
\text { security }\end{array}$ & $\begin{array}{l}\text { Value: } \\
\text { Value of climate } \\
\text { regulation } \\
\text { - avoided costs of } \\
\text { negative climate } \\
\text { impacts }(€) \\
\text { - intrinsic, health } \\
\text { and social values of } \\
\text { stable climate }\end{array}$ \\
\hline
\end{tabular}

Figure 38: Example 3: Cultural services: Nature tourism

\begin{tabular}{|c|c|c|c|}
\hline \multicolumn{4}{|c|}{ Nature tourism } \\
\hline $\begin{array}{l}\text { Structure: } \\
\text { Preffered natural areas } \\
\text { (ha), accessibility } \\
\text { - area of preferred types of } \\
\text { nature that attract nature } \\
\text { tourism } \\
\text { - accessibility to these } \\
\text { areas }\end{array}$ & $\begin{array}{l}\text { Function: } \\
\text { Natural events, } \\
\text { phenology } \\
\text { - seasonal } \\
\text { changes of } \\
\text { natural events or } \\
\text { stability of } \\
\text { landscape that } \\
\text { attract people to } \\
\text { nature }\end{array}$ & $\begin{array}{l}\text { Benefit: } \\
\text { Employment }(n), \\
\text { recreation, } \\
\text { experience } \\
\text { - the employment } \\
\text { rate in nature } \\
\text { tourism } \\
\text { - recreation to } \\
\text { nature tourists }\end{array}$ & $\begin{array}{l}\text { Value: } \\
\text { Values of nature } \\
\text { tourism } \\
\text { - tourism revenue } \\
(€), \\
\text { - employment (n) } \\
\text { (local, regional, } \\
\text { national) } \\
\text { - health } \\
\text { - intrinsic value }\end{array}$ \\
\hline
\end{tabular}




\subsection{Recommendations and future use}

Work on describing ecosystem services has been developed for some time now. The Convention on Biological Diversity (CBD) and the Millennium Ecosystem Assessment (MEA) have driven the area forward considerably. However, work on developing indicators is still experimental and there is still work underway to facilitate the data availability.

The Ad Hoc Group recommends that the Nordic countries make pilot studies and experiments on the basis of a large number of Nordic studies on ecosystem services and biodiversity. These pilot studies should be organized in a multidisciplinary way and cover several government agencies including national statistical offices. The ideas of SEEA EEA should be further developed and integrated with the ecosystem assessment approach. The aim of the pilots and experiments should be to find methods to link the ecosystems and their services to economic and social considerations.

The statistical community has until now been involved to a limited extent in the provision of data for the national strategies and the development of indicators related to ecosystem services. Agriculture and tourism statistics, water and fishery related statistics have been used in assessments. It is common to use research related studies for the monitoring and assessment of ecosystem services. The availability of data through the studies helps the assessments, but they are difficult to compare and it is not common for the results of the research to carry on for several years thus leaving the assessment with old data quickly.

The UN has developed a tool within the environmental accounts to facilitate a comprehensive data production that can link the ecosystems with the economy at large. Tests have been undertaken through pilot studies around the world, including Australia and Sweden to see how the environmental accounts can respond to the increased need for more data on ecosystems.

There are great potentials to use the large amounts of data and understanding available at the statistical offices to increase the knowledgebase on ecosystem services. However, as this is a new area there is little room for experimental work and developments within the operating budgets of the statistical offices. In order to continue to follow the work on the Economics of Ecosystems and Biodiversity (TEEB) indicators that are reliable and of sound quality has to be incorporated. 
Issues that are still debated, concern the weighting used in the valuation of ecosystem services and the lack of internationally agreed standards on how to convert them into monetary terms. The fact that data on the physical attributes come a long way when used appropriately and should not be under estimated in the discussion. The physical attributes (hectares, amounts and tonnes) are what they are while a value of recreation or particular services depends highly on the tool of measurement and the weights applied. 


\title{
9. Discussions and conclusions
}

\author{
9.1 Thoughts on indicators - and the framework \\ to use
}

Throughout this report the reasoning has been to use existing frameworks on accounts and statistics that are established, not only in the Nordic countries but worldwide and where the Nordic countries are at the forefront. It is well known that there is a need for a range of indicators to follow the measures and targets put in place by our governments and parliaments. On the other hand a main task given to the Ad Hoc Group from the Nordic Council of Ministers was to "suggest how to increase the use of already existing indicators that can complement GDP initially with a focus on the environmental dimension".

It is impossible to have one indicator or index that will give the ultimate answer to policy issues that are complex in nature.

The aggregate known as Gross Domestic Product (GDP) has long been the most used indicator for measuring economic performance but it has also since long been widely agreed that GDP, while important, is not a measure of welfare or well-being. It provides at best a partial indication of average material standard of living here and now.

In the wake of Rio and Rio+20 a plethora of suggestions for complementary measures and indicators have been put forth. Now that the sustainable development goals have been accepted by the UN General Assembly, the next step is to establish indicator for monitoring progress. Time has come to formulate and decide how to monitor and track progress towards these goals. Reliable and relevant statistics will be core elements in these efforts. The establishment and regular publication of Nordic environmental-economic accounts would provide a good example that could inspire other countries to follow.

On the micro level, environmental aspects are taken into account when cost benefit analyses are made for a specific project although measures of environmental consequences are assessed right away without reference to the use of these measures as indicators. 
On the macro level the outlook is somewhat different. Criteria for evaluating the usefulness of indicators at this level focus on whether they are relevant, reliable and transparent. Moreover, they should be produced on a regular basis and be comparable internationally.

Choice or selection of indicators should be dependent on purpose, in what context the indicators should be used, target group (audience) and properties. Policy makers, researchers and lobbyists are all using a variety of tools to assess what decisions to take and to describe the problems and opportunities at hand.

A recent report for the Nordic Council of Ministers (Hass \& Palm, 2012) has arrived at conclusions regarding use of indicator complementary to GDP, with which the Ad Hoc Group agrees:

- Indicators need to be used appropriately. For example, indicators which are best used for awareness-raising cannot always be appropriately used for monitoring policies. Indicators used for monitoring need to be constructed specifically to address and keep track of policy goals.

- Complex, aggregated indicators are typically only appropriate for awareness-raising, and data quality and international comparability are often questionable.

- Attempts to develop "Green GDP" figures encounter a range of problems, above all that all valuation methods proposed for assigning prices to environmental goods and services yield prices that are not consistent with and cannot be added to the marketbased prices in the present system of national accounts.

- These problems also arise for attempts to integrate the value of ecosystem services in national accounting. While much useful work has been done and can be further developed on identifying and describing physical ecosystem services, in measuring the amounts and the importance of such services to human users and stakeholders, and in analysis and evaluation of the different types of "value" of these services, the fundamental problem of incompatible types of prices remains a stumbling block to full integration in national accounting.

- The statistical offices of the Nordic countries have a long history of working with "satellite accounts" for the environment, in combining national accounts with environmental information and in modelling and analysis of a range of environmental issues, based on linking such national accounting and environmental data. These 
environmental accounts may be the best approach to respond to the needs and demands of policy-making that require the link between environment and the economy to be made.

- In relation to further development of existing modules, the report strongly recommends that priority on material flow accounting move from overall economy-wide figures to substances with less mass but higher environmental impacts, such as hazardous chemicals and waste.

The bottom line of these observations is that while it is important to develop analysis and methods to value eco-systems services and elements of a green GDP, the main effort when it comes to developing indicators complementary to GDP should be to develop the SEEA framework and thus the use thereof so as to provide a solid and reliable basis for economy environment analysis and policy formulation through build-up and maintenance of consistent satellite accounts.

It provides not only a base for a multitude of indicators but also a variety of options for in-depth analysis that all sum up to the headline indicators. It can be indicators on e.g. energy use, that measures how much energy is used in an economy and if the use of energy by industry, sector or household, even by type of fuel, is becoming more efficient. That is, do the economy and the companies driving the economy become better at managing the resources in their production processes while still engaging in creating value added and economic growth? The statistics show that for the Nordic countries the material intensity is becoming better with each year.

The SEEA is still evolving and expanding with new areas of environmental economic information. For example, the statisticians around the world and in the Nordic countries are now looking into how to include aspects of ecosystem services and functions into the accounting framework and how to interlink this information with the economy. In 2014, the UN published a first result of that work in the publication System of Environmental-Economic Accounting 2012: Experimental Ecosystem Accounting.

Other important areas that are developing with more and better accounts and statistics are within the water and waste area as well as environmental economics such as environmentally related subsidies and information on monetary flows of investments in environmental protection. 


\subsubsection{Interpretation}

Interpretation of statistics in general and indicators in particular must be done carefully. It is commonplace nowadays that an increase in GDP, whether conventional or "green", does not necessarily imply an increase in well-being. Actually this is why the demand for complementary indicators has arisen. We need however to observe that some of these indicators are not unambiguous either, in the sense that an increase or decrease of its numerical value immediately can be interpreted as an improvement. This is the case for some of the indicators discussed in this report. For instance, could an increase in environmental protection expenditures reflect the increase of national policy demands in combating environmental degradation, or is it just the level of money spent that year for reducing the degradation of the environment.

Another instance where interpretations need to be done with care is with regards to the indicator domestic material consumption, DMC, where weights of different resources and products are summed up without any consideration of their heterogeneity or their impacts on the environment. Another caveat concerns international comparisons.

\subsubsection{Integration}

GDP summarizes the economic activity in one single number but it is important to be aware of that the national accounts as a framework and accounting system provide for a much broader picture of the economy and its development as a basis for policy analysis and decisions. Other aspects covered by the national accounts include the economic structure, employment, inflation, foreign trade, balance of payments, etc. The strengths of the national accounts are that these aspects of the economy can be seen within the same framework and that data and indicators based on the national accounts are coherent and integrated.

Therefore, it is also important to note, that the further development of our information basis for a broader analysis of the development of welfare, wellbeing and more broadly sustainable development should be based on further extension of an integrated multipurpose framework, which can provide relevant data for the different aspects of the development. This is much more important than focusing on the unrealistic goal of providing on alternative catch-all indicator that should be used instead of the GDP. 
Ambitions to integrate and summarize such a broader mapping in a single number such as genuine savings or ecological footprints are fraught with difficulties and uncertainties in particular when assessments of future development are involved. When it comes to systematically integrating environmental aspects into policy decisions and strike a balance between sometimes conflicting goals, SEEA environmental accounts will potentially have an increasingly important role, depending on the efforts put into this approach.

\subsection{Recommendations}

Throughout this report, recommendations have been proposed in each chapter. They range from proposing a common Nordic Environmental Account to be published annually through the Nordic Council of Ministers to arranging an event for policy makers. The event would provide a platform for a thematic discussion on environmentally related welfare indicators that has been proposed in this report.

The continued work recommended in the report could be taken up through new or existing cross sectoral networks and committees within the Nordic Council of Ministers such as the environment and Economic working group (MEG).

The conclusions and recommendations in the report are:

- It is recommended to produce a yearly Nordic Environmental and Economic Account. The existing statistical frameworks, the national accounts and the environmental accounts, will be used to integrate economic data with environmental data, in a fully consistent and coherent manner. The particular indicators are described in Table 2 in Chapter 1.

- The Nordic Environmental and Economic Account can be used as a tool to analyze important policy issues, such as (i) greening of all sectors (not just "green" sectors), (ii) analysis of structural changes and important factors contributing to environmental pressures, (iii) assessments of "footprints", and (iv) policy instrument design.

- The Nordic Environmental and Economic Accounts are recommended to start on issues related to the use of natural resources, the use of renewable and non-renewable energy, emissions to air of greenhouse gases and air pollution, environmental economic aspects such as environmental taxes and the production of environmental goods and services. All of these 
areas will be complemented with information on the economy through GDP, population, employment and other aspects in line with the national accounts.

- Considering that the Nordic Environmental and Economic Account is still an evolving area where new fields of data are explored, it is pertinent to revisit the area e.g. every third year to ensure that newly developed indicators are quickly incorporated in the structure of measurement indicators published by the Nordic Council of Ministers.

- The recommendation from the group concerning environmentaleconomic models is to increase the awareness of the availability of existing models to a larger group of users in order to expand on the knowledge and the development of models that can answer a broader range of questions. It could for example be done through seminars or workshops.

- It is also recommended to create a new platform where the integration of social issues into the economic and environmental sphere can be discussed and further enhanced. The Ad Hoc Group is planning to arrange a workshop gathering relevant expertise and provide input to such an effort.

- It is also recommended to continue the development of the statistics so that they can help in answering the questions that the policy institutions and the researchers are raising. 


\section{References}

Danmarks statistik (2013). Grønne nationalregnskaber og det grønne BNP Metoder og muligheder: http://www.dst.dk/pukora/epub/upload/19683/groennat.pdf

Bragadóttir, Hrafnhildur, Danielsson, Carl von Utfall, Magnusson, Roland, Seppänen, Sampo, Stefansdotter, Amanda \& Sundén, David (2014). The Use of Economic Instruments In Nordic Environmental Policy 2010-2013. TemaNord 2014:549. http://dx.doi.org/10.6027/TN2014-549

Bruvoll, A. \& Medin, H. (2003). Factors behind the environmental Kuznets curve, evidence from Norway, Environmental and Resource Economics, 24(1): 27-48.

Bruvoll Taran Fæhn, Annegrete (2007). Driving forces behind the environmental pressure in Nordic countries - comparative decomposition analyses: An assessment of alternative methodological approaches. TemaNord 2007:507. http://dx.doi.org/10.6027/TN2007-507

Bruvoll, Annegrete, Ibenholt, Karin, Ahvenharju, Sanna, Bröckl, Marika, Martinsen, Louise \& Zandersen, Marianne (2012). Measuring green jobs?: An evaluation of definitions and statistics for green activities. TemaNord 2012:534. http://dx.doi.org/10.6027/TN2012-534

Cambridge Econometrics (2004). Analysis of the introduction of emission allowance trading schemes in Sweden. Report for the Environmental statistics division of Statistics Sweden. 08 March 2004. http://www.scb.se/statistik/MI/MI1202/ 2004A01/MI1202_2004A01_BR_MIFT0401.pdf

DG Clima (2015). Web-site on the EU ETS: http://ec.europa.eu/clima/policies/ ets/index_en.htm

European Commission (2015). MAES Mapping and Assessment of Ecosystems and their Services. http://biodiversity.europa.eu/maes

EEA (2015). CICES - Common International Classification of Ecosystem Services. http://cices.eu/

EEA (2013). Air quality in Europe - 2013 report. EEA report No 9/2013.

Eurostat (2015). Environmental accounts - establishing the links between the environment and the economy. Background article. http://ec.europa.eu/eurostat/ statistics-explained/index.php/Environmental_accounts_-_establishing_the_links_between_the_environment_and_the_economy

Eurostat (2014a). 21st Meeting of the European Statistical System Committee: European Strategy for Environmental Accounts Work Programme Objective 2.21.

http://ec.europa.eu/eurostat/documents/1798247/6079569/ESSC-2014-21-EN24-EuropeanStrategy-env.pdf

Eurostat: Rademacher, W. and Steurer, A. (2014b). Do we need natural capital accounts for measuring the performance of societies towards sustainable development, and if so, which ones? http://ec.europa.eu/eurostat/documents/1798247/ 6079569/Do+we+need+natural+capital+accounts/50cafce5-ff89-4dec-9a0941c3b8871a6a

Eurostat (2013a). Economy-wide Material Flow Accounts (EW-MFA) Compilation Guide 2013: http://epp.eurostat.ec.europa.eu/portal/page/portal/ environmental_accounts/documents/2013_EW-MFA_Guide_10Sep2013.pdf 
Eurostat (2013b). Compilation Guide (2013) for Eurostat's Air Emissions Accounts (AEA)- revision of part $B$ of the Manual for Air Emissions Accounts (AEA), 2009 edition. http://ec.europa.eu/eurostat/documents/1798247/6191533/2013-EWMFA-Guide-10Sep2013.pdf/54087dfb-1fb0-40f2-b1e4-64ed22ae3f4c

Eurostat (2009). Handbook on Environmental Goods and Services Sector. Eurostat Methodologies and Working papers. 2009 edition. http://ec.europa.eu/eurostat/ documents/3859598/5910217/KS-RA-09-012-EN.PDF/01d1733e-46b6-4da892e6-766a65d7fd60?version=1.0

Hass, Julie L. \& Palm, Viveka (2012). Using the right environmental indicators: Tracking progress, raising awareness and supporting analysis: Nordic perspectives on indicators, statistics and accounts for managing the environment and the pressures from economic activities. TemaNord 2012:535. http://dx.doi.org/10.6027/

TN2012-535

Ingelhart, Ronald and Welzel, Christian (2005). Modernization, Cultural Change, and Democracy: The Human Development Sequence. Cambridge: Cambridge University Press, 2005. As cited in Equality, individuality and social trust, Global Utmaning, 2012. ISBN: 978-91-86995-13-3. http://www.globalutmaning.se/ wp-content/uploads/2012/02/The-Nordic-Way-20121.pdf

Jensen, P.R. and Olsen, T. (2003). Analysis of changes in air emissions in Denmark 1980-2001, Statistics Denmark.

Magne Skjelvik, John, Bruvoll, Annegrete \& Ibenholt, Karin (2011). Greening the economy: Nordic experiences and challenges. TemaNord 2011:532. http://dx.doi.org/10.6027/TN2011-532

Mazza, Leonardo, Bröckl, Marika, Ahvenharju, Sanna, ten Brink, Patrick \& Pursula, Tiina (2013). Natural Capital in a Nordic context: Status and Challenges in the Decade of Biodiversity. TemaNord 2013:526. http://dx.doi.org/10.6027/TN2013-526

Miljøstyrelsen (2013). Håndtering af miljøøkonomiske effekter og markedsfejl i makromodeller. Miljøstyrelsen 20 marts 2013. http://www.copenhageneconomics.com/dyn/resources/Publication/publicationPDF/0/230/0/

Håndter-

ing\%20af\%20miljøøkonomiske\%20effekter\%20og\%20markedsfejl\%20i\%20makr omodeller.pdf

Nordic Council of Ministers (2000). Nordic Environment-Economic Indicators Nordic Natural-and Environment Accounts - Part III. Copenhagen 2000. TemaNord 2000:515. http://dx.doi.org/10.6027/TN2010-515

Nordic Council of Ministers (NCM 2014). Nordic Statistical Yearbook 2014. Volume 52. Nord 2014:001. http://www.norden.org/en/fakta-om-norden-1

Nordic Council of Ministers, (2013). A Good Life in a Sustainable Nordic Region. Nordic Strategy for Sustainable Development. http://norden.diva-portal.org/smash/ get/diva2:701472/FULLTEXT01.pdf

NOU (2005). Enkle signaler i en kompleks verden — Forslag til et nasjonalt

indikatorsett for bærekraftig utvikling. Norges Offentlige utredninger 2005:5. www.regjeringen.no/no/dokumenter/nou-2005-05/id119844/

National statistical offices in Sweden, Denmark, Finland and Norway (1995). Nordic Natural Resource and Environmental Accounting. Funded by the Nordic council of Ministers. http://www.scb.se/statistik/MI/MI1202/2000I02/MIFT9501.pdf

National Statistical offices in Norway, Sweden, Finland \& Denmark (2003). Energy Taxes in the Nordic Countries - Does the polluter pay? Final report Grant Agreement nr. 200141200022 March 2003. Funded by the European Commission, Eurostat. 
http://www.scb.se/statistik/MI/MI1202/2004A01/

MI1202_2004A01_BR_MIFT0404.pdf

Nurmela, Juha and Mäenpää, Ilmo (2014). Equal amount of greenhouse gas emissions from urban and rural households. Tieto \& Trendit. (in Finnish).

http://tietotrenditblogi.stat.fi/mag/admin/r/8/88/

OECD (2014). Green Growth Indicators 2014. OECD Green Growth Studies, OECD Publishing. http://www.oecd-ilibrary.org/docserver/download/

9713101e.pdf?expires=1433673061\&id=id\&accname=oid029024\&check-

sum=119F775B01B39E8799F4692BC8D3BCE1

OECD (2013). Environment at a Glance 2013: OECD indicators, OECD Publishing. http://dx.doi.org/10.1787/9789264185715-en

OECD (2012). OECD Environmental Outlook to 2050: The Consequences of Inaction. OECD Publishing: http://dx.doi.org/10.1787/9789264122246-en

OECD (2011). Towards Green Growth. http://www.oecd-ilibrary.org/docserver/ download $/ 9711061$ e.pdf?expires $=1452679128 \& i d=i d \&$ accname $=$ oid029024\&checksum=9FB3C7C615AA61D7FCD1609D4DE10090

OECD (2008). OECD Environmental Outlook to 2030. OECD Publishing: http://www.oecd.org/env/indicators-modelling-outlooks/40200582.pdf

Palm, V. \& Samakovlis, E.(2004). Långt kvar till grön NNP. Välfärd, NR 42004. http://www.scb.se/statistik/_publikationer/BE0801_2004K04_TI_11_A05ST0404.pdf

Peters, Glen \& Solli, Christian (2010). Global carbon footprints - Methods and import/export corrected results from the Nordic countries in global carbon footprint studies. TemaNord 2010:592. http://dx.doi.org/10.6027/TN2010-592

SCB (2015a). Environmental Accounts - a jubilee. MIR 2015:5. Statistiska centralbyrån. http://www.scb.se/Statistik/_Publikationer/ MI1301_2014A01_BR_MI71BR1505.pdf

SCB (2015b). Land accounts for biodiversity - a methodological study. MIR 2015:03. Statistiska centralbyrån. http://www.scb.se/Statistik/_Publikationer/ MI1301_2014A01_BR_MI71BR1503.pdf

SCB (2014). Evaluation of Environmental Protection Expenditure Accounts in Sweden and its implementation. https://circabc.europa.eu/sd/a/

7f109e45-a763-4e0a-80b5-6cfbce809cb4/SE-EPEA-05121.2013.003-2013.346.pdf

SCB (2007). Sustainable development indicators based on environmental accounts.

SCB (2005). Social namea with a coupling to Sustainable Development Indicators including environmental industry.

SSB (2013). Environmental protection expenditure accounts (EPEA). Ref.

Ares(2014)10857 - 06/01/2014. circabc.europa.eu/sd/a/0879aad0-1ab9-4a45bb79-4e1db8c61eb1/NO-EPEA-50904.2012.004-2012438.pdf

UN (2015). Millennium Development Goals and Beyond 2015. http://www.un.org/millenniumgoals/

UNEP (2015). Sustainable consumption and production indicators for the future SDGS. UNEP Discussion Paper - March 2015.

UNEP (2004). The use of economic instruments in environmental policy: Opportunities and challenges. UNEP/ETB/2003/9.

UN General Assembly (2015). Sixty-eighth session Agenda items 14, 19 (a) and 118 Report of the Open Working Group of the General Assembly on Sustainable Development Goals. http://www.un.org/ga/search/view_doc.asp?symbol=A/68/970\&Lang=E 
UN (2014). System of Environmental- Economic Accounting 2012 - Central Framework, New York, 2014. http://unstats.un.org/unsd/envaccounting/ seeaRev/SEEA_CF_Final_en.pdf

UN (2007). System of Environmental-Economic Accounting for Water (SEEA Water) http://unstats.un.org/unsd/envaccounting/seeaw/seeawaterwebversion.pdf

Wadeskog, A. \& Palm, V. (2003). Structural decomposition of environmental accounts data - the Swedish case, Statistics Sweden.

Wier, Mette, Block, Christoffersen, Line, Jensen, S., Trine, Pedersen, G., Ole, Keiding, Hans and Munksgaard, Jesper (2005). Evaluating sustainability of household consumption-Using DEA to assess environmental performance. Economic Systems Research, 17:4, 425-447.

World Commission on Environment and Development (1987). Our Common Future, Chapter 12, "Towards Common Action: Proposals for Institutional and Legal Change", quote from p. 314 in the OUP paperback edition.

World Values Survey (WVS), fourth wave (1991-2001). 


\section{Sammanfattning}

Nordiska ministerrådet föreslås ta steget att årligen genomföra en koordinerad uppföljning av utvecklingen av ekonomin, miljö och sociala förhållanden i de nordiska länderna genom relevanta ämbetsmannakommittéer och arbetsgrupper under dess paraply. Sådan samordning kommer att bidra till en mer integrerad diskussion inom dessa områden. Trots många initiativ att mäta hållbar utveckling från olika infallsvinklar krävs ytterligare drivkrafter för att ge goda förutsättningar för en konsistent diskussion om hur en grön, inkluderande och ekonomiskt gynnsam utveckling kan se ut.

Den här rapporten av Ad hoc-gruppen för kompletterande välfärdsmått behandlar några av den nordiska regionens resultat inom miljöekonomisk statistik och räkenskaper. Den presenterar sedan olika initiativ till utökning av kunskapsbaser inom ekosystemtjänster och miljöekonomiska modeller. Integreringen av ekonomisk statistik för att mäta produktion och konsumtion med data om energianvändning, utsläpp av klimatpåverkande gaser i kombination med ekonomiska styrmedel möjliggör en djupanalys av policies rörande miljöekonomi och hållbar utveckling samtidigt som den tillhandahåller jämförbara makroindikatorer.

Resultaten och rekommendationer i denna rapport är avsedda för och kan bli användbara för olika intressenter. Ministerier, såsom finans-miljöoch näringsdepartment kan få användning av den evidensbaserade ansatsen som de föreslagna indikatorerna är. Forskningsinstitut kan förbättra sina miljö- och ekonomiska modeller genom att använda samma indata till dessa.

Viktigt att notera i den här diskussionen är att statistiken och räkenskaperna som föreslås i den här rapporten redan finns tillgänliga i de allra flesta nordiska länderna. Det medför att det inte finns behov av nya rapporteringskrav eller ny datadatainsamling, utan rekommendationerna fokuserar på en demonstration av statistiken i nya kontexter. 


\section{Ad hoc-gruppens uppgift}

Gruppen gavs ett mandat att arbeta med åtta olika uppgifter. Dessa bestod i t.ex. av att föreslå hur det vore möjligt att utöka användningen av redan framtagna indikatorer och statistik. Dessa skulle då komplettera måttet för Bruttonationalprodukten (BNP) med startpunkt i ett vidare grepp för att mäta välfärd med ett initialt fokus på miljödimensionen.

En kartläggning av pågående initiativ och processer har gjorts som täcker internationella och nordiska arbeten inom området integrering av miljö och ekonomistatistik till räkenskaper. Nordisk och internationell policy stärker riktningen mot ett integrerat sätt att tänka på miljö och ekonomiska plattformar för beslutsfattande. Mångfalden av olika policyoch strategiinitiativ från FN, OECD och Europeiska Unionen visar på att kunskapsbasen utökas (och förbättras när det gäller statistikens kvalitet).

I över 20 år har den globala statistiska gemenskapen utvecklat området och ramverket för miljöekonomiska räkenskaper (System of Environmental-Economic Accounts (SEEA). Nu har en samsyn etablerats inom det statistiska samfundet och hos FN, hur denna typ av information ska beräknas och produceras. Enkelt formulerat använder ramverket ekonomisk statistik och ekonomiska modeller, såsom input-output tabeller, och integrerar detta med miljöstatistik. Denna länkning mellan de två statistiska områdena är vanligast att göra genom en gemensam klassifikation, för ekonomiska aktiviteter för deras produktion eller konsumtion, t.ex. industrier, offentliga myndigheter och hushållen.

\section{Rekommendationerna från ad hoc-gruppen}

Huvudrekommendationen från ad hoc-gruppen är att fortsätta med utvecklingen av miljöekonomiska räkenskaper. När det gäller rekommendationen och förslaget rörande användningen av existerande data inom nya områden och i nya kontexter är att integrera data genom att använda FN:s system för miljöekonomiska räkenskaper (SEEA).

Det här är ett område där de nordiska länderna är föregångsländer globalt. Ad hoc-gruppen föreslår därför att årliga nordiska miljöekonomiska räkenskaper produceras inom ramen för Nordiska ministerrådet. Att årligen producera en nordisk sammanställning baserad på miljöekonomiska räkenskaper betyder nya indikatorer och tabeller som fångar ekonomisk och miljö relaterad information tillsammans.

Rent praktiskt betyder det att statistiken kombinerar t.ex. ekonomins förädlingsvärde för en specifik industri eller en serviceverksamhet med 
t.ex. deras respektive energianvändning, eller utsläpp till luft eller miljörelaterade skatter.

Ad hoc-gruppen föreslår att de nordiska länderna kommer att fortsätta att vidareutveckla möjligheterna att använda ett mer integrerat angreppssätt genom statistiksystemet. Detta även inom sina processer för beslutsfattande i syfte att ta hänsyn till ekonomi, miljö och sociala förhållanden på ett balanserat sätt. Förhoppningen är att detta arbete kan vara en startpunkt för liknande arbeten i andra regioner och delar av världen och t.ex. bidra till övervakningen och uppföljningsprocessen av det globala arbetet med FN:s hållbarhetsmål.

De miljöekonomiska räkenskaperna är konsistenta, uttömmande och fokuserade på information på en detaljerad branschnivå, som länkar till nationalräkenskaperna. De tillhandahåller en mångfacetterad informationsbas för att tydliggöra interaktioner mellan ekonomi och miljö. De är instrumentella för att förstå strukturen och funktionen av vår ekonomi och de är både efterfrågade och högst användbara för att kunna analysera flera viktiga policyfrågor. Exempel på sådan analys finns i denna rapport.

EU har skapat en förordning för några av statistikområdena som täcks av ramverket för miljöräkenskaperna. Sådana data ska rapporteras av Europeiska statistiksystemet på årlig basis över: luft-, energi- och miljöskyddskostnadsräkenskaper, miljöskatter per bransch, miljöföretag och materialflödesräkenskaper. Systemet är designat så att statistiken följer ekonomiska aktörer, deras produktion och konsumtionsmönster och detta kan följas från både ett miljö- och ett ekonomiskt perspektiv. Statistiken produceras idag av nästan alla nordiska länder och kan därför anses vara lättillgänglig. Dessa data ger en förutsättning för en sammanhängande bas från vilka nordiska miljöekonomiska räkenskaper kan produceras.

Sammanfattningsvis är de viktigaste slutsatserna och rekommendationerna i rapporten:

- Att producera årliga nordiska miljöekonomiska räkenskaper och publicera dessa via Nordiska ministerrådets hemsida. Existerande statistiska ramverk, nationalräkenskaperna och miljöekonomiska räkenskaper är fullt konsistenta med varandra. Indikatorer som föreslås publiceras presenteras i kapitel 1, tabell 2 i denna rapport.

- Nordisk miljöekonomiska räkenskaper kan vara användbara verktyg för att analysera viktiga policyfrågor, såsom: (i) graden av en grönare ekonomi, inom alla sektorer och inte bara den "gröna sektorn" (miljöföretag), (ii) den globala påverkan av nationella 
konsumtionsmönster, som är justerade för import och export, eller "fotavtrycksanalys", (iii) "dekomponeringsanalyser", som belyser vikten av olika faktorer, inklusive policyinstrument, bakom trender och förändringar från alla sektorer i ekonomin. (iv) detaljerad analys på sektors- och branschnivå, som en bas för att utforma effektiva instrument och mått för miljöpolicy.

- Nordiska miljöekonomiska räkenskaper kan påbörjas med information som är relaterad till användning av naturresurser, användning av förnyelsebar och icke förnyelsebar energi, utsläpp till luft och klimat, miljöekonomiska instrument såsom miljöskatter och produktion av varor och tjänster inom miljösektorn. Eftersom denna statistik finns tillgänglig idag behövs inga bredare initiativ. Alla dessa områden kompletteras med existerande information om ekonomin, genom mått som BNP, befolkning and andra aspekter i linje med nationalräkenskaper.

- Miljöekonomiska räkenskaper är ett område som vidareutvecklas, där nya områden undersöks för att inkluderas i ramverket på en global basis. Därför är det av vikt att överväga, kanske vart tredje år, rekommendationerna om vilka indikatorer som tas fram för att hantera nya områden genom revidering.

- Beträffande miljöekonomiska modeller framhåller ad hoc-gruppen att det är viktigt att utöka kunskapen om tillgängligheten av miljöekonomiska räkenskaper för att kunna förbättra konsistensen mellan olika modeller. Det kan t.ex. göras via seminarier eller workshops.

- Gruppen rekommenderar även att en ny plattform skapas där en diskussion och utveckling av integrering av sociala frågor till ekonomi och miljöfrågorna kan ske. Ad hoc-gruppen planerar att stimulera ett sådant arbete genom en workshop som samlar relevant expertis. Det finns idag ett ramverk för sociala räkenskaper, som liksom miljöekonomiska räkenskaper är ett satellitsystem till nationalräkenskaperna som möjliggör en integrering av frågorna. 


\section{Förbättringar i framtiden}

Den här rapporten visar hur ett miljöekonomiskt statistiksystem kan användas i ett nordiskt perspektiv för att följa upp miljöekonomisk utveckling. Med ett integrerat statistiksystem finns det många möjligheter att utveckla relevanta indikatorer, som svarar mot specifika frågor och möjliggör harmoniserad utvärdering inom och mellan de nordiska länderna och i förhållande till exempelvis EU.

Statistiken är också i ett format som möjliggör användning av dem som indata till miljöekonomiska modeller och några av användningsområdena beskrivs i denna rapport.

Genom att fortsätta utvecklingen av nya områden inom miljöekonomiska räkenskaper finns det möjligheter att expandera kunskapsbasen och dataunderlaget. Några sådana möjliga områden är t.ex. utvecklingen av vatten- och skogsräkenskaper, eller nya typer av markräkenskaper som kan ligga till grund för studier av ekosystemtjänster. Ytterligare ett intressant område inom miljöekonomiska räkenskaper är vidareutvecklingen av statistik över miljöekonomiska instrument. Dessa kan användas för att expandera kunskapen för att designa nya policyinitiativ och uppföljningsstrategier.

Att integrera mer sociala data med miljö- och ekonomisk statistik för att utveckla och visa på indikatorer som kan användas som ett komplement till BNP i en bredare analys av välfärd är ett område som behöver fortsätta att stärkas. Det finns redan idag några områden som är relativt lätt att inkludera, sysselsättning och utbildning är ett par sådana.

Det här arbetet är i linje med ny utveckling som sker idag. Noterbart är arbetet med de nya av FN:s generalförsamling beslutade globala hållbarhetsmålen. Tidiga nordiska miljöräkenskaper blir ett banbrytande bidrag till att utveckla tillförlitliga och relevanta mått på framgång mot hållbarhetsmålen. Det är också i linje med det arbete som OECD gör inom ramen för grön tillväxtstrategi och de framsteg som Nordiska ministerrådet gör inom området om cirkulär ekonomi. 


\section{Appendix 1: Methodology}

\section{GDP and beyond}

The Gross Domestic Product (GDP) is - at least in principle - the value (measured in current market prices) of the national production of goods and services during a time period (see below, headline National accounts: GDP and value added). It summarizes a myriad of results from the production activities of a national economy in one single number. From the very beginning it has been clear that GDP has weaknesses as a measure of welfare. It does not account for e.g. leisure, natural resource depletion, environmental degradation or, for instance, household production. In addition most of the contribution by the public sector is measured by the costs of production since market valuations in this part of an economy are largely lacking. Simon Kuznets, Nobel prize winner, noted already in 1934 that the welfare of a nation can scarcely be inferred from a measurement of national income. Neither can increases in GDP be considered to increase human welfare. Income distributions as well as other socio-economic aspects have to be taken into account. Despite this longstanding common understanding, GDP is still often used as a simple measure of progress and wealth.

In the 1970s the drawbacks of using GDP as a catch-all measure of progress or welfare came increasingly to the fore in the wake the oil crisis and growing awareness of perceived limits to growth due to resource scarcity. There are two central aspects that come into focus when looking at GDP from an environmental sustainability point of view:

- Market prices that are used to measure the value of production, for example in the national accounts, do not reflect the social economic value of production of goods if not corrected for negative or positive external effects on the environment. An important application of this principle is the need for adjusting carbon pricing to reflect the negative external effects on the environment in relation to curbing climate change. Such a price on GHG emissions could be achieved through a global carbon tax or an international net of emission restrictions and trading systems, which is now emerging. The price on carbon (i.e. on emissions of greenhouse 
gases) should optimally reflect the global sum of marginal social damage costs of global climate change which is of course very difficult to assess. In practice the shadow price on emissions restrictions that are sufficient to curb climate change below a politically set level $2^{\circ} \mathrm{C}$ will do. Presently however the implicit price of carbon is negative in many parts of the world due to governments' subsidies of the consumption of fossil fuels.

- GDP is a flow measure and does not account for depreciation of capital beyond the extent to which such depreciation is reflected in current market prices. The assessment of the yearly depreciation of capital that is needed to arrive at a Net National Product (NNP) is, in itself, a difficult exercise that requires some simplifying assumptions. Traditionally no costs for the use of natural resources are subtracted when the NNP is calculated. This means that the NNP does not account for the depletion of natural resources, be they renewable (e.g. fish or timber) or non-renewable (e.g. oil or metallic and nonmetallic minerals). Thus, it can be argued that the economic result of all economic activities, measured by the NNP, is overstated, since not all capital costs are included in the calculations.

Although some corrections could be introduced to try to take account of environmental costs of production these would not be sufficient to establish whether the economic development is on a sustainable path since social concerns (income distribution etc.) as well as long term resource depletion, environmental deterioration and "planetary boundaries" are mainly left out of the calculations.

To assess whether it is possible to sustain standards of living and a country's current use of scarce resources, the World Bank has developed "genuine savings" which is defined as current income minus current consumption levels. If this is positive, then there is a sustainable contribution to wealth (real, human and natural capital). This assessment would however, given all the uncertainties regarding the estimated economic costs and benefits involved, only serve as a rough indication of sustainability.

Nevertheless it might be worth noting that the World Bank in its analysis of genuine savings found that developed countries showed a positive genuine saving (build-up of human capital) tended to have a negative development due to high levels of extraction of raw materials and natural resources. 
It is also worth emphasizing that genuine savings and other purely economic measures can show positive trends but could well coincide with environmental degradation and depletion of natural resources.

It should also be observed that, although no countries have established green GDP calculations and the UN statistical community does not provide a methodology for these types of calculations in either the SNA or SEEA statistical standards, some pilot assessments of "green GDP" by Nordic countries seem to show that if these calculations are relatively stable or "well behaved" it would not lead to a dramatic shift in the picture of the development given by traditional national accounts. On the other hand if the green GDP is not well behaved but shows large annual fluctuations it would be problematic to use it for policy making for that reason.

Against this backdrop a common conclusion has been that for the time being and the foreseeable future the lack of reliable monetary assessments of costs and benefits of variables involved in a calculation of a green GDP as well as the inherent uncertainties that besets such an endeavour, environmental accounts should rather stick to the physical units for the measurements of physical flows and stocks i.e. tonnes, cubic metres, litres etc. To the extent that market transactions of the physical quantities take place it is of course also possible to measure the transactions by market prices.

The Stiglitz-Sen-Fitoussi Commission on measurement of economic performance and social progress, appointed by the French president Nicholas Sarkozy in 2008, thus concluded that a valuation of sustainable development should be based on a well-defined "dashboard" of indicators showing variations of underlying stocks of capital, real, human or natural. The commission noted that the assessment of sustainability is complementary to the question of current well-being and must be examined separately. Confusion may arise when one tries to combine current well-being and sustainability into a single indicator. The commission provides a telling analogy; "when driving a car, a meter that added up in one single number the current speed of the vehicle and the remaining level of gasoline would not be of any help to the driver. Both pieces of information are however critical and need to be displayed in distinct clearly visible areas of the dashboard". 53 
The OECD has reached similar conclusions in its report from 2011 on green growth - Towards Green Growth: Monitoring Progress, OECD indicators (OECD 2011) and some of its "headline indicators" coincide with those presented in our report.

The present work also links to this vein of thought. Rather than to dig deep into the intricacies of a green GDP, the thrust of the effort is on developing a Nordic set of already existing indicators and measures, which relate to the SEEA Central Framework and could be used besides GDP as a satellite environmental account that could be coupled to traditional SNA national accounts and provide input for thorough transparent and reliable analysis of the interplay between economy and environment. A common Nordic effort in this field would be a path breaking contribution to the follow-up of new sustainable development goals.

\section{National accounts: GDP and value added}

The general purpose of the national accounts is to provide a systematic statistical framework for summarising and analysing economic events, and wealth of an economy and its components, such as industries and public sectors. The national accounts are described in detail in the System of National Accounts (UN) and the European System of Accounts (Eurostat).

The gross domestic product is a key indicator defined as: an aggregate measure of production equal to the sum of the gross values added of all resident institutional units engaged in production (plus any taxes, and minus any subsidies, on products not included in the value of their outputs). The sum of the final uses of goods and services (all uses except intermediate consumption) measured in purchasers' prices, less the value of imports of goods and services, or the sum of primary incomes distributed by resident producer units (OECD dictionary).

The area is covered by EU Regulation No 549/2013 of the European Parliament and of the Council on the European system of national and regional accounts in the EU. 


\section{Energy accounts}

The energy accounts belong to the system of environmental accounts (SEEA) main area of physical flow accounts (see SEEA-CF chapter 3). As such they aim at describing the physical flows of energy within the economy and between the natural environment and the economy. The accounting framework is a set of supply and use tables that are based on the expansion of monetary supply and use tables used in the SNA.

There is a conceptual difference between the energy accounts and the energy balances. The simplest explanation is that the energy accounts follow the definitions of national accounts, while the energy balances follow its own guidelines. The most significant difference are that energy accounts are presented according to industries within the economy (by NACE) with the system boundary being resident units and the energy balances are presented according to their own definition of "sectors" within the economy with the system boundary being the national territory.

Energy accounts are covered by EU Regulation 691/2011 consolidated version on European Environmental Economic Accounts. By 2017 Eurostat will have made their first data collection under this regulation.

\section{Economy-Wide Material Flow Accounts}

Economy-wide material flow accounts (EW-MFA) is a statistical/accounting tool, which is used to describe the physical flows of natural resources, products and waste, etc. in and out of a domestic economy. The EW-MFA reporting to Eurostat describes the extraction of natural resources from the environment to the domestic economy and the foreign trade flows between the domestic economy and the rest of the world. The accounts include all types of natural resources, which can be measured by tonnes and all types of products imported and exported. If the material flow accounts also include so-called residuals, i.e. waste, air emissions, etc., and accumulations of materials in the domestic economy, a more complete the picture of the flows to and from the economy to the environment can be developed. When calculating Total Material Flows, all types of natural resources and products, with the exception of water, are included in the accounts. A specific classification, including approximately 60 categories of materials, has been developed by Eurostat for the reporting of the EWMFA accounts that include resource extraction and trade flows. 
Only flows crossing the system boundary (between the environment and the economy) are included in the economy wide material flow accounts. This means that material flows within the economy, for instance flows from one industry to another, are not represented in EW-MFA.

The economy is demarcated by the conventions of the national accounting system (resident units).

EW-MFA is covered by EU Regulation 691/2011 consolidated version on European Environmental Economic Accounts.

\section{Air emissions accounts}

The area is covered by EU Regulation 691/2011 consolidated version on European Environmental Economic Accounts and contains the collection of data for 14 pollutants: Carbon dioxide, nitrous oxide, methane, perfluorocarbons, hydrofluorocarbons, sulphur hexafluoride, nitrogen oxides, non-methane volatile organic compounds, carbon monoxide, particulate matter $<10$ and $<2,5$, sulphur dioxide and ammonia.

The national emissions inventories are calculated according to the so-called territory principle, i.e. the emissions are attributed to the country where the fuel sales occurred and are distributed on technical emission sources.

The air emission accounts, however, are prepared according to the residence principle, i.e. the emissions are attributed to the country in which the economic operators causing the emissions are resident, and the emissions are classified according to economic activities (the NACE industry classification).

The statistics on emissions may differ significantly depending on whether the national inventory or air emissions accounts method is used. In Norway and Denmark, international maritime navigation contributes to a large degree to the differences between these two approaches, see the example below in Figure 39.

In Box 1 the differences in definitions are explained. 
Box 1. Territory versus residence principle

National emissions inventories. Territory principle (UNFCCC and CLRTAP)

- The emissions are attributed to the country where the emissions takes place.

- Emissions are assigned to processes which are classified according to the technical nature.

- Emissions from international ships and aircrafts are allocated to countries in which the fuel is sold.

Air emission accounts. Residence principle

- The emissions are attributed to the country in which the economic operator is resident.

- Emissions are classified according to the economic activity following the NACE classification of the system of national accounts.

- Emissions from international ships and aircrafts are allocated to countries in which the operator of the ship/aircraft is resident.

Source: Eurostat Statistics Explained 2015.

Figure 39 visualises the difference between the greenhouse gas emissions as reported to the UNFCCC (national inventories) and to Eurostat via the environmental accounts (air emissions accounts). For all countries, the data reported to Eurostat are always slightly higher than those reported to UNFCCC. This is due to the adjustments for the residence principle for the data under the environmental accounts framework. It basically means that transportation activities carried out by national residents abroad are accounted for within the environmental accounts and they are not included in the reporting to the UNFCCC. The reason for the large difference in Denmark is due to the importance of the shipping industry. 
Figure 39: Greenhouse gas emissions in Nordic Countries 2011

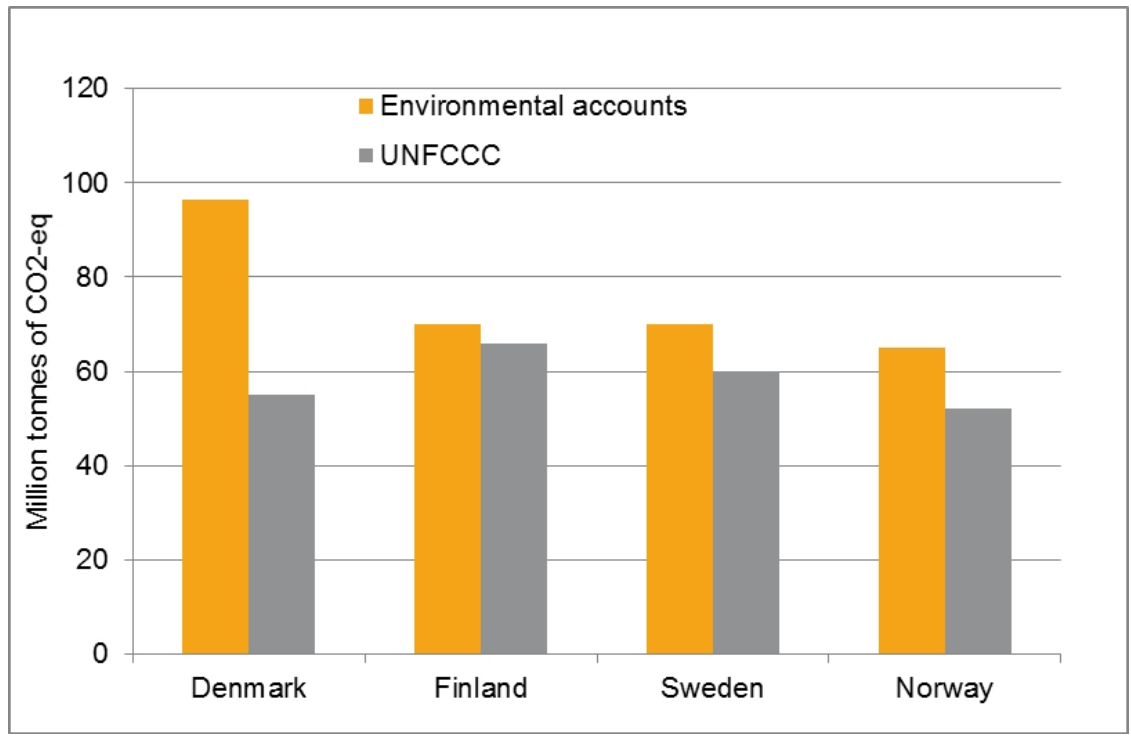

Below, in figure 40, data reported to the LRTAP convention and to Eurostat via regulation 691/2011 are described in the same way.

Figure 40 illustrates the differences between the inventory emission figures and the air emission accounts figures for NOx and SOx in 2012.

The most conspicuous feature is the large difference between the Danish inventory and Danish accounts data. According to the environmental accounts emission data, the Danish emissions of NOx in 2012, were 1,069 thousand tonnes. This level was the third highest among the European countries. Only Germany and UK had higher emissions. The by far most important emission source when classified by NACE, for the Danish NOx emissions is "Transportation and storage" with 997 thousand tonnes in 2012. No other European country had such high emissions from this NACE. For comparison, the total Norwegian NOx emissions from NACE activities this year were 255 thousand tonnes and of this "Transportation and storage" made up 150 thousand tonnes. 
Figure 40: Emissions of NOx and SOx, according to inventory data and accounts data. Thousand tonnes. Nordic countries. 2012

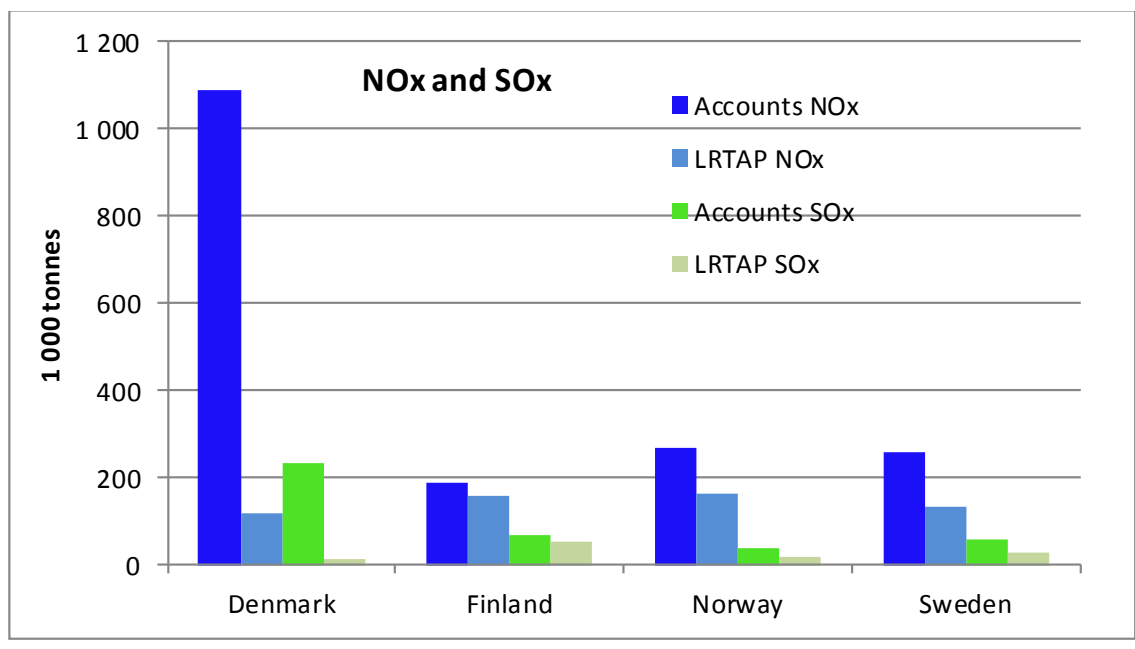

Note: No data for Iceland.

Source: Eurostat/EEA (National totals for the entire territory) http://www.eea.europa.eu/data-and maps/data/data-viewers/air-emissions-viewer-Irtap and Eurostat, environmental accounts data http://appsso.eurostat.ec.europa.eu/nui/ show.do?dataset=env_ac_ainah_r2\&lang=en

\section{Environmental taxes}

The area is covered by EU Regulation 691/2011 consolidated version on European Environmental Economic Accounts.

Environmental taxes must first of all be classified as taxes in the national accounts (ESA 2010) and consist of compulsory, unrequited payments, in cash or in kind, which are levied by general government or by the institutions of the European Union. They fall within the following ESA 95 categories: taxes on production and imports (D.2), current taxes on income, wealth, etc. (D.5), capital taxes (D.91).

An environmental tax is a tax whose tax base is a physical unit (or a proxy of it) of something that has a proven, specific, negative impact on the environment. (SEEA-CF 2012: §4.150).

Data on environmentally related taxes need, as other data, to be seen in context and interpreted with care. There is, first, the question of whether to include and how to interpret taxes that may have been introduced for other purposes, including not least fiscal motives, and not necessarily as a "Pigovian" tax on an environmental externality. Many ana- 
lysts tend to conclude that the effect of taxes, and other economic instruments on behaviour, should be the deciding criterion, and would include taxes motivated by energy policies as well as fiscally motivated duties as "environmentally related", as the effect is in practice not dependent on the name or stated motivation for a tax or charge, as long as it has a positive environmental effect.

Indicators for environmentally related taxes are most frequently expressed as a percentage of total tax revenues or total government revenues or as a percentage of Gross Domestic Product (GDP). For international comparisons, these indicators need to be seen in the context of other economic instruments used nationally, such as fees for collection and treatment of waste streams such as for car batteries, tires, packaging, EE-waste and deposit/refund schemes that are privately administered, following on contractual agreements between environmental authorities and business sectors. Above all, any revenue from auctions of greenhouse gas emission permits may be very important supplementary information to data on carbon or greenhouse gas taxes levied in different countries.

Because of very different economic and energy structures, as well as different tax systems in different countries, evaluation of environmental policies in each country is probably best seen in relation to the trend, rather than just the level, of environmentally related taxes in relation to total revenue or to GDP. 
Table 4: Economic instruments used in the Nordic countries

\begin{tabular}{|c|c|c|c|c|}
\hline Energy and air pollution & DK & FI & NO & SE \\
\hline Excise tax on electricity consumption & $\mathrm{x}$ & $\mathrm{x}$ & $x$ & $x$ \\
\hline Excise tax on fuel oil products etc. & $\mathrm{x}$ & $\mathrm{x}$ & $\mathrm{x}$ & $x$ \\
\hline Excise tax on transportation fuels & $\mathrm{x}$ & $x$ & $x$ & $x$ \\
\hline $\mathrm{CO}_{2}$ tax on fuel oil & $x$ & $x$ & $x$ & $x$ \\
\hline $\mathrm{CO}_{2}$ tax on transportation fuels & $\mathrm{x}$ & $x$ & $x$ & $x$ \\
\hline Inclusion of GHG-intensive sectors in the EU ETS & $x$ & $x$ & $x$ & $x$ \\
\hline $\mathrm{SO}_{2} \operatorname{tax}$ & $\mathrm{x}$ & & $x$ & $x$ \\
\hline $\mathrm{NO}_{\mathrm{x}} \operatorname{tax}$ & $\mathrm{x}$ & & $\mathrm{x}$ & $\mathrm{x}$ \\
\hline Subsidy schemes for renewable energy, energy efficiency etc. & $\mathrm{x}$ & $\mathrm{x}$ & $\mathrm{x}$ & $\mathrm{x}$ \\
\hline \multicolumn{5}{|l|}{ Water pollution } \\
\hline Water effluent tax & $\mathrm{x}$ & & & \\
\hline Water supply tax & $\mathrm{x}$ & & & \\
\hline \multicolumn{5}{|l|}{ Waste } \\
\hline Tax on waste put in landfill & $\mathrm{x}$ & $\mathrm{x}$ & $\mathrm{x}$ & $x$ \\
\hline Tax on incinerated waste & $x$ & & $\mathrm{x}$ & $(X)$ \\
\hline $\begin{array}{l}\text { Taxes, deposit-refund systems or other collection systems on beverage } \\
\text { containers/packaging }\end{array}$ & $\mathrm{x}$ & $\mathrm{x}$ & $\mathrm{x}$ & $x$ \\
\hline Taxes on other packaging & $\mathrm{x}$ & & & $x$ \\
\hline $\begin{array}{l}\text { Charges to finance collection and treatment, or deposit-refund systems for } \\
\text { products: ELVs, batteries, tyres, lubrication oil or pesticides }\end{array}$ & $\mathrm{x}$ & $\mathrm{x}$ & $\mathrm{x}$ & $\mathrm{x}$ \\
\hline Tax on GHGs (industrial gases) & $\mathrm{x}$ & & $\mathrm{x}$ & \\
\hline Tax on PVC, phthalates and chlorinated solvents & $\mathrm{x}$ & & & \\
\hline \multicolumn{5}{|l|}{ Transport } \\
\hline Vehicle registration or sales tax & $\mathrm{x}$ & $\mathrm{x}$ & $\mathrm{x}$ & \\
\hline Annual circulation tax & $\mathrm{x}$ & $\mathrm{x}$ & $\mathrm{x}$ & $\mathrm{x}$ \\
\hline Environmental related or noise charges on aviation & & $x$ & $x$ & $x$ \\
\hline Road congestion tax & & & & $x$ \\
\hline Inclusion of aviation in the EU ETS & $\mathrm{x}$ & $\mathrm{x}$ & $\mathrm{x}$ & $x$ \\
\hline \multicolumn{5}{|l|}{ Agriculture and natural resources } \\
\hline Tax on extraction of raw materials & $\mathrm{x}$ & & & $x$ \\
\hline Tax on pesticides & $\mathrm{x}$ & & $x$ & $x$ \\
\hline Tax on fertiliser use & $\mathrm{x}$ & & & $(\mathrm{X})$ \\
\hline Tradable fishing quotas & $x$ & & & \\
\hline
\end{tabular}

Note: (X) means that the economic instrument has been removed since 2009.

Source: Bragadóttir et al. (2014).

\section{Environmental goods and services sector}

The area is covered by EU Regulation 691/2011 consolidated version on European Environmental Economic Accounts.

The environmental goods and services sector (EGSS) module of the European Statistical System aims to collect data on the output, employment, exports and value added generated in the production of goods and services that are used to measure, prevent, limit, minimise and correct environmental damage and manage natural resources. 
Environmental protection (EP) includes all activities and actions which have as their main purpose the prevention, reduction and elimination of pollution and of any other degradation of the environment. Those activities and actions include all measures taken in order to restore the environment after it has been degraded. Activities which, while beneficial to the environment, primarily satisfy the technical needs or the internal requirements for hygiene or safety and security of an enterprise or other institution are excluded from this definition.

Resource management (RM) includes the preservation, maintenance and enhancement of the stock of natural resources and therefore the safeguarding of those resources against depletion.

The first and most important criterion for a product to be an environmental good or service is that its "main purpose" (the terms "prime objective" or "primary purpose" or "end purpose" are used with the same meaning) is environmental protection or resource management, whereby the main purpose is mainly determined by the technical nature of the product (2009 EGSS handbook, p. 29-31).

\section{Environmental protection expenditure}

Since the 1990s, data on environmental expenditures have been collected by the OECD and Eurostat. In its most recent form, reporting of environmental protection expenditures are covered by EU Regulation 691/2011 consolidated version on European Environmental Economic Accounts.

Data on environmental protection expenditure measure how much an individual company, a government and households have paid to reduce its own environmental burden, such as expenditures to reduce emissions to air and water or to protect landscape and biodiversity. Some of these measures are taken to comply with environmental policy or laws; some of these measures are taken because the company or the household has identified a specific need through their own environmental concerns.

Data are reported according to the Classification of Environmental Activities part for environmental protection (see Annex 1 of SEEA-CF 2012) and are broken down by aggregated NACE industries, governments and households. 
The interpretation of data needs to be done carefully. For example: high environmental expenditure as a percentage of Gross Domestic Product (GDP) could be due to a combination of (i) a large backlog of environmental problems, i.e. hot spot that need to be remedied (ii) ambitious efforts from governments to reach stringent targets, (iii) inefficient and wasteful practices, and (iv) policies which give priority to measures that are easily measured, such as end-of-pipe and clean-up and remediation measures rather than integrated technologies and preventative measures which are more difficult to measure and report. The same factors, in the other direction, could explain low figures. Thorough analysis is needed to clarify which factors are behind both low and high figures.

What is known from the statistics are the actual levels spent on reducing the environmental burden and degradation.

\section{The NACE classification}

\begin{tabular}{ll} 
Table 5: Statistical Classification of Economic Activities in the European Community(NACE) \\
\hline Code & Label \\
\hline A & Agriculture, forestry and fishing \\
B & Mining and quarrying \\
C & Manufacturing \\
D & Electricity, gas, steam and air conditioning supply \\
E & Water supply; sewerage, waste management and remediation activities \\
F & Construction \\
G & Wholesale and retail trade; repair of motor vehicles and motorcycles \\
H & Transportation and storage \\
I & Accommodation and food service activities \\
J & Information and communication \\
K & Financial and insurance activities \\
L & Real estate activities \\
M & Professional, scientific and technical activities \\
N & Administrative and support service activities \\
O & Public administration and defence; compulsory social security \\
P & Education \\
Q & Human health and social work activities \\
R & Arts, entertainment and recreation \\
S & Other service activities \\
T & Activities of households as employers; undifferentiated goods- and services-producing activities \\
& of households for own use \\
U & Activities of extraterritorial organisations and bodies \\
\end{tabular}





\section{Appendix 2: On-going initiatives and processes}

This is an inventory of the many initiatives and processes that are currently on-going in various institutions that have green economy or sustainability issues on their agenda. It is the contribution to the action point 4, to suggest a way to report an overview of on-going Nordic initiatives on the theme of establishing regular measurements to complement GDP. During the meetings of the Ad Hoc Group we have discussed the various processes that are on-going in this field and decided to report them in this annex.

The main recommendation from the group is to continue the development of the statistics so that it can help answer some of the questions that the policy institutions and the researchers are discussing. We will start with the Nordic initiatives and then go on to international initiatives that we are also following. The sustainability discussion has been on-going for a long time, but the terminology and the focus vary over time. The focus in this report is to understand how the knowledge can be institutionalised, so that it continues to be updated and used by many actors.

Ideally the new measurements that prove valuable should be taken up and used in order to inform policy at the national or international level.

\section{The Nordic Council of Ministers (NCM)}

Green Growth has been on the agenda since 2010, when the Nordic ministers discussed this theme at the session of the Nordic Council. This year a new project on the "circular economy" is highlighted as part of this work. The concept of circular economy is gaining more and more prevalence in current economic and environmental thinking. The discourse is focussing on reusing and "upcycling" as well as a thinking of the way we organize our societies. http://www.norden.org/en/theme/green-growth

Indicators have been chosen to follow-up the sustainable development, in the broad categories of welfare, ecosystems, sustainable use of resources and education \& research and innovation. http://dx.doi.org/ 10.6027/ANP2013-757 
Reports from NCM group for environmental economy (MEG) are available online. It is a treasure trove of reports that investigate the use of economic instruments and environmental technologies and new concepts in the environmental economic sphere with a focus on the Nordic countries. http://www.norden.org/sv/nordiska-ministerraadet/ministerraad/ nordiska-ministerraadet-foer-miljoe-mr-m/institutioner-samarbetsorgan -och-arbetsgrupper/arbetsgrupper/miljoe-och-ekonomigruppen-meg/ publikationer-och-rapporter

Some reports of particular interest are:

1. The Use of Economic Instruments in Nordic Environmental Policy 2010-2013: http://dx.doi.org/10.6027/TN2014-549

2. Natural Capital in a Nordic Context: http://dx.doi.org/10.6027/ TN2013-526

3. Measuring Green Jobs?: http://dx.doi.org/10.6027/TN2012-534

4. Using the right environmental indicators: http://dx.doi.org/ $10.6027 / \mathrm{TN} 2012-535$

5. Global carbon footprints: http://dx.doi.org/10.6027/TN2010-592

6. Bioeconomy. The Nordic Council of Ministers have established a Nordic Bioeconomy Initiative (2013-2018), inter alia to develop and improve methods for sustainable production and use of living marine and terrestrial resources, while reducing environmental impacts and resources: http://www.norden.org/en/theme/nordic-bioeconomy/

\section{National initiatives including Statistical Offices}

The statistical offices of Denmark, Finland, Norway and Sweden are all committed to the development of the System of Environmental and Economic Accounting. Annual statistics are sent to Eurostat on air emissions, environmental taxes and economy-wide material flows. Also statistics on energy use by industry, Environmental goods and services sector (size, employment and export) and Environmental protection expenditures will soon follow. 


\section{Denmark}

- Report on Green national accounts (environmental-economic accounts) from Statistics Denmark (DST): http://dst.dk/da/ Statistik/Publikationer/VisPub.aspx?cid=19683

- During the period 2015-17 Statistics Denmark will develop a full system of Green National Accounts (environmental-economic accounts) according to the System of Environmental and Economic Accounts as the Danish Parliament decided in the 2015 budget to finance the development. Statistics Denmark's homepage for the Environmental and Economic Accounts: http://www.dst.dk/da/ Statistik/emner/groent-nationalregnskab

- Report on mapping and valuing ecosystem services in Denmark. DCE - Danish Centre for Environment and Energy: http://dce2.au.dk/pub/SR147.pdf

- Report on Environmental Goods and Services. Statistics Denmark: http://www.dst.dk/da/Statistik/Publikationer/VisPub?cid=22253

- A Sustainable Denmark. Ministry of Finance: http://www.fm.dk/ publikationer/2014/et-baeredygtigt-danmark-udvikling-i-balance

\section{Finland}

Statistics Finland annually publishes data on environmental accounts. The areas that are covered as regular statistics are emissions to air accounts, physical energy flow accounts, economy-wide material flow accounts, environmental protection expenditures and environmental taxes: http://www.tilastokeskus.fi/tup/ymparistotilinpidon-teemasivut/ index_en.html

\section{TEEB published early 2015}

This report presents the results from the research project National Assessment of the Economics of Ecosystem Services in Finland (TEEB Finland). The report offers an overview of the steering mechanisms related to ecosystem services and the need for their reform. It also provides an assessment of the current state of national accounting of natural capital and some recommendations on developing this accounting. The data in the study can be used, for example, in implementing Finland's National Biodiversity Strategy and Action Plan and in meeting our international obligations. The report also features a summary of the most significant ecosystem services in Finland and the factors that affect their provision. Additionally, it includes recommenda- 
tions for assessing the status of ecosystem services and developing the services through the use of various indicators. In connection to the report, an Internet site "Finnish ecosystem service indicators" (www. biodiversity.fi/ecosystemservices) was established, presenting information on the development of various ecosystem services: https://helda.helsinki.fi/ bitstream/handle/10138/152815/FE_1_2015.pdf?sequence=1

This project aimed to initiate a systematic national process for the integration of ecosystem services and related biodiversity (i.e. natural capital) into all levels of decision-making. TEEB for Finland was executed according to the models of previous international TEEB studies (e.g. TEEB Nordic) and alongside with EU's MAES project (Mapping and Assessment of Ecosystems and their Services). The TEEB for Finland provides preliminary estimates on the economic importance of some key ecosystem services. The main focus has been on those so far under-recognized regulating and cultural services, but not forgetting traditional provisioning services, the value of which has been traditionally recognized due to their vital importance for the Finnish economy and society.

\section{Bioeconomy strategy}

The objective of the Finnish Bioeconomy Strategy is to generate new economic growth and new jobs from an increase in the bioeconomy business and from high added value products and services while securing the operating conditions for the nature's ecosystems: http://www.tem.fi/ files/40366/The_Finnish_Bioeconomy_Strategy.pdf

\section{Norway}

The NORwegian Economic and Environmental Accounts Project (NOREEA) was first established in 1997 as a cooperative project between the Division for National Accounts and the Division for Environment Statistics at Statistics Norway. Funding for this project has come from Eurostat, Statistics Norway and the Norwegian Ministry of the Environment.

There were initially three major areas included in the larger NOREEA system. One area of development focused on connecting the environmental statistics to the economic statistics (NAMEA). A second area involved separating out environment related information already included in the economic statistics. A final area included was the valuation of important natural resources. 
Now the areas that are covered as regular statistics are emissions to air accounts, physical energy flow accounts, economy-wide material flow accounts, environmental protection expenditures and environmental economic instruments like environmental taxes and emissions permits. As part of the publications of emissions to air and physical energy flow accounts, also indicators like emission intensities and energy intensities are presented as well as decomposition analysis.

Valuation of important natural resources is included in analysis of SDI and National wealth calculations.

- Environmental accounts websites:

- http://www.ssb.no/en/natur-ogmiljo?de=Environmental+accounts

- http://www.ssb.no/natur-og-miljo?de=Miljøregnskap

- Specific website for the regular publications:

- MFA: http://www.ssb.no/en/natur-og-miljo/statistikker/ materialstrom

- Air emissions accounts: http://www.ssb.no/en/natur-ogmiljo/statistikker/nrmiljo

- Energy accounts: http://www.ssb.no/en/energi-ogindustri/statistikker/energiregnskap

- Environmental instruments: http://www.ssb.no/en/natur-ogmiljo/statistikker/miljovirk

\section{Sustainable development indicators}

A web-site was established in 2014 describing the development within each of the indicators in the Norwegian SDI. The indicators will be updated on a regular basis. See https://www.ssb.no/natur-og-miljo/ nokkeltall/indikatorer-for-barekraftig-utvikling

In 2012, a report was published including addition information relevant to a broader analysis of each of the indicators (see http://www.ssb.no/ a/publikasjoner/pdf/sa_129/sa_129.pdf).

Research seeks to refine sustainable development indicators at Statistics Norway. Projects include:

- BIOPOLICY is an interdisciplinary project with the purpose of analyzing appropriate economic policy means for biodiversity protection in open lowlands and forests, with biodiversity targets specified in the context of the Nature Index for Norway. 
- Nature index: http://www.miljodirektoratet.no/no/Tema/Arter-ognaturtyper/Naturindeks-for-Norge/

- ECONOR - The Economy of the North. The purpose of the ECONOR project is to provide an updated overview of economy, living conditions and environment in the circumpolar Arctic, with data and knowledge provided by the circumpolar ECONOR network of statisticians and researchers.

- Natural resource wealth and ecosystem services. The purpose of the project is to further develop and apply the research expertise of Statistics Norway on natural research wealth and ecosystem services, in interdisciplinary cooperation with other research institutes and government agencies.

- Sustainable development indicators (SDI) in the context of the precautionary principle. The project aims at strengthening the sustainable development indicators by establishing early warnings based on expert opinions on uncertainty and critical developments and the need for immediate action. The objective is to integrate the precautionary principle into sustainable development analysis in situations where there are uncertain and potentially serious consequences for the environment and other societal concerns.

\section{Sweden}

\section{Statistics Sweden (SCB)}

The System for Environmental and Economic Accounts started to develop an information system in 1993. Now the areas covered are emissions to air and to water, energy use, chemicals use, material use, environmental protection expenditure, environmental goods and services, and environmental economic instruments like environmental taxes, environmentally related subsidies and emissions rights. Within the system the same definitions of industries, product groups and sectors are used as in the economic national accounts. This makes it possible to also use the economic statistics and calculate the environmental pressure from consumption. http://www.scb.se/en_/Finding-statistics/Statistics-by-subject-area/ Environment/Environmental-accounts-and-sustainable-development/ System-of-Environmental-and-Economic-Accounts/ 


\section{PRINCE (Policy Relevant Indicators for National Consumption and Environment)}

Research project on the environmental pressure from consumption financed by the research funding of the Environmental Protection Agency. SCB, Chalmers, KTH, SEI, CML and NTNU research how to create a follow-up of the environmental pressure from consumption in this three year project.

\section{Outside the Nordic region}

\section{Stiglitz-Sen-Fitoussi-commisions report}

- http://ec.europa.eu/eurostat/documents/118025/118123/

Fitoussi+Commission+report/7bac2480-4658-439f-b022e6542ebf714e

The work is now being followed up by the OECD. The High Level Expert Group brings together an independent group of members of international standing with relevant experience in the field of well-being and progress measurement. These include: Joseph E. Stiglitz, Nobel Prize in economics, Professor, Columbia University; Jean-Paul Fitoussi, Professeur émérite, Sciences-Po Paris; Angus S. Deaton, Professor, Princeton University; Martine Durand, OECD Chief Statistician; Jil Matheson, UK National Statistician; Thomas Piketty, Professor, Paris School of Economics; Walter Radermacher, Director-General, Eurostat; and Arthur A. Stone, Professor, Psychiatry and Psychology Departments, Stony Brook University.

- http://www.oecd.org/newsroom/statisticsexpertstocontinueworkof stiglitz-sen-fitoussicommissiononmeasuringprogress.htm

Europe 2020: a strategy for smart, sustainable and inclusive growth was presented by the European Commission in 2010.

\section{Europe Sustainable development strategy}

- http://register.consilium.europa.eu/doc/srv?l=EN\&f=ST\%2010117 $\% 202006 \% 20$ INIT

The strategy is being followed up with an extensive indicator set for the European statistical system and the countries: http://ec.europa.eu/ eurostat/web/sdi/indicators 


\section{Beyond GDP}

The commission presented 2009 a plan for modernising the measuring system. The aim is described on the website as: "The Beyond GDP initiative is about developing indicators that are as clear and appealing as GDP, but more inclusive of environmental and social aspects of progress." http://eur-lex.europa.eu/LexUriServ/LexUriServ.do?uri=COM:2009:0433:FIN:EN:PDF

As part of that modernising process a legal framework for reporting environmental accounts data was decided on in 2011: http://eur-lex.europa.eu/legal-content/EN/ALL/?uri=CELEX:32011R0691

EU: Indicators for resource efficiency: http://ec.europa.eu/environment/ resource_efficiency/targets_indicators/roadmap/index_en.htm

\section{Examples of EU research projects}

- Brainpool http://www.brainpoolproject.eu/about-2/who-we-are/ They asked among other topics: Is there a demand for Beyond GDP indicators? And if there is, where is it? Through desk research, interviews and workshops with policy actors in five European countries, as well as at the OECD and EU, they concluded that there is demand for what could be called Beyond GDP policy-making, but this has not yet been linked very well to a demand for Beyond GDP indicators: http://www.brainpoolproject.eu/beyond-gdp-demand/

- e-Frame, European Framework for Measuring Progress, aims at fostering the on-going debate on the measurement of well-being and the progress of societies, and involves four major National Statistical Institutes. The project has involved major stocktaking activities of Beyond GDP indicators, as well as attempts to harmonise measurement approaches: http://www.eframeproject.eu/

- NETGREEN (Network for a Green Economy) started in 2013, and to create a database of indicators relevant for the measurement of different conceptions of the green economy. The project held workshops and discussed different conceptual ideas on how to reach a sustainable economy: http://netgreen-project.eu/

\section{New Climate Economy http://newclimateeconomy.net/}

The Global Commission on the Economy and Climate is a major international initiative to analyse and communicate the economic benefits and costs of acting on climate change. Chaired by former President of Mexico Felipe Calderón, the Commission comprises former heads of government and finance ministers and leaders in the fields of economics and business. The New Climate Economy is the Commission's flagship project. It pro- 
vides independent and authoritative evidence on the relationship between actions which can strengthen economic performance and those which reduce the risk of dangerous climate change. The project is undertaken by a global partnership of research institutes and a core team led by Programme Director Helen Mountford. An Advisory Panel of worldleading economists, chaired by Lord Nicholas Stern carried out an expert review of the work.

UNSD United nation statistical division are working on the indicator system framework for the post 2015 process.

The UN city group, the London Group on environmental accounting (http://unstats.un.org/unsd/envaccounting/londongroup/) meets regularly to discuss the implementation and harmonisation and development of environmental economic accounting: http://unstats.un.org/unsd/ envaccounting/default.asp

See for example paper from the meeting in 2014: Do we need natural capital accounts, and if so, which ones? http://unstats.un.org/unsd/ envaccounting/londongroup/meeting20/LG20_BK_g.pdf

\section{World Bank http://www.worldbank.org/}

- Adjusted Net Savings (including/excluding particulate emissions damage):

- http://data.worldbank.org/indicator/NY.ADJ.SVNG.GN.ZS

- http://data.worldbank.org/indicator/NY.ADJ.SVNX.CD

- Environment:

- http://www.worldbank.org/en/topic/environment

- The Waves project: Wealth Accounting and the Valuation of Ecosystem Services. WAVES is a global partnership that aims to promote sustainable development by ensuring that natural resources are mainstreamed in development planning and national economic accounts:

- http://www.wavespartnership.org/

\section{Club of Rome http://www.clubofrome.org/}

A case study which uses the Swedish economy as a case study for circular economy and discusses employment and climate gases has been published: http://www.clubofrome.org/cms/wp-content/uploads/2015/ 04/Final-version-Swedish-Study-13-04-15-till-tryck-ny.pdf 


\section{OECD environmental indicators}

Over the years, the OECD has accumulated practical experience not only in developing, but also in using environmental indicators in its policy work. The indicators are used as a specific tool for evaluating environmental performance, and for monitoring the implementation of the OECD Environmental Strategy for the first decade of the 21st century.

- http://www.oecd.org/env/indicators-modelling-outlooks/ 24993546.pdf

- http://www.keepeek.com/Digital-Asset-Management/oecd/ environment/environment-at-a-glance-2013_9789264185715en\#page1

\section{OECD Task Force for Environmental Accounts}

OECD is working on setting up environmental data in the SEEA format. So far, emissions to air have been published. Work on fossil fuel resources is also underway for selected countries.

\section{GGGI (Global Green Growth Institute), http://gggi.org/}

GGGI was founded on the belief that economic growth and environmental sustainability are not merely compatible objectives; their integration is essential for the future of humankind. We work with partners in the public and private sector in developing and emerging countries around the world to put green growth at the heart of economic planning.

\section{An article from "Nature" on alternatives to GDP:}

- http://www.nature.com/news/ development-time-to-leave-gdp-behind-1.14499 
Nordic Council of Ministers

Ved Stranden 18

DK-1061 Copenhagen $\mathrm{K}$

www.norden.org

\section{Making the environment count}

In 2013, the Nordic Ministers for the Environment decided to strenghten the measurement of green estimates of welfare and socio-economic developments. The report Making the Environment Count is describing how statistics on the environment and the economy thorugh the System of Environmental-Economic Accounts can be used to enable cross-sectorial analysis. The report proposes indicators that can be compiled annually in a Nordic context through existing statistics linking economic statistics to environmental statistics.

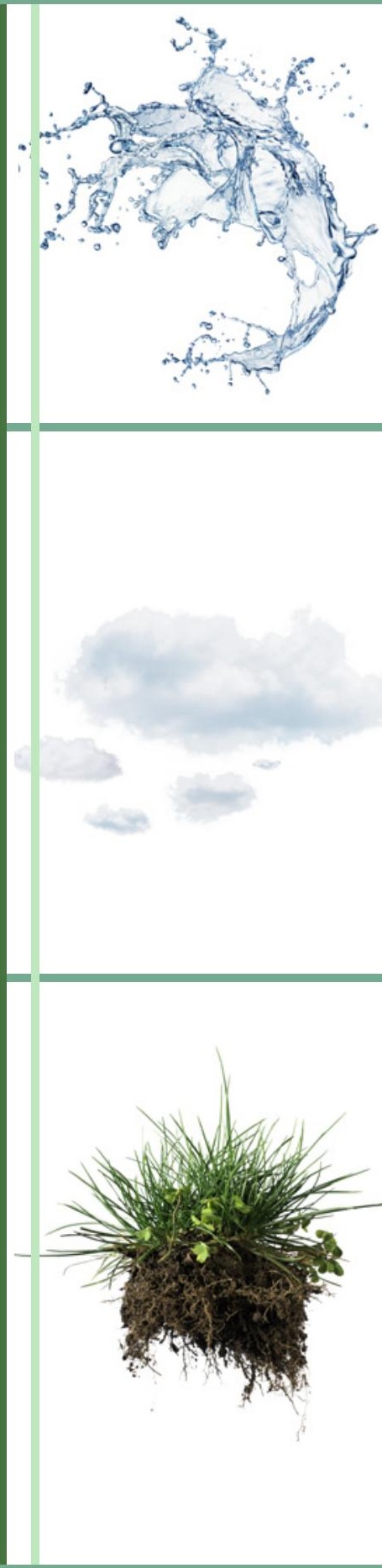

